\title{
ADVANCED THERMOSONIC WIRE BONDING USING HIGH FREQUENCY ULTRASONIC POWER: OPTIMIZATION, BONDABILITY, AND RELIABILITY
}

\author{
A Thesis presented to \\ the Faculty of California Polytechnic State University, \\ San Luis Obispo
}

In Partial Fulfillment

of the Requirements for the Degree

Master of Science in Mechanical Engineering

by

Minh-Nhat Ba Le

June 2009 
(C) 2009

Minh-Nhat Ba Le

All rights reserved 


\title{
Abstract \\ ADVANCED THERMOSONIC WIRE BONDING USING HIGH FREQUENCY ULTRASONIC POWER: OPTIMIZATION, BONDABILITY, AND RELIABILITY
}

\author{
Minh-Nhat Ba Le
}

June 2009

Gold wire bonding typically uses $60 \mathrm{KHz}$ ultrasonic frequency. Studies have been reported that increasing ultrasonic frequency from $60 \mathrm{KHz}$ to $120 \mathrm{KHz}$ can decrease bonding time, lower bonding temperature, and/or improve the bondability of $\mathrm{Au}$ metalized organic substrates. This thesis presents a systematic study of the effects of $120 \mathrm{KHz}$ ultrasonic frequency on the reliability of fine pitch gold wire bonding. Two wire sizes, 25.4 and $17.8 \mu \mathrm{m}$ in diameter (1.0 and 0.7 mil, respectively) were used. The gold wires were bonded to metalized pads over organic substrates with five different metallization. The studies were carried out using a thermosonic ball bonder that is able to easily switch from ultrasonic frequency from $60 \mathrm{KHz}$ to $120 \mathrm{KHz}$ by changing the ultrasonic transducer and the ultrasonic generator. Bonding parameters were optimized through design of experiment methodology for four different cases: $60 \mathrm{KHz}$ with $25.4 \mu \mathrm{m}$ wire, $60 \mathrm{KHz}$ with $17.8 \mu \mathrm{m}$ wire, $120 \mathrm{KHz}$ with $25.4 \mu \mathrm{m}$ wire, and $120 \mathrm{KHz}$ with $17.8 \mu \mathrm{m}$ wire. The integrity of wire bonds was evaluated by the wire pull and the ball bond shear tests. With the optimized bonding parameters, over 2,250 bonds were made for each frequency and wire size. The samples were then divided into three groups. The first group was subjected to temperature cycling from $55^{\circ} \mathrm{C}$ to $+125^{\circ} \mathrm{C}$ with one hour per cycle for up to 1000 cycles. The second group was subject to thermal aging at $125^{\circ} \mathrm{C}$ for up to 1000 hours. The third group was subject to humidity at $85^{\circ} \mathrm{C} / 85 \%$ relative humidity (RH) for up to 1000 hours. The bond integrity was evaluated through the wire pull and the ball shear tests immediately after bonding, and after each 150, 300, 500, and 1000 hours time interval in the reliability tests. The pull and shear data are then analyzed to compare the wire bond performance between different ultrasonic frequencies.

Keywords: Thermosonic, wire bonding, high frequency, reliability, $120 \mathrm{KHz}$ 


\section{Acknowledgements}

First and foremost, a very special thanks to my friends and family who helped me through this project. Thanks to Chị Anh and her family for putting up with me for an entire week while I trained at Teledyne. Thanks to my immediate family for getting me to this point in the first place.

This project was graciously sponsored by Teledyne Microelectronics. A special thank you goes to Teledyne for all their help, training, support, and use of equipment. Thanks specifically to Dr. CV Pham for initiating this project with Cal Poly and for your continuing collaboration with us. Thanks to Daniel Yu for dropping whatever you were doing to escort me into Teledyne when I arrived to conduct the testing. Thanks to Fred Tackitt for gathering the test data for me from Teledyne database. Thanks to Robert Street for allowing the use of the test chambers at Teledyne and for getting the samples out of the ovens right on schedule. Thanks to the ladies in the test lab for all the help you've given even when I was interrupting your work. Thank you to Semiconductor Packaging Materials and K\&S for supplying the bond wires. Thanks to Gaiser for supplying the capillaries used in the study as well as for allowing me use of your images for my thesis.

Thank you to F\&K Delvotec for loaning us the wire bonder that made this project possible. Thanks to Said Kazemi, Rick Bailey, and the rest of the team at F\&K Delvotec for all your help. Special thanks go to HH Lee and Mrs. Lee, who not only spent a whole day at F\&K to train me on the use of the machine but also personally delivered the bonder to Cal Poly from Irvine. Your help and your work are greatly appreciated.

Thanks to Dr. Pan, Dr. Niku, and the rest of the faculty of Cal Poly. Your skills and enthusiasm for teaching are unmatched and thanks to you, I am now a proud educated member of society. Your tireless efforts will no doubt be great boon to a new generation of competent, responsible engineers who will bring mankind to greater heights than ever before.

Thanks to the countless people that I have not had space to mention. Your help and guidance are always remembered and appreciated. Without you, I would not be where I am today. 


\section{Table of Contents}

List of Tables.......................................................................................................... $\mathrm{x}$

List of Figures................................................................................................ viii

Chapter 1. Introduction ...........................................................................................1

$1.1 \quad$ Problem statement................................................................. 2

Chapter 2. Background information ................................................................4

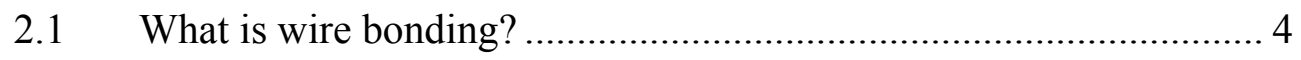

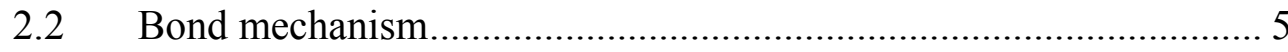

2.3 Bond techniques...................................................................... 5

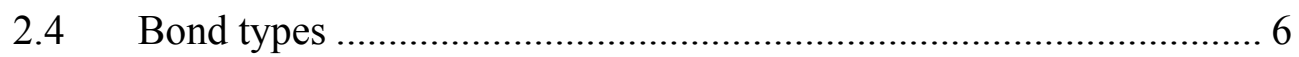

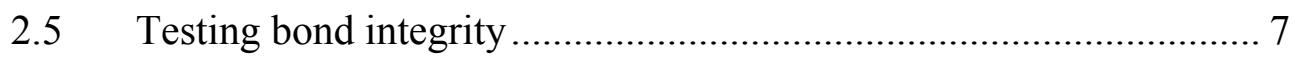

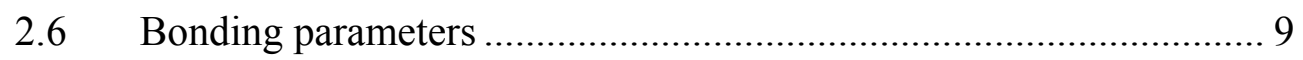

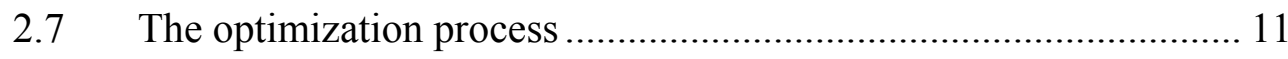

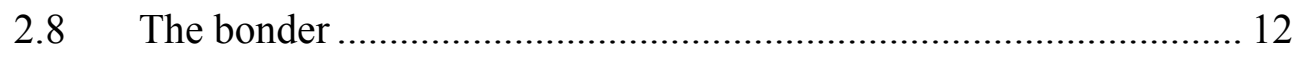

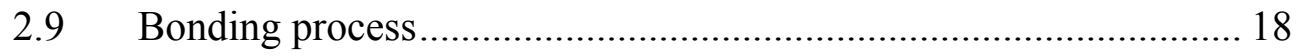

2.10 Pull and shear tests............................................................... 20

Chapter 3. Literature review .......................................................................22

3.1 Bonding mechanism, diffusion, and intermetallic formation ......... 22

3.2 Ultrasonic deformation of metals......................................... 23

3.3 Effects of ultrasonic frequency ............................................... 25

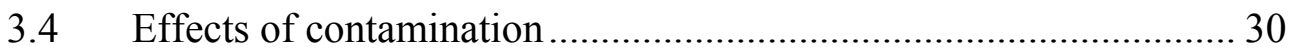

3.5 Effects of flexible substrates.................................................. 32 


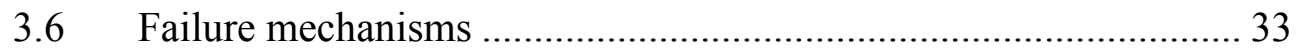

3.7 Optimization of wire bond parameters ...................................... 35

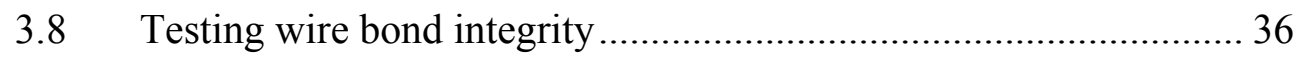

3.9 Bond reliability ................................................................. 48

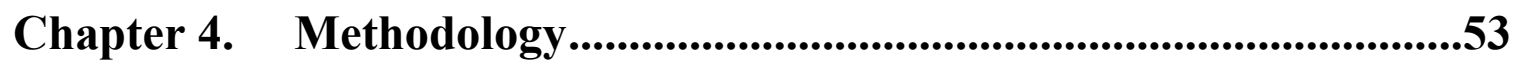

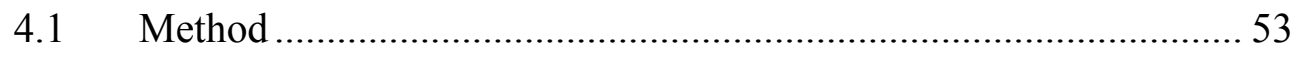

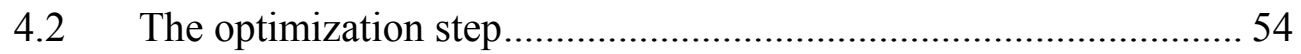

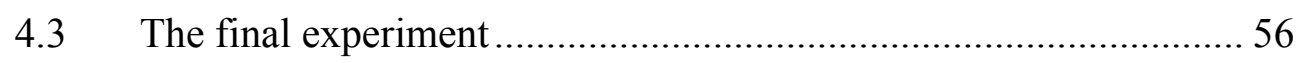

Chapter 5. Results...............................................................................................58

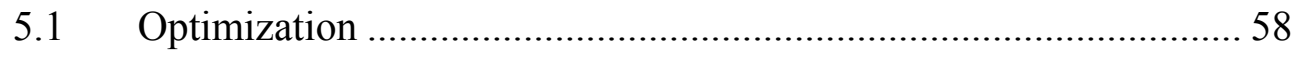

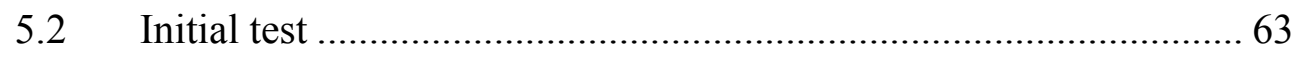

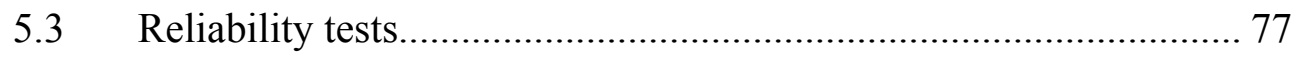

5.3.1 Test type …................................................................ 77

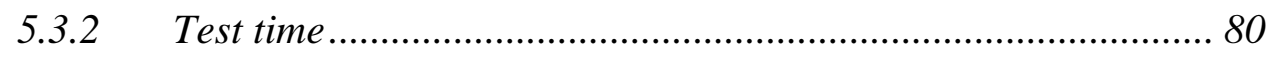

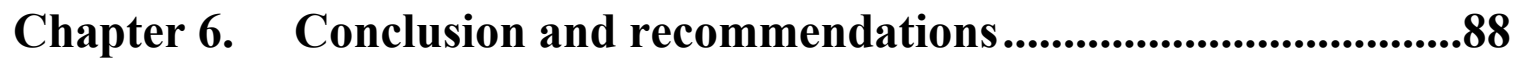

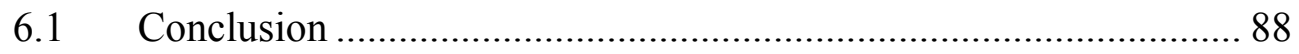

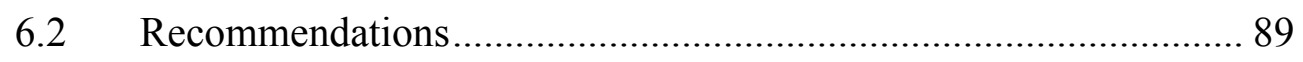

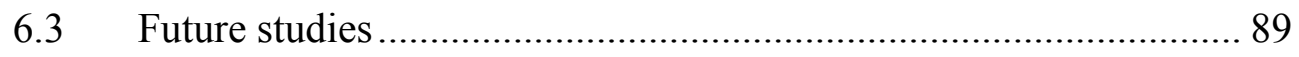

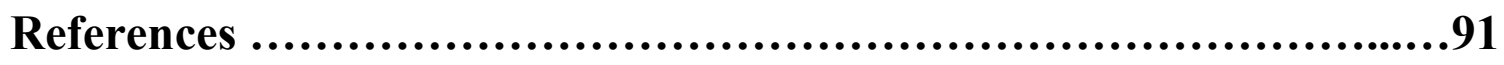




\section{List of Tables}

Table 2-1 Bond weight setting vs. actual bonding force 18

Table 3-1 Partial list of impurities that can cause poor bond adhesion [Harman,

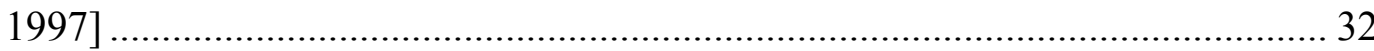

Table 5-1 Pull strength, shear strength, and failure modes of $17.8 \mu \mathrm{m}$ Au wire bonds at $120 \mathrm{kHz}$

Table 5-2 Pull strength, shear strength, and failure modes of $25.4 \mu \mathrm{m}$ Au wire bonds at $120 \mathrm{kHz}$ 60

Table 5-3 Pull strength, shear strength, and failure modes of $17.8 \mu \mathrm{m}$ Au wire bonds at $60 \mathrm{kHz}$

Table 5-4 Pull strength, shear strength, and failure modes of $25.4 \mu \mathrm{m}$ Au wire bonds at $60 \mathrm{kHz}$

Table 5-5 Optimized bonding parameters

Table 5-6 Mean pull strength and shear strength for the corresponding optimized bonding parameters

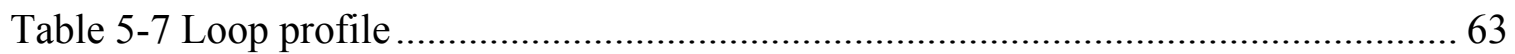

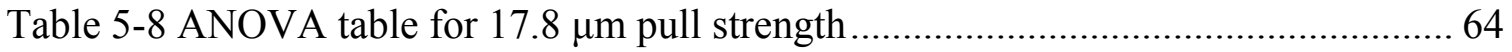

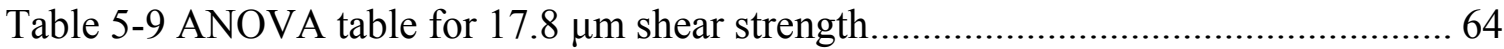

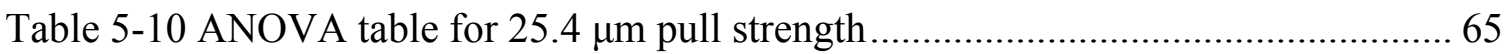

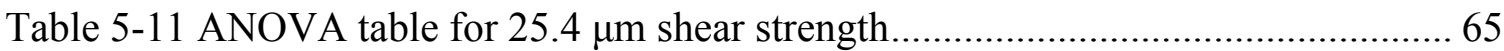

Table 5-12 Pull failure modes for $17.8 \mu \mathrm{m}$ wires bonded at $60 \mathrm{KHz}$ on metallizations 1,3 , and 5 .

Table 5-13 Pull failure modes for $17.8 \mu \mathrm{m}$ wires bonded at $60 \mathrm{KHz}$ on metallizations 2 and 4.

Table 5-14 Shear failure modes for $17.8 \mu \mathrm{m}$ wires bonded at $60 \mathrm{KHz}$. 72

Table 5-15 Pull failure modes for $17.8 \mu \mathrm{m}$ wires bonded at $120 \mathrm{KHz}$ on metallizations 1,3 , and 5 .

Table 5-16 Pull failure modes for $17.8 \mu \mathrm{m}$ wires bonded at $120 \mathrm{KHz}$ on metallizations 2 and 4 .

Table 5-17 Shear failure modes for $17.8 \mu \mathrm{m}$ wires bonded at $120 \mathrm{KHz}$. 
Table 5-18 Pull failure modes for $25.4 \mu \mathrm{m}$ wires bonded at $60 \mathrm{KHz}$ on

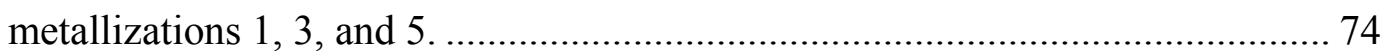

Table 5-19 Pull failure modes for $25.4 \mu \mathrm{m}$ wires bonded at $60 \mathrm{KHz}$ on

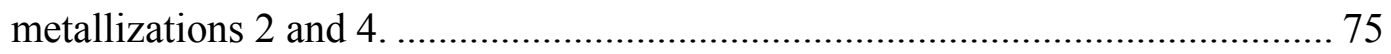

Table 5-20 Shear failure modes for $25.4 \mu \mathrm{m}$ wires bonded at $60 \mathrm{KHz}$........................ 75

Table 5-21 Pull failure modes for $25.4 \mu \mathrm{m}$ wires bonded at $120 \mathrm{KHz}$ on

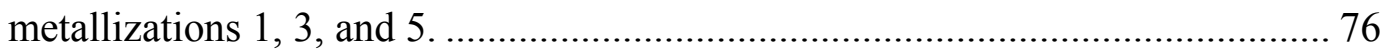

Table 5-22 Pull failure modes for $25.4 \mu \mathrm{m}$ wires bonded at $60 \mathrm{KHz}$ on

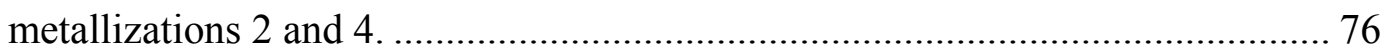

Table 5-23 Shear failure modes for $25.4 \mu \mathrm{m}$ wires bonded at $120 \mathrm{KHz}$....................... 77 


\section{List of Figures}

Figure 2.1 Stud bumping to connect the magnetic head of a hard drive to copper traces [Hutchinson Technology, Hutchinson, Minnesota, found in Harman,

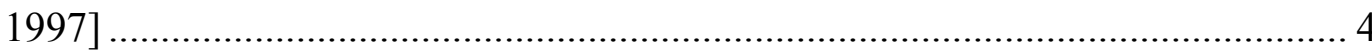

Figure 2.2 The heat-affected zone in a thermosonic wire bond......................................... 9

Figure 2.3 Pull vs. Shear strength as a function of applied ultrasonic power................... 11

Figure 2.4 The F\&K Delvotec 5410 wire bonder........................................................... 13

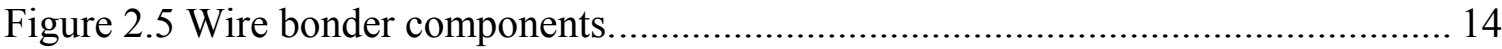

Figure 2.6 The $60 \mathrm{KHz}$ (K-Sine) and $120 \mathrm{KHz}$ (USG-60) ultrasonic generators............. 15

Figure 2.7 The heated work chuck temperature controller (ATV TR-120D, top) and EFO control unit (Uthe Model 228, bottom).......................................................... 16

Figure 2.8 Capillary tip geometry (Image courtesy of Gaiser Tool Company.)............... 16

Figure 2.9 Cross section profile of bottle neck capillary for super high pitch wire bonding. The spacing between bonds is $70 \mu \mathrm{m}$ or less [Harman, 1997] .............. 17

Figure 2.10 The steps to form a thermosonic ball/wedge bond (Image courtesy of Gaiser Tool Company.)

Figure 2.11 Dage 4000 wire bond tester with the WP100 wire pull cartridge installed.

Figure 3.1 Weld area growth as a function of bond dwell time, (A) $2 \mathrm{~ms}$, (B) $4 \mathrm{~ms}$,

(C) $6 \mathrm{~ms}$, (D) $16 \mathrm{~ms}$ [Harman, 1997] 24

Figure 3.2 Exaggerated deformation of bond pad and flexible substrate after bonding. With enough vertical force, the bond pad may even delaminate

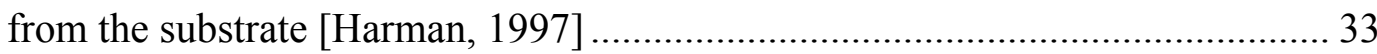

Figure 3.3 Wire bond pull test for ball-wedge bond (top) and wedge-wedge bond

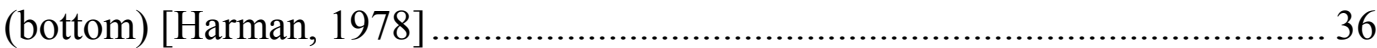

Figure 3.4 Force components of a wire bond pull test [Harman, 1978] ……………….... 37

Figure 3.5 Schematic diagram of a manual shear probe [Harman, 1997] ......................... 41

Figure 3.6 Schematic diagram of an early shear tester [Jellison, found in Harman,

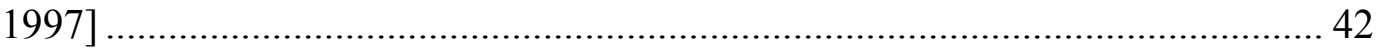

Figure 3.7 Friction rewelding of a gold ball bond [Weiner, found in Harman, 1997] ..... 45 
Figure 4.1 Substrate division for experiments 1 and 2 ......................................... 55

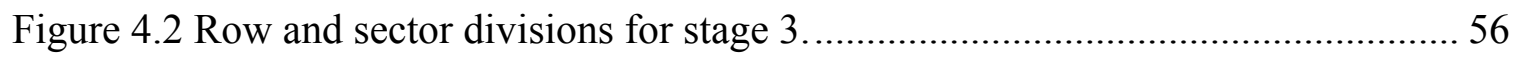

Figure 4.3 Sector and parameter division for the final substrate ..................................57

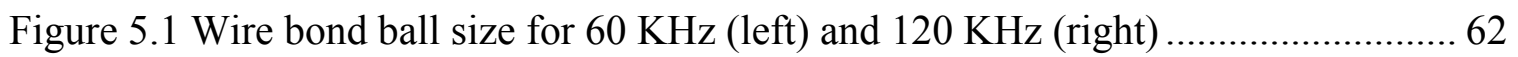

Figure 5.2 Frequency and metallization interactions influencing pull strength for $17.8 \mu \mathrm{m}$ wire size. The rise and fall of the $60 \mathrm{KHz}$ curve indicates strong interaction. The relatively flat $120 \mathrm{KHz}$ curve indicates that the interaction is weak and that bonds made at that frequency are robust against lifts ..... 66

Figure 5.3 Frequency and metallization interactions influencing shear strength for $17.8 \mu \mathrm{m}$ wire size. Strong interactions are visible here. Not even $120 \mathrm{KHz}$ bonds are immune to the poor bond conditions on Metallizations 2 and 4.

Figure 5.4 Frequency and metallization interactions influencing pull strength for $25.4 \mu \mathrm{m}$ wire size. 68

Figure 5.5 Frequency and metallization interactions influencing shear strength for

$25.4 \mu \mathrm{m}$ wire size. 69

Figure 5.6 Effects of test interval on pull strength for $17.8 \mu \mathrm{m}$ wire size. ..................... 81

Figure 5.7 Effects of test interval on shear strength for $17.8 \mu \mathrm{m}$ wire size..................... 82

Figure 5.8 Effects of test interval on pull strength for $25.4 \mu \mathrm{m}$ wire size. ...................... 84

Figure 5.9 Effects of test interval on shear strength for $25.4 \mu \mathrm{m}$ wire size. ................... 84

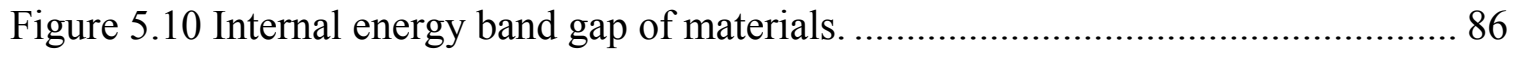




\section{Chapter 1. Introduction}

Wire bonding is a commonly used technology in electronics manufacturing. In packaging of integrated circuits, wire bonds are the primary interconnects between the silicon chip and the lead frames. Having robust bonds is of crucial importance since just one broken wire bond would render an entire (often very expensive) chip completely useless. In high speed production, this would have a negative effect on yield and would ultimately impact the bottom line. This particular study focuses on fine wire ball-wedge thermosonic gold to gold bonds. The wires are either 25.4 or $17.8 \mu \mathrm{m}$ in diameter and are bonded to gold pads composed of several different metallization. The study aims to determine whether switching from industry standard $60 \mathrm{KHz}$ ultrasonic energy to 120 $\mathrm{KHz}$ high frequency would reduce the bonding time required. If the bonding time is indeed lower and bond integrity is still the same, production throughput will be higher. Bonding parameters are first established to delicately balance these factors since they play a direct role in bond quality. Bond integrity is tested by the industry standard pull and shear tests to check wire and bond integrity, respectively. After the optimized bonding parameters are established for each combination of frequency and wire size (a total of four), sets of samples are created. The samples are subjected to a set of reliability tests. An initial set of wires are tested immediately after bonding. After each 150, 300, 500, and 1000 hours time interval, pull and shear tests are conducted again. The reliability tests are humidity $\left(85 \%\right.$ relative humidity at $\left.85^{\circ} \mathrm{C}\right)$, thermal cycling $\left(-55^{\circ}\right.$ to $\left.125^{\circ} \mathrm{C}\right)$, and thermal aging $\left(125^{\circ} \mathrm{C}\right)$. The experiment is designed so that the bonds made are orthogonally distributed on the substrate and the tests conducted are on randomly determined "sectors". The pull and shear data are then analyzed to determine whether the 
bond integrity varies between the ultrasonic frequencies and whether production throughput will be improved. The final samples were made on substrates composed of different metallizations. The results show that optimization parameters are different for different metallization since bonds made on certain metallization are weaker than others as seen in the pull and shear test data. They also show that higher ultrasonic frequency requires less power to make bonds in the same amount of time (energy, the product of power and time, is the quantity of interest, and energy needs remain the same). By extension, this means that bonds made with higher ultrasonic frequency requires less time. The bonds also are not weakened by reliability tests, making the high frequency switch highly desirable.

\subsection{Problem statement}

Would changing the ultrasonic frequency of thermosonic gold/gold wire bonding affect the bond quality positively, especially concerning bonding time as a method of improving productivity, and how reliable are the wire bonds made with higher ultrasonic frequency? This is the problem this thesis addresses. Specifically, the contribution of this project to the greater pool of wire bonding knowledge is for gold-on-gold wire bonding, will changing the ultrasonic frequency impact the production throughput, and will the reliability tests (thermal aging, thermal cycling, and thermal/humidity) reveal any weaknesses that the high frequency bonds may have? This thesis also offers a possible hypothesis to the mechanism of diffusion after the bonds are formed and during thermal stress tests. Previous studies focus on the effect and bondability of high frequency ultrasonic power but none focused on it as a way to improve throughput and check reliability. It is worthwhile to answer these questions since streamlining production 
techniques is always desirable, as is a thorough understanding of the long term effects of switching to those new techniques. 


\section{Chapter 2. Background information}

\subsection{What is wire bonding?}

Wire bonding is an advanced technique used in the electronics manufacturing industry. It is the primary method of connecting integrated circuits to the outside world. Each year, billions of wire bonds are made to provide interconnects for power transistors, microprocessors, and countless other devices. As semiconductor devices are diced from wafers, these dies need to be packaged in a robust manner for consumer use. The spindly legs seen on familiar black plastic packages are connected to the integrated circuits inside through these wire bonds. As the technology matures, innovative uses of wire bonding have been found to solve different problems. For example, Figure 2.1 shows stud bumps (ball bonding without the subsequent wedge bond) used to connect a hard disk drive's magnetic recording head to the copper interconnects.

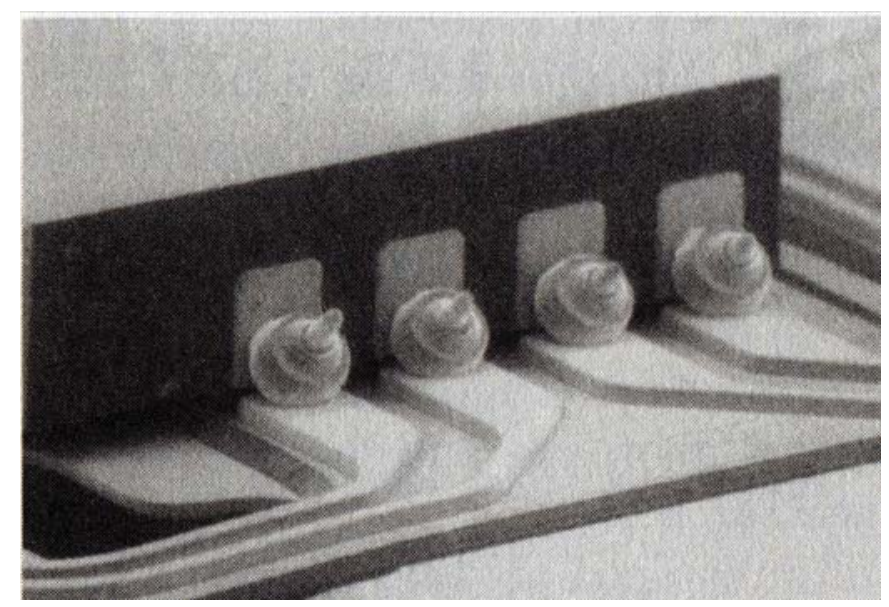

Figure 2.1 Stud bumping to connect the magnetic head of a hard drive to copper traces [Hutchinson Technology, Hutchinson, Minnesota, found in Harman, 1997] 


\subsection{Bond mechanism}

The diffusion of atoms across the bond interface is the primary weld mechanism of wire bonds. Per Fick's law, the thickness of the diffusion layer is described by

$$
x=\sqrt{\left(D_{0} e^{-Q / R T}\right) t}
$$

where $Q$ is the activation energy required to initiate diffusion. The energy input into the bond interface is provided by kinetic energy (ultrasonic scrub) or thermal energy (heat), or both. The deformation of the wire provides intimate contact at the bond interface and allows a larger area where atoms can diffuse through. The scrubbing motion of the ultrasonic tip cleans the surface of bond inhibiting contaminants while transferring energy to the joint.

At the macroscopic level, materials are approximated as homogeneous. However, materials are made up of discrete building blocks at the microscopic level. For metallic crystals, these building blocks are the individual atoms and each atom carries a specific level of internal energy. The distribution of these energy levels is normal and the average value is the bulk internal energy of the material. At the far right end of the distribution is the activation energy. The ultrasonic and thermal energy are transferred to these atoms. As the internal energy of atoms at the interface rise and overcome the activation energy, these atoms penetrate deeper into the bond pad.

\subsection{Bond techniques}

The earliest wire bonds were made using a technique named thermocompression bonding. The bond tool exerts pressure on the wire, pressing it to the bond pad. The wire 
and the pad are heated until the bond forms. Often, this technique requires excessive amounts of power due to the amount of heat needed to enable plastic deformation. Also, this technique is limited to products that are not damaged by high heat. As the size of the devices shrinks, their heat sensitivity increases. Today, very few devices can withstand the temperatures required for thermocompression bonding and this technique has been replaced with ultrasonic or thermosonic bonding.

Thermosonic wire bonding uses ultrasonic energy as the primary energy source. Typically, $70 \%$ of the activation energy is provided by ultrasound and the rest comes from the heated substrate. Since part of the energy comes from heat, the ultrasonic power does not need to be too high, allowing the process to avoid excessive deformation of the wire normally associated with too much ultrasonic power. However, thermosonic wire bonding is subjected to process variation if the temperature in the substrate is not fully controlled and the temperature is not allowed enough time to stabilize.

Ultrasonic energy has come to replace the thermal energy used in wire bonding. Bonds can be formed with much less energy because it is distributed more efficiently. Also, since no heat is used, it is convenient to eliminate the extra equipment and complexity it requires. This is the technique of choice when products are sensitive to heat.

\subsection{Bond types}

While this study focused exclusively on ball/wedge bonding gold wires to gold metallized substrates, the industry has been bonding one metal to another for decades. For example, aluminum wires are used in high power devices, and more recently, the industry is starting to use copper as the wire of choice due to the high material cost of 
gold. Each material chosen for wire bonding has its own challenges to overcome while bringing several key advantages. Also, as different conditions generate different requirements, the bonding tool and technique are modified to fit them. Ball/wedge bonding greatly limits the pitch of the bonding pads since the balls require a specific pad size to avoid registration and alignment issues as well as shorting to neighboring bonds. Very fine pitch wire bonding then calls for wedge/wedge bonding, which uses a different bonding tool from ball/wedge bonding and is able to fit in very small bond pads. However, wedge/wedge bonding is not multidirectional and would require that the chip die be rotated, adding a layer of complexity to the manufacturing process.

\subsection{Testing bond integrity}

The industry standards for checking bond integrity are the pull and shear tests. The pull test, meant to check the repeatability of bonding, is typically a destructive test. A small hook is inserted into the loop of the wire bond and pulled up, breaking the wire. The failure mode indicates the condition of the bond. If the wire breaks at the neck or the heel (where the wire joins the ball and wedge joints, respectively), the ultrasonic power applied was too great and the wire was excessively weakened during bonding. Ideally,

the wire should break at the loop where the hook was placed and the pull strength should be near the tensile strength of the wire. The integrity of the wedge bond is also tested by the pull test. If the joint lifts, the bond was not good.

The shear test is another destructive test for determining how much of a weld was made between the ball and the pad. A sharp steel tool is pushed across the side of the ball bond, shearing it. The force required to shear the ball is measured and the joint is inspected to see how much shear remnants remain on the pad. Through visual inspection 
of the remnants, possible reason for poor bond integrity may be identified such as formation of intermetallic layers, Kirkendall voids, or other reasons inhibiting diffusion. The most desirable failure mode of a shear test is ball shear, where the tool cuts across the ball, leaving remnants behind on the pad. Ball lift is a failure mode where the bond was so poorly made that the shearing blade breaks the bond and lifts the ball off of the pad. When the ball is properly welded to the pad but the pad does not adhere to the substrate, pad lift results. These failure modes identify problems with bonding parameters and manufacturing.

Additional advanced techniques can be employed to study wire bonds. The pull and shear test can quantify bond integrity at the macroscopic level. Visual inspection is limited to the magnification power an optical microscope can achieve. Wire bonds can be cross sectioned and processed so that the sample can be examined by a Scanning Electron Microscope. The electron's much shorter wavelength allows magnification power several orders of amplitude higher than is possible, allowing one to study the bond interface directly. The grain boundaries of the ball, the intermetallic layer (and Kirkendall or Horsting voids), if available, the different layers of thin metal films, etc... can be studied closely and meaningful conclusions can be drawn. While mechanical slicing and polishing is the typical process used to prepare SEM samples, a more advanced technique has been in use that can make far more precise cuts into the sample. The Focused Ion Beam can be carefully controlled to section a sample to minute, specific thicknesses so that the scientist can focus on areas of interest. 


\subsection{Bonding parameters}

Four factors determine the strength of a ball/wedge bond. These are ultrasonic power, time (how long the power is applied), bonding force (how much pressure is applied on the joint as the ultrasonic power is applied), and substrate temperature. Minimum power, time, pressure, and temperature are required to make a bond. Increasing the ultrasonic power and time will increase the ball deformation, resulting in a larger ball and larger weld area, leading to stronger bonds. The bonding pressure needs to be enough to create and maintain intimate contact between the ball and the pad during application of energy. The substrates need to be hot enough to provide the thermal energy required for diffusion.

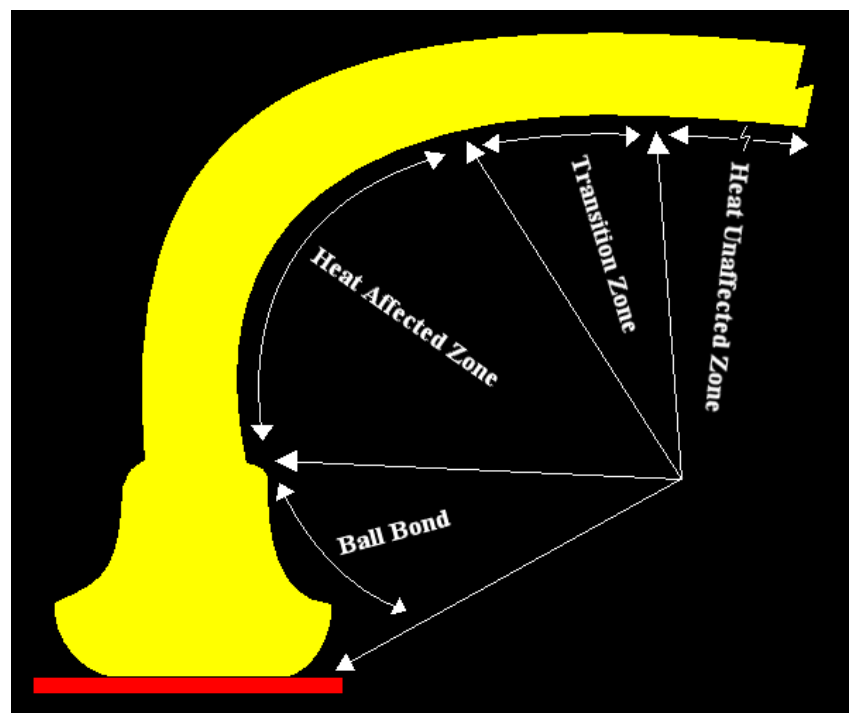

Figure 2.2 The heat-affected zone in a thermosonic wire bond.

The shear strength of the ball bond increases with higher applications of ultrasonic power, but it starts to flatten out at certain peak strength. This is due to the finite size of the ball. Higher power levels will deform the ball more, making the weld area bigger. However, higher applications of power lead to lower pull strength as the ultrasonic energy will damage the wire at the joint. At the neck of the ball is the heat 
affected zone (Figure 2.2). In this area, the material's grain sizes are much larger since the material is annealed during electronic flame off. High ultrasonic energy will weaken this area further, resulting in lower pull strength. The ultrasonic weakening effect is also evident at the wedge bond.

The length of time that the ultrasonic power is applied is related to the power level. The important quantity is energy, which is the product of power and time. Higher power level requires less time to output the same amount of energy. Vice versa, lower power levels require more time. Hypothetically, if $120 \mathrm{KHz}$ ultrasonic frequency is more efficient at transferring power to the bonds, the required energy for diffusion is less. The time required for making bonds is correspondingly less if the power is maintained at the same level.

At higher ultrasonic power levels, the transfer of energy weakens the neck of the joint. The pull strength drops off as ultrasonic power increases. A graph of the pull and shear strength vs. ultrasonic power is shown in Figure 2.3. At lower power levels, there is not enough energy input into the interface to initialize diffusion and bonds cannot be formed. At higher power levels, the shear strength starts to reach its asymptotic value but the pull strength suffers as the wire is overworked and begins to fail. The optimized power level is where the pull and shear curves meet, and it signifies the maximum ball shear strength without compromising the wire pull strength. Higher power leads to higher shear strength and lower pull strength and vice versa.

The pressure that the capillary applies on the bond needs to be high enough to provide intimate contact between the ball and the pad. However, too much pressure 
would induce too much friction and inhibit the efficient transfer of energy from the vibrating capillary to the ball.

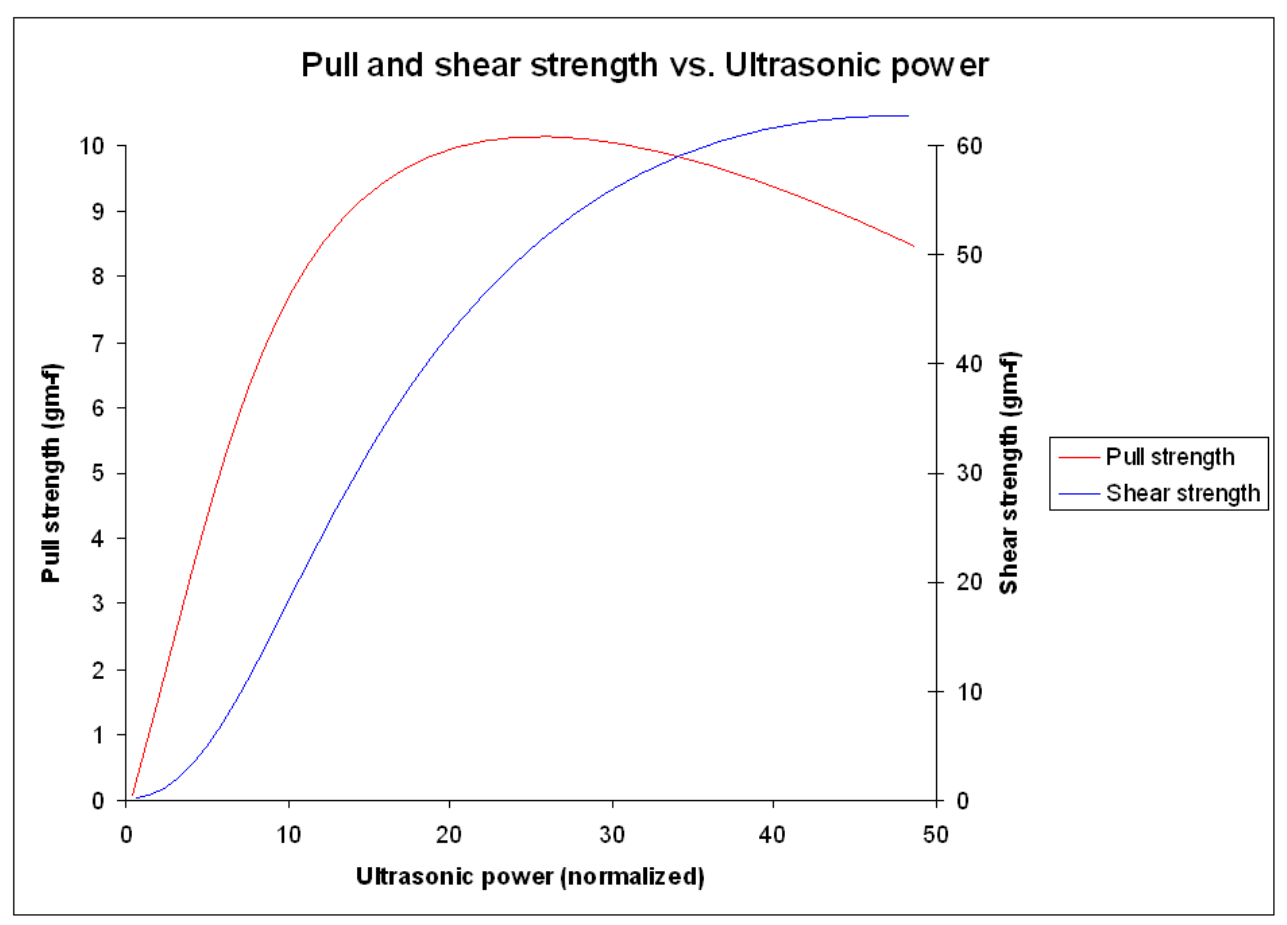

Figure 2.3 Pull vs. Shear strength as a function of applied ultrasonic power.

For organic substrates, the heat input is limited by the substrate's glass transition temperature. Above this limit, the substrate may become damaged and is aggravated further with application of bond weight and ultrasonic power. The organic substrate in this experiment burns out when heated above $145^{\circ} \mathrm{C}$. When substrates can handle higher temperatures, it is a good idea to set them high to ensure good bonds while being mindful of power consumption.

\subsection{The optimization process}

The optimization process creates the optimized set of bonding parameters for making these bonds. The previously mentioned parameters (power, time, pressure, and 
temperature) have to be delicately balanced to ensure good and consistent bonds. The optimization process in this project is done in three stages, starting with a broad range for each parameter. They are refined in subsequent steps and the final, semi-optimized bonding parameters are chosen to use for the final experiment. At the end of each stage is a set of pull and shear tests used to determine how to refine the parameters.

\subsection{The bonder}

The F\&K Delvotec 5410 wire bonder used in this project is shown in Figure 2.4. (A) is the microscope, (B) are the ultrasonic generators, (C) is the wire spool housing, (D) is the control panel, $(\mathrm{E})$ is the ultrasonic transducer assembly including capillary, $(\mathrm{F})$ is the heated work chuck, and $(\mathrm{G})$ is the manipulator. Figure 2.5 shows the main components of the bonder. (A) is the substrate mounted onto the heated work chuck, (B) is the transducer horn with the capillary attached, (C) is the wire clamp solenoid, and (D) is the EFO tip.

The wire spool sits atop the bond head and routes the wire through some tubing and into the capillary. The electronic flame-off (EFO) controller is the Uthe Model 228-1, capable of controlling the duration and level of voltage and current going through the EFO tip. By altering these parameters, the controller can help determine the size of the ball created. The tip is attached to the machine near the capillary. On command, the solenoid moves the EFO tip into position and a high voltage spark is generated between the tip and the wire tail, locally heating the tail until it melts. Surface tension takes over and draws the molten metal into a ball. The capillary itself is attached to the transducer horn, which is a stainless steel shaft connected to a piezoelectric driver. The entire bond head is actuated by stepper motors mounted inside the machine. On the bonder stage, a 
chuck holds the substrate firmly in place and provides the thermal energy by heating it. The TR-120D from ATV Technology of Germany monitors and regulates the temperature of the chuck through a wired connection. A manipulator moves the platform on which the chuck sits and positions the bond pad where the wire bond is to be made.

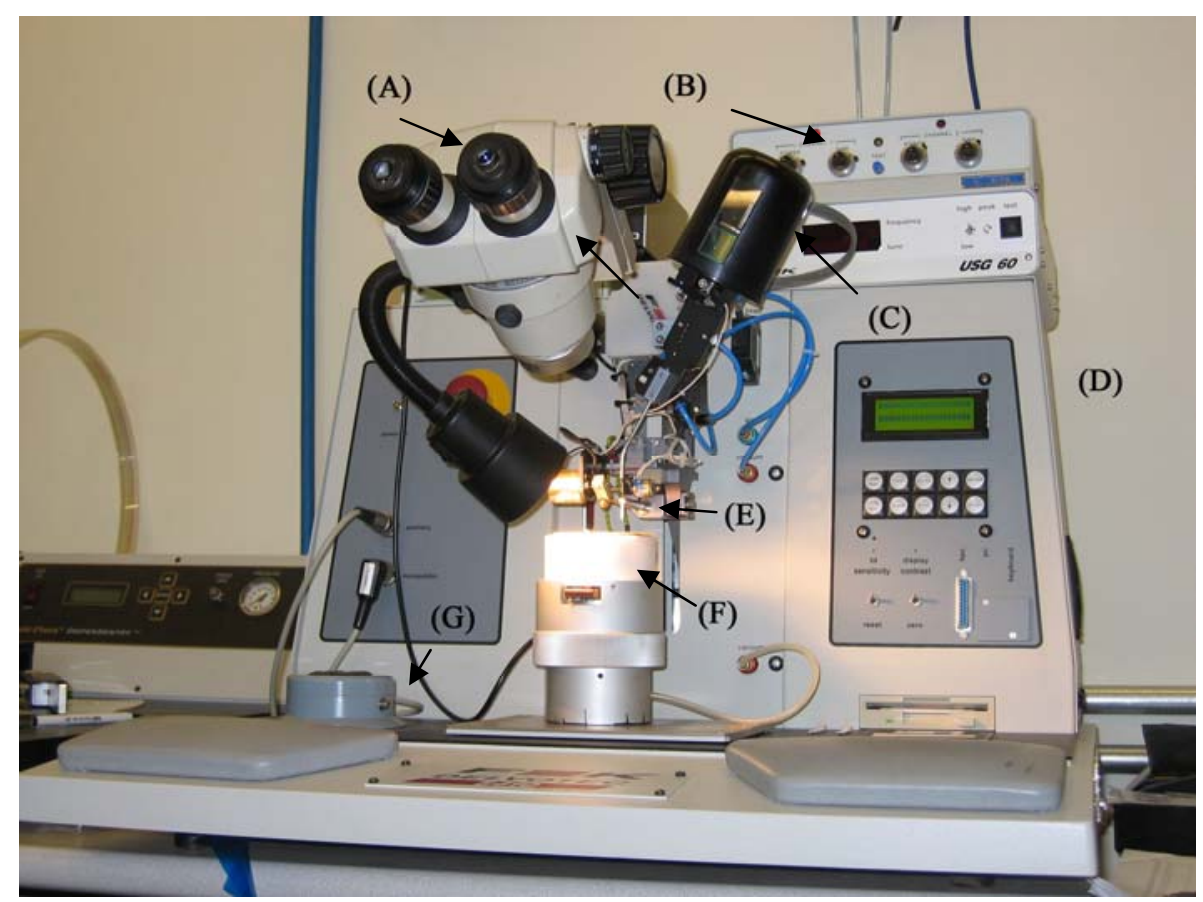

Figure 2.4 The F\&K Delvotec 5410 wire bonder. 


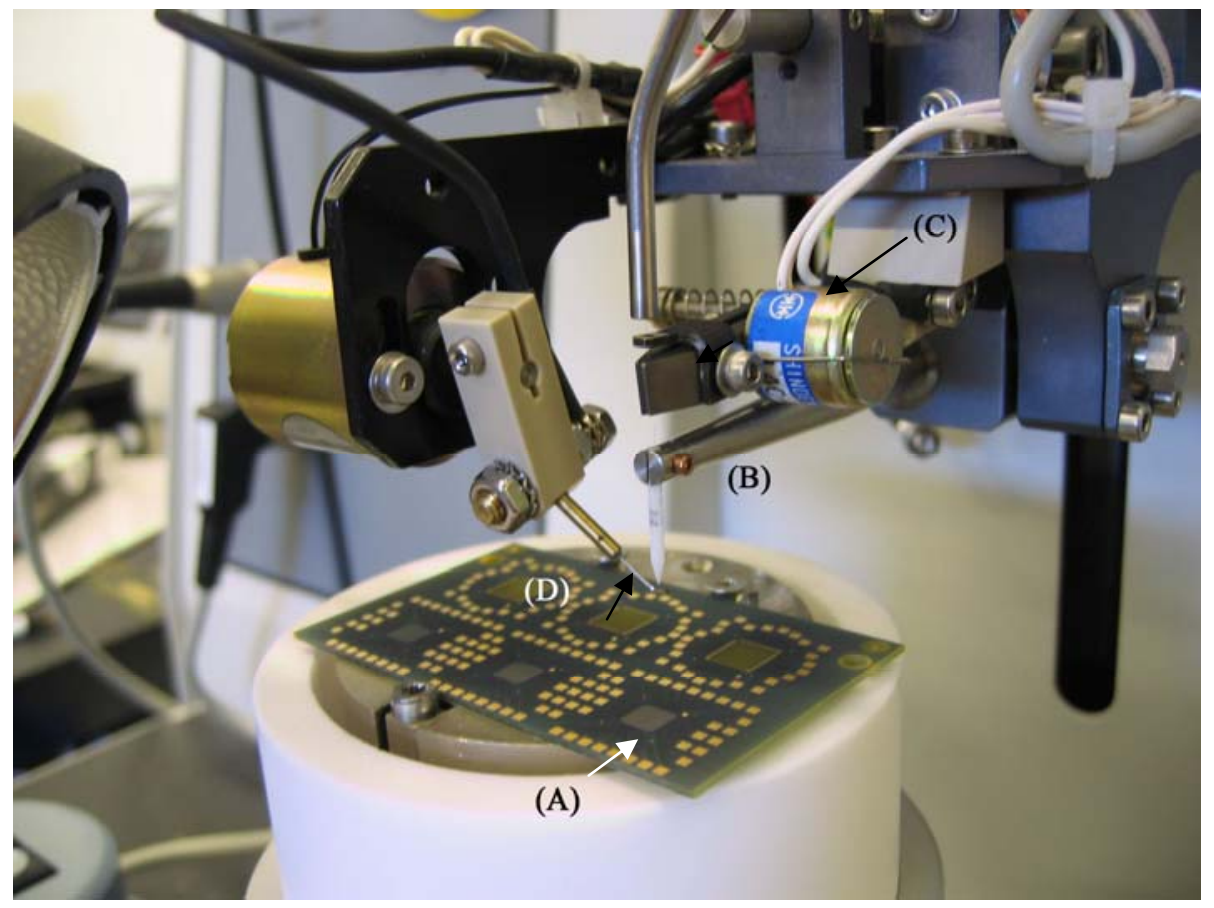

Figure 2.5 Wire bonder components.

The wire spools came from two separate sources. The $17.8 \mu \mathrm{m}$ wire was generously provided by Semiconductor Packaging Materials (SPM) with a minimum tensile strength of 4 gram-f and 3 to $6 \%$ elongation. K\&S provided the $25.4 \mu \mathrm{m}$ wire, which has minimum tensile strength of 7 gram-f at 5 to $8 \%$ elongation. Wires made for ball/wedge bonds have different elongation percentages than wires made for wedge bonding.

Each ultrasonic frequency requires a different transducer and generator. The transducer shape is optimized for the frequency of vibration since the ultrasonic energy is greatest at the point of the transducer horn tip's maximum displacement. The ultrasonic generator creates the input to actuate the piezoelectric crystals to drive the transducer horn. The $60 \mathrm{KHz}$ generator is a unit from K-Sine, model K1400DEL, capable of outputting up to 5 Watts of power. The $120 \mathrm{KHz}$ generator is a modified F\&K Delvotec USG-60 and outputs 3.6 Watts in high mode. Attached to the transducers are capillaries. 
Each capillary is designed for a particular wire size, as a $17.8 \mu \mathrm{m}$ capillary is too tight for a $25.4 \mu \mathrm{m}$ wire to exit through and a $25.4 \mu \mathrm{m}$ capillary is too big to hold the ball made from $17.8 \mu \mathrm{m}$ wire. The $14 \mathrm{~mm}$ long capillaries were made by Gaiser. Changing the wire spool only requires the capillary to be changed out.

To change the bonding frequency, the transducer and the ultrasonic generator need to be changed. When reinstalling the transducer horn, the PZT power lines need to be reconnected, and the capillary needs to be adjusted to ensure perpendicularity to the bond pads. This is achieved by making a bond onto a bond pad without the wire threaded through. The bond tip will leave an imprint on the pad. This imprint is inspected visually. An aligned transducer will leave a perfectly circular imprint. A circle with one side missing indicates a leaning capillary and the transducer needs to be adjusted. Typically, the EFO tip position will need to be adjusted as well to ensure a reliable spark before bonds are made.

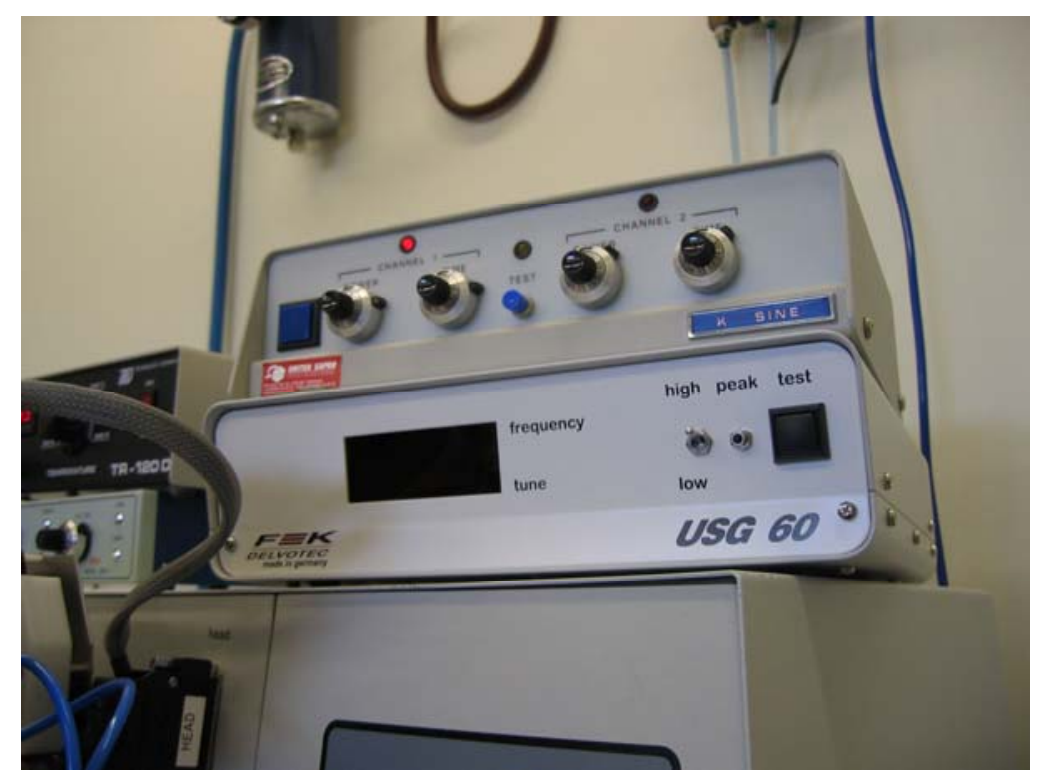

Figure 2.6 The $60 \mathrm{KHz}$ (K-Sine) and $120 \mathrm{KHz}$ (USG-60) ultrasonic generators. 


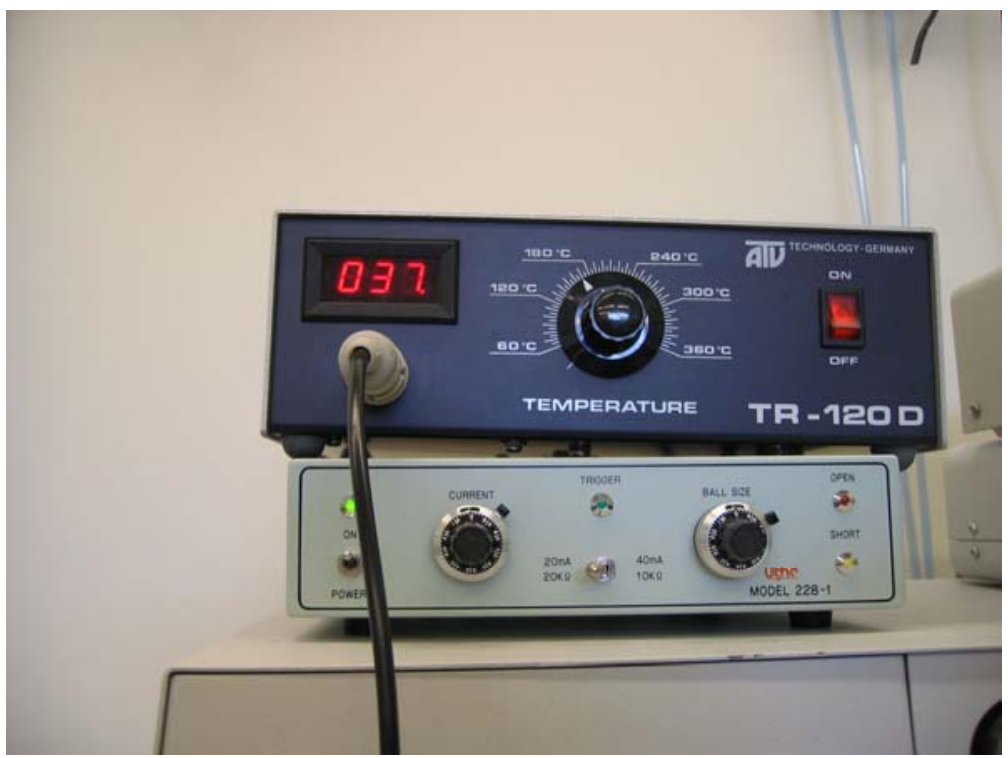

Figure 2.7 The heated work chuck temperature controller (ATV TR-120D, top) and EFO control unit (Uthe Model 228, bottom).

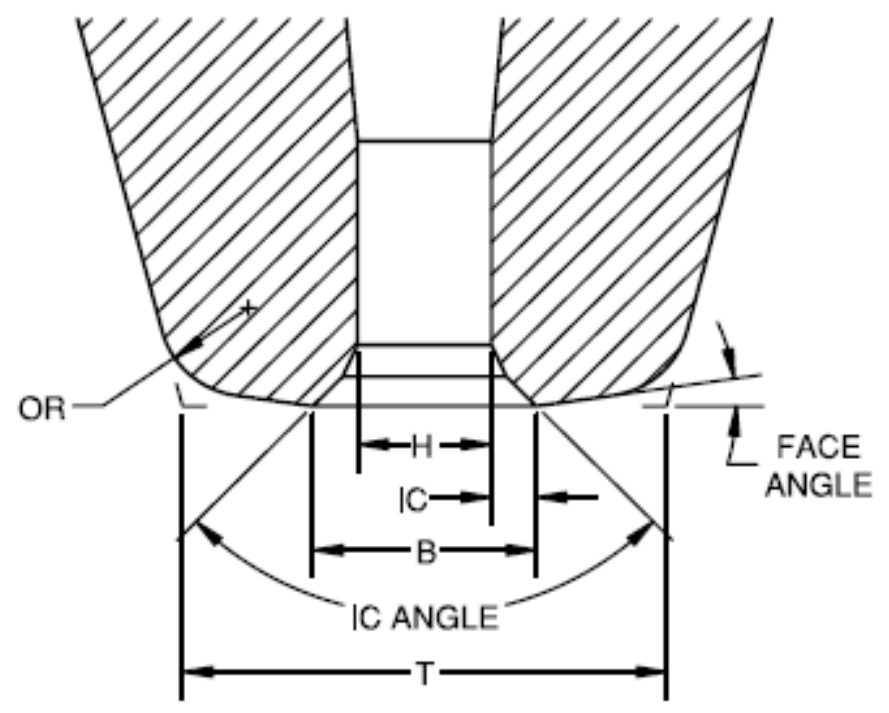

Figure 2.8 Capillary tip geometry (Image courtesy of Gaiser Tool Company.) 


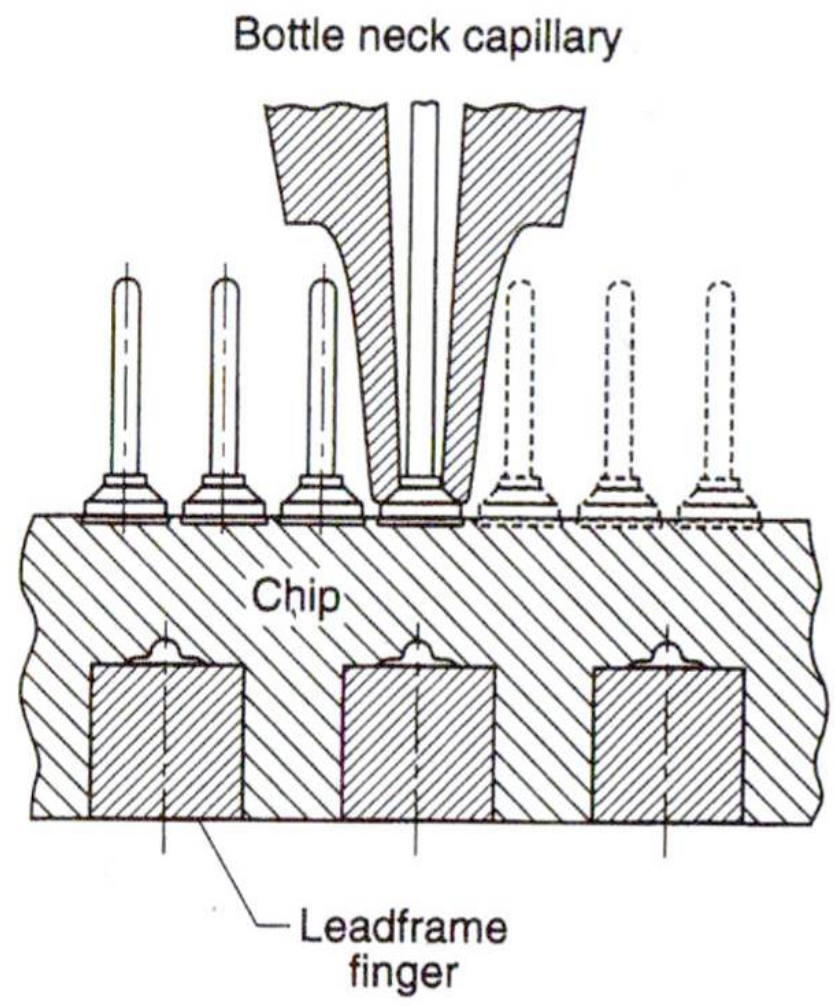

Figure 2.9 Cross section profile of bottle neck capillary for super high pitch

wire bonding. The spacing between bonds is $70 \mu \mathrm{m}$ or less [Harman, 1997]

All the bonding parameters are computer controlled. The operating program is read through a floppy disk drive. Once the operating system is downloaded and the machine is reset to home position, the bond program can be downloaded. The bond program contains all the relevant information needed to create consistent wire bonds, such as search height, bond power, dwell time, and pressure, loop height, reverse factor, second bond parameters, and tail length. This feature allows the machine's operator to transfer bonder settings across different machines so that one machine's optimized bond parameters can serve as the initial starting point for the optimization process of another.

The power output of the ultrasonic generators is stepped down by the bonder as fractions of 255. For example, a machine setting of 55 means that 55/255 of the maximum power output of the generator is passed through to make the bond. The 
bonding time is in units of milliseconds. The bonding force, referred to as bond weight by the manufacturer, is listed below in Table 2-1. The bonder has a function to ramp from a beginning to an end bond weight in a linear profile. This function was not used in this study.

Table 2-1 Bond weight setting vs. actual bonding force

\begin{tabular}{cc}
\hline Force Setting & Bond weight $(\mathrm{g})$ \\
\hline 1 & 20 \\
5 & 25 \\
10 & 35 \\
15 & 50 \\
20 & 70 \\
25 & 90 \\
\hline
\end{tabular}

\subsection{Bonding process}

Figure 2.10 outlines the bonding steps. When the wire is fed through the capillary, a small segment, called a tail, is left at the tip. On the first step in the bonding process, the EFO unit fires a spark at the tail, melting the thin wire. The molten metal then draws itself up into a ball due to surface tension and solidifies. The capillary then moves down to the search height of the first bond, allowing the technician to precisely locate the first bond. When the position is correct, the bond head makes the bond, applying pressure and ultrasonic energy as programmed. The bonder then moves to the second location, depending on the settings, in such a way to create the proper loop profile. The bonder stops at the search height for the second bond based on settings, waiting for user input before making the wedge bond. After the second bond has been made, the bonder moves up to create the tail. The tail length is also determined by settings. In automatic mode, 
both of these waits are bypassed. The bond head moves back to the waiting position, ready for another bond.

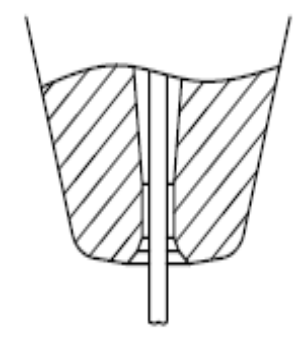

1. The bonding process begins with a threaded capillary.

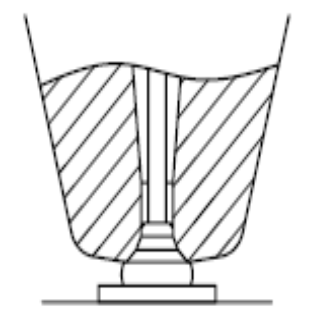

4. Force and Ultrasonic Energy are applied over Time and the Ball Bond is made.

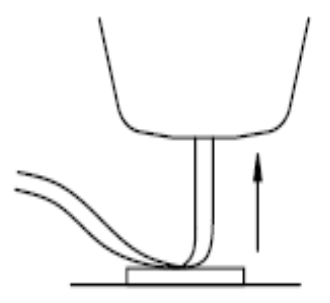

7. The capillary rises with the Wire Clamps off for a specific distance.

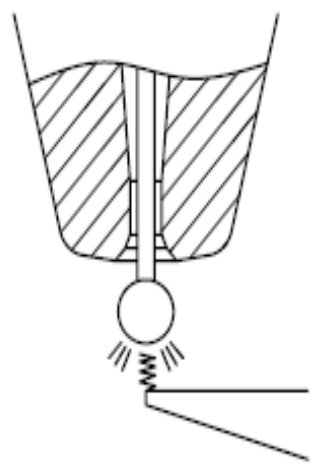

2. Electrical Flame Off (EFO) forms the free air ball.

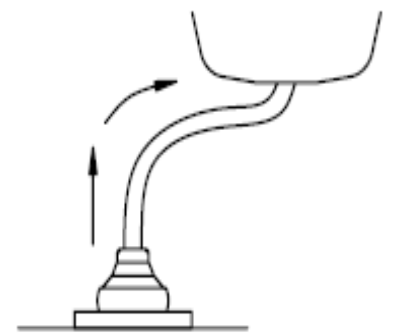

5. The Looping Sequence

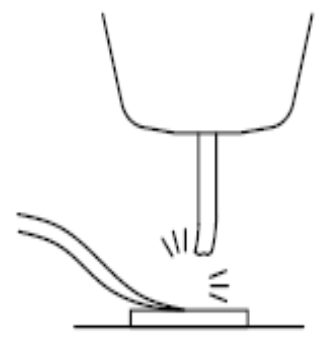

8. The Wire Clamps are applied and the wire breaks away from the 2nd Bond leaving a specific tail length.

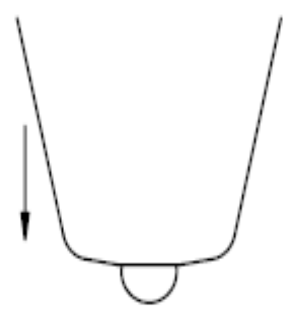

3. The capillary captures the Free Air Ball in the Chamfer Diameter and descends to the Bond Site.

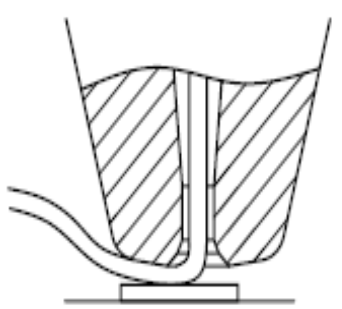

6. Force and Ultrasonic Energy are applied over Time to make the Stitch Bond.

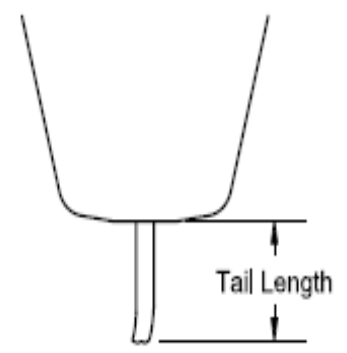

9. The Tail Length after breaking away from the 2nd Bond.

Figure 2.10 The steps to form a thermosonic ball/wedge bond (Image courtesy of Gaiser Tool Company.) 


\subsection{Pull and shear tests}

The pull and shear tests were conducted on a Dage 4000 bond tester. The machine is capable of conducting pull and shear tests by attaching the appropriate cartridge. For the pull test, the WP100 cartridge is a small hook connected to strain gauges. The computer records the readings and converts it into force at the hook upon wire breaking. The hook needs to be placed at the right location for the value to be meaningful. If not, the breaking strength of the wire needs to be determined based on the loop profile and geometry. The BS250 ball shear cartridge is a small tool steel shear blade attached to strain gauges. By accepting user input, the computer then brings the shear blade to the desired shear height before starting the shear test. This way, consistent and meaningful shear test result can be obtained. The position of the pull hook or shear blade is controlled by the attached joysticks. The left stick controls the position of the stage where the test sample is attached. The right stick controls the orientation of the hook as well as the height. The type of test is chosen by the operating system installed on a computer. The captured test data are also stored there to be retrieved and processed later. 


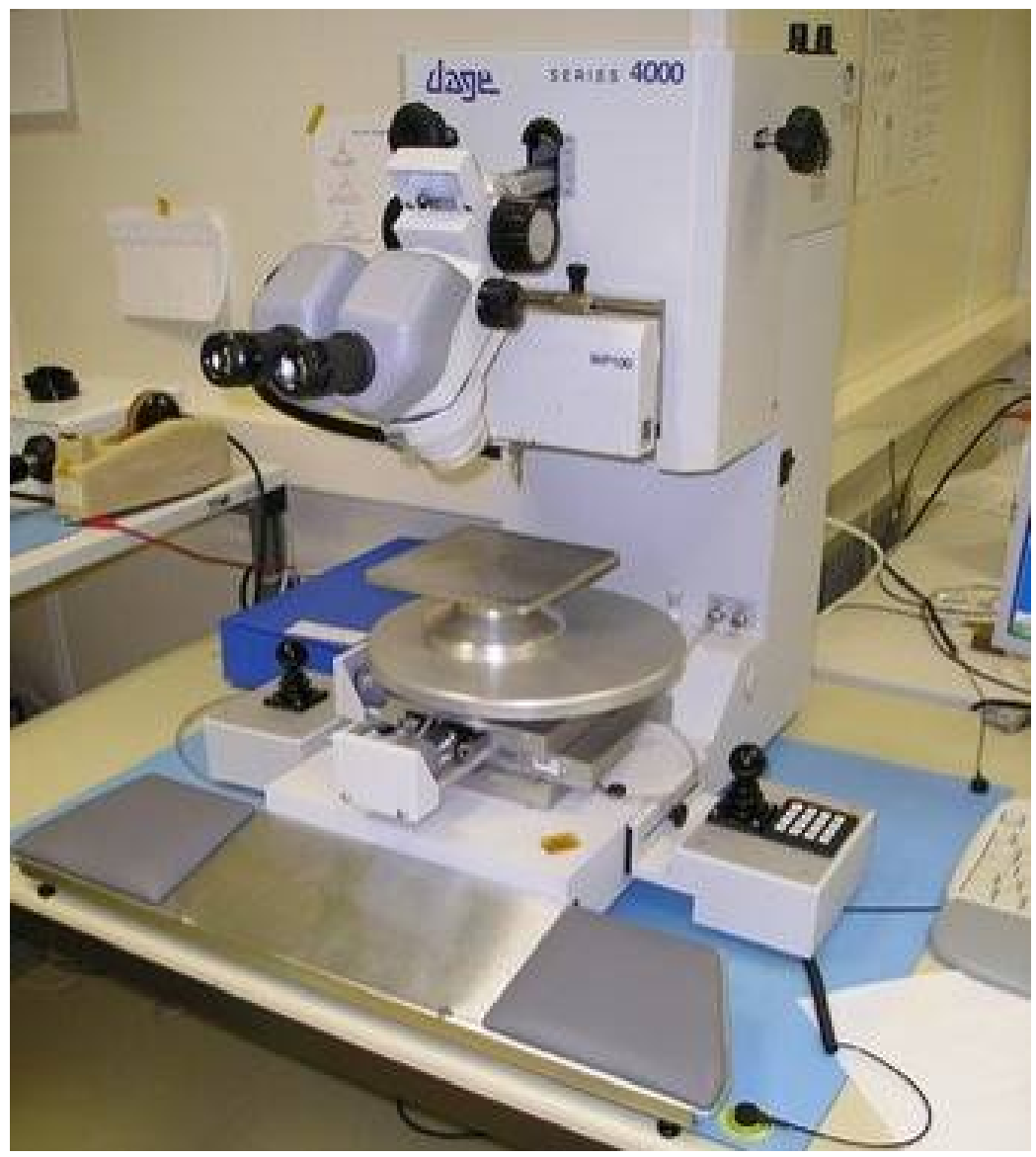

Figure 2.11 Dage 4000 wire bond tester with the WP100 wire pull cartridge installed. 


\section{Chapter 3. Literature review}

\subsection{Bonding mechanism, diffusion, and intermetallic formation}

The diffusion mechanism of wire bonding results in the formation of intermetallic layers, alloys made up of different amounts of the bonding metals. Materials have vacancies in their crystalline structure [where an atom should be but is not] caused by defects, contamination [doping and impurities], grain boundaries, and mechanical stress [as plastic deformation]. As energy is applied to the material, atoms jump into nearby vacancies and other atoms migrate into the freshly made hole. The end result is something resembling movement of crystal vacancies. Wire bonding employs this mechanism. The wire is deformed to form an intimate contact patch, and then atoms diffuse across this interface. If the wire and the bond pad materials are dissimilar, an intermetallic layer forms.

Intermetallic compounds are typically indicators of a good bond. However, uncontrolled growth of intermetallics results in failures of wire bonds that reduce yield and reliability. The diffusion rate of gold into aluminum is different from aluminum into gold and these rates are temperature dependent. When bonding to thin film, the depth of the metallization layer is much thinner than the size of the bonded gold ball and thus may be completely consumed by the process. The mass movement of vacancies and full consumption of one base metal can form voids or pores. These are called Kirkendall voids and they can cause a wire bond to become an open electrical connection. Another type of voids form around contamination left over on the bond interface. These are Horsting voids and are often mistaken for Kirkendall voids [Horsting, 1972]. 
Recent legislative changes required manufacturers to convert to environmentally friendly processes, such as lead-free solder or halogen-free epoxy. These new processes necessitate the use of higher temperatures (due to epoxy chemical properties requiring different processes) in production which in turn presents new challenges to the wire bond engineer. High temperatures influence the growth of intermetallic layers and Kirkendall voids lead to electrical and mechanical failures of wire bonds. Also, different intermetallic compounds have different electrical and mechanical properties. For example, purple plague, $\mathrm{AuAl}_{2}$, has three times the resistance of gold or aluminum and is extremely hard and brittle while $\mathrm{Au}_{4} \mathrm{Al}$ has 12 times the resistance of either base metal [Muller, et al., 2006].

Several failure mechanisms of intermetallic compounds exist. The more common ones include nonuniform or no formation of intermetallics, microcracks or voids in the intermetallic compounds, and corrosion of the compounds due to humidity. When intermetallic compounds fail to form or form irregularly [i.e. IMC's forming only in certain spots in the weld area], the root cause is a barrier that inhibits the diffusion process, such as a layer of aluminum oxide that was so thick that the combination of substrate heat, ultrasonic scrub, and bonding pressure could not remove, or a layer of organic contamination that was left over from the fabrication of the bonding pads. All of these failure modes are made apparent when the pull and/or shear test register greatly reduce bond strength [Muller, et al., 2006].

\subsection{Ultrasonic deformation of metals}

Before diffusion can occur, there needs to be intimate contact between the wire and the bond pad. To enable this, the wire is plastically deformed and pressed into the 
pad surface. Historically, this is achieved in thermocompression bonding by heating the wire and then applying the bonding pressure. Typically, the temperatures needed for this process is extremely high and would destroy modern integrated circuits. Ultrasonic energy has largely replaced heat as the source of energy for both deformation and diffusion.

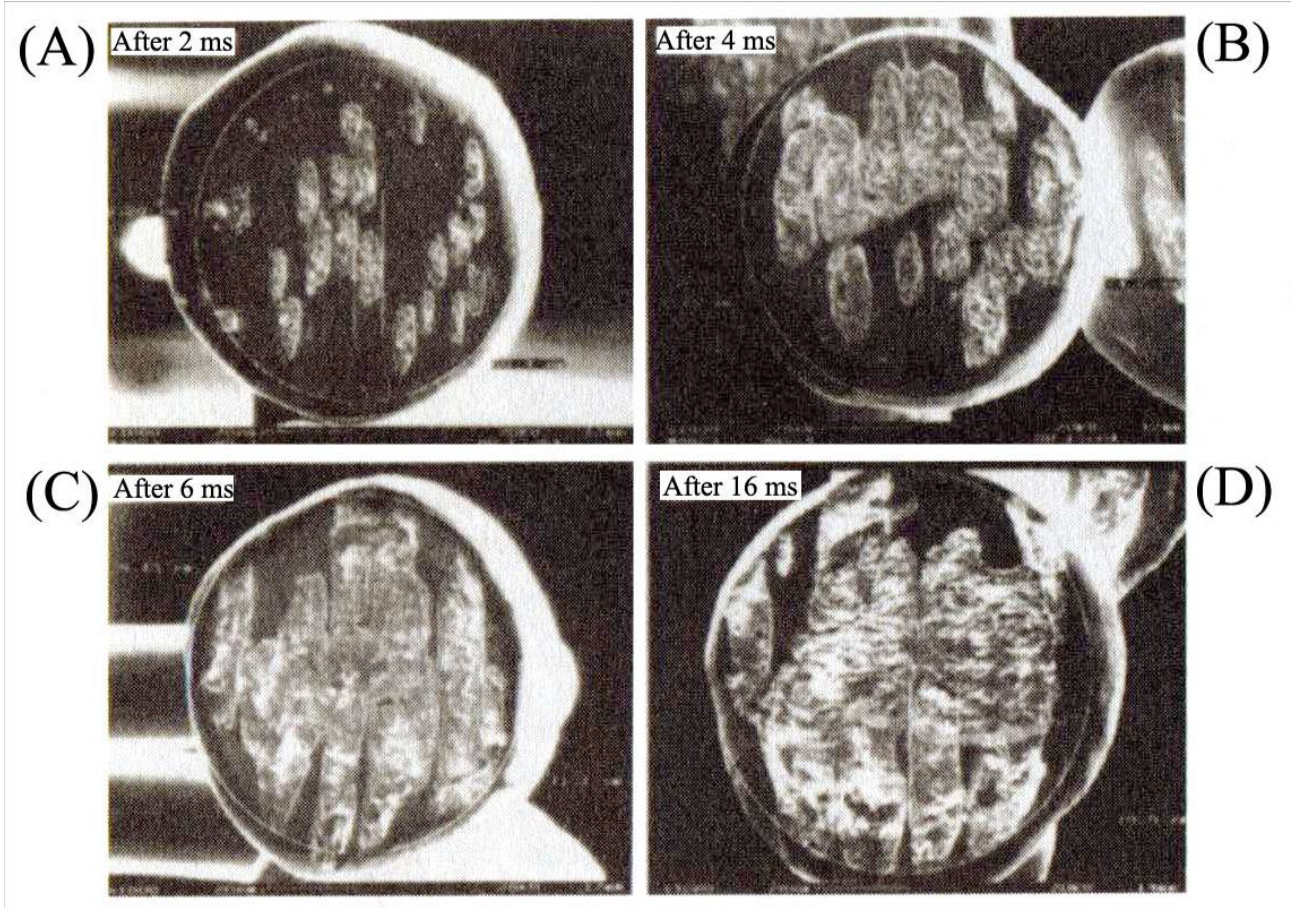

Figure 3.1 Weld area growth as a function of bond dwell time, (A) $2 \mathrm{~ms}$, (B) 4 ms, (C) 6 ms, (D) 16 ms [Harman, 1997]

When ultrasonic energy is applied to metals, they become soft and more easily deformed. The mechanism is very similar to application of intense heat energy, except acoustic softening requires much less energy for the same amount of deformation. For single crystal aluminum, it takes as much as 10 million times more thermal energy density to bring the aluminum to zero apparent stress state than acoustic energy $\left[10^{22} \mathrm{vs}\right.$. $\left.10^{15} \mathrm{eV} / \mathrm{cm}^{3}\right]$. Acoustic energy is absorbed by the metals at dislocations in the metal lattice and grain boundaries, regions known to play parts in plastic deformation, and is 
not attenuated in the defect-free regions. Thermal energy is instead distributed amongst all the atoms in the lattice, even those not participating in deformation, making ultrasound enormously more efficient than heat when the desired effect is plastic deformation, a key feature in wire bonding. Similarly, ultrasonic energy is more efficient when used as activation agent for diffusion [Langenecker, 1996]

Applied ultrasonic energy causes localized heating at crystal lattice dislocations. It has been reported that as much as $50 \%$ of the electrical energy input is converted into heat [Langenecker, 1996]. Also depending on the frequency of ultrasound applied, heated zones occur at various points along a metal specimen's axis. The acoustic radiation also reduced the grain size within the specimen's structure. Further experimentation showed that there is no structural difference between a specimen broken by ultrasound and melted apart by a torch [Langenecker, 1996].

Wire bonding requires that the wire is plastically deformed to form intimate contact at the bond interface and that the material's internal energy is raised above the threshold energy for diffusion to occur. Both thermal and ultrasonic energy can accomplish this. However, the way the energy is absorbed by the crystalline structure means that significantly less energy is required to deform the wire and enable diffusion by using ultrasound. Higher frequencies are even more efficient at delivering power and much research has been done to study such effects, though none have been done in a systematic approach aimed for production.

\subsection{Effects of ultrasonic frequency}

When bonding dissimilar metals, byproducts of diffusion form as intermetallic compounds. The intermetallic layer of the highest quality wire bonds are always 
developed through the finest phase growth, free of contamination and not afflicted by unoptimized bonding parameters. Crucially, the ultrasonic power used to create these wire bonds should be fine tuned to ensure that the interfacial atoms are excited above the threshold energy without overbonding.

It is known that ultrasonic energy is absorbed at dislocations, grain boundaries, impurities, etc..., and this mechanism is responsible for the metal softening effect observed by Langenecker [Langenecker, 1996]. While this effect is similar to that seen when metal specimens are heated, the energy density required by ultrasound is ten times less than that required by thermal energy to produce deformation in aluminum with no applied stress, signifying that ultrasound is far more efficient at delivering its energy than heat. The higher the ultrasonic frequency, the more efficiently energy is delivered to the bond [Ramsey and Alfaro, 1991].

The threshold energy required to initiate diffusion is reached by the product of ultrasonic power and dwell time. With higher ultrasonic frequencies, wire bonds can be made at substantially reduced dwell times without significant impact to bond quality, if any. There is, however, an upper limit to the highest ultrasonic frequency that can be used before bonds are damaged, regardless of dwell times. The authors dub this phenomenon "reactivity enhancement" and noted that the total surface area of intermetallic formation, a metric for bond adhesion, increased from 20 to $100 \%$ of the bond intimate contact area. Higher ultrasonic frequency enhances reactivity and leads to generation of intermetallic phases at initial bonding that is otherwise not seen until the sample has been thermal aged for several hours [Ramsey and Alfaro, 1991]. 
One caveat with reactivity enhancement is that overbonding is easier. Metals become work hardened and eventually fracture if ultrasonic energy is applied for too long, which leads to overly deformed bonds and generally compromised structural integrity [Ramsey and Alfaro, 1991]. However, if steps are taken to control the bond deformation, higher ultrasonic frequencies can significantly shorten bonding dwell times, leading to greater production throughput with much higher bond quality.

Ramsey and Alfaro's earlier study on high frequency ball bonding concluded that higher frequencies significantly lower the bonding power and change other bonding parameters required to ensure strong bonds. In fact, thermosonic bonding even results in overbonding when higher frequencies are used. At high enough frequencies, room temperature bonding is possible. For substrates that cannot be subjected to high temperatures without adverse effects, room temperature bonding would be ideal to avoid material glass transition, which leads to severe mechanical problems [Ramsey and Alfaro, 1997].

Thermal energy is substituted by ultrasonic energy in phonon processes. Quanta of vibrational energy, phonons are generated and interact with each other, resulting in thermal reactions at the macroscopic level. Experiments with metal specimen have determined that there is no discernable difference metallurgically speaking between thermal and ultrasonic energy absorption: a specimen requires much less stress to cause a specific level of deformation by absorbing heat or ultrasonic energy (the latter at room temperature) [Langenecker, 1996].Localized heating and dislocation movement and slip occurs at lattice discontinuities for ultrasonic energy instead of occurring at bulk for thermal energy [Ramsey and Alfaro, 1997]. 
Since phonon generation is attributed to both ultrasonic and thermal energy, higher energy input from one type lowers the demand for energy from the other. Since higher ultrasonic frequency creates more phonons, less thermal energy is required to raise the internal energy of the crystal lattice. This means that bonding power, bonding time, or preheat temperature can all be reduced as appropriate. Therefore, processes that would like to avoid heat can use high frequency ultrasonic power to achieve this goal, and processes that require higher throughput can also use high frequency to shorten bond dwell time.

Plastic deformation enables intimate contact at the bond interface, but excessive deformation is undesirable since it weakens the neck of the wire and impacts the bond pad pitch. Overbonding is the main cause of excessive deformation, but this can sometimes be unavoidable as the level of ultrasonic power required to initiate and sustain diffusion causes too much acoustic softening. Doubling the ultrasonic frequency to enhance reactivity created robust bonds that require much lower bond dwell times and did not deform excessively [Gonzales et al., 1996]. For high speed production, switching to high frequency ultrasonic energy solves many problems presented by demand for high throughput of fine pitch wire bonds.

Early research into high frequency wire bonding all show that bonds can be made at lower preheat temperature with shorter bond dwell times, and the bonds would not excessively deform [Ramsey and Alfaro, 1997; Gonzales et al., 1996]. However, no studies systematically compared wire bonds made with different ultrasonic frequencies while tightly controlling all other parameters until recently. Charles et al. compared wire bonds made at $60 \mathrm{KHz}$ to those made at $100 \mathrm{KHz}$ and investigated the impact of higher 
frequency (specifically $100 \mathrm{KHz}$ ) ultrasonic energy on thermosonic wire bonding. All equipment and parameters are controlled as much as possible to provide direct comparison between 60 and $100 \mathrm{KHz}$ bonds. Two identical machines were set up for the experiment with the only differences being the ultrasonic transducer and generator. One technician operated both machines. The ball bond diameters are measured in both directions parallel and perpendicular to ultrasonic scrub. The free air ball size was carefully controlled to ensure repeatability. The majority of the bonds are single ball bonds only. A select few were complete bonds with both first (ball) and second (wedge) bonds. The primary test method is the ball bond shear test. For complete bonds, pull tests were also conducted. Thermal aging studies were performed at various temperatures $\left(125^{\circ} \mathrm{C}\right.$ to $\left.200^{\circ} \mathrm{C}\right)$. The test data was analyzed using the F-test at $99 \%$ confidence level [Charles et al., 2002].

The results of the study confirmed conclusions drawn by other authors (Ramsey and Alfaro, Gonzales et al.) Charles et al. quantified the time saved by using the high frequency system. Despite the fact that the higher frequency is more finicky to pick out the right optimized bonding parameters for, robust bonds can be made by the $100 \mathrm{KHz}$ system with dwell times that are 30 to $60 \%$ shorter than by $60 \mathrm{KHz}$. The bonds made with the higher frequency also registered higher shear strength and the increase cannot be accounted for by the size of the ball. For both frequencies, progressive thermal aging significantly increased the shear strength [Charles et al., 2002]. The conclusions drawn add further credence to the hypothesis that higher ultrasonic frequencies make stronger bond using less dwell times and formed bonds are subject to the same environmental effects regardless of bond frequency. 
In another study into wire bondability, it is once again confirmed that stronger wire bonds can be made with less dwell time and lower deformation by using high frequency ultrasound [Chan et al., 2008]. The authors also experimented with how the ultrasonic energy is delivered to the bond site. Almost all wire bonding is done through an open control loop with the power input into the transducer fixed at predetermined amplitude. However, as soon as micro welds begin forming, the increased drag causes a resonance frequency shift. The transducer becomes out of tune and the energy transferred into the bond interface is less than the maximum. A closed loop system monitors the frequency shift and adjusts the power to match, ensuring that the bond receives the entire amount of energy it requires throughout the whole bond dwell time [Chan et al., 2008]. The result is that the closed loop system requires a lower peak power input to form a robust bond thanks to its ability to adjust power on the fly without applying so much power that the bond is excessively deformed.

\subsection{Effects of contamination}

Contamination is one of the greatest inhibitors of wire bonding by forming barriers at the bond interface and prevents atoms from diffusing. Even after bonds have been formed successfully, surface contaminants could become seeds where voids form after extended thermal aging. These are Horsting voids and are commonly mistaken for Kirkendall voids [Horsting, 1972]. Surface contaminants are most likely created during fabrication and sometimes from improper storage.

While other metals are cheaper than gold and offer a tempting, less expensive alternative, only gold is free from corrosion. For example, one of the many problems facing copper bonding is the formation of copper oxide upon exposure to standard 
atmosphere. To prevent this, inert gases are continuously pumped over the copper during bonding. Copper wires must be properly stored to ensure cleanliness. For gold on gold bonds, the source of contamination is organic photoresist left over from the fabrication of the substrate. This is another common surface contaminant seen in wire bonding. These surface films are stable at lower temperatures (below $\sim 250^{\circ} \mathrm{C}$ ) and need to be cleared away before bonding can occur [Jellison, 1977]. Table 2 lists some impurities that can lead to weakbonds.

The bonding mechanism includes sweeping away surface contaminants by shear displacements at the bond interface. For thermocompression bonding, the shear displacement comes from the expansion of the ball or the wire as it deforms. For thermosonic bonding, the ultrasonic vibration also aids in clearing the surface contaminants. Eventually, the weld starts to grow, and its growth rate is dictated by the nature of the contamination [Jellison, 1975].

The dependence of thermocompression bonds on temperature is directly related to the level of organic contamination on the bonding surface. Higher temperatures make breaking down the contamination easier and good bonds can then form. The surface can also be cleaned before bonding by ultraviolet radiation or plasma scrub. When the contaminated substrates were properly cleaned, the bondability of the metallization was restored. The temperatures required to make good bonds were significantly lower than before the substrates were cleaned [Jellison, 1977]. 
Table 3-1 Partial list of impurities that can cause poor bond adhesion

[Harman, 1997]

\section{Contaminant type}

\begin{tabular}{ll}
\hline Halogens & Plasma etching (dry processing) \\
& Epoxy outgassing \\
& Silox etch \\
& Solvents \\
& Photoresist stripper \\
\hline Contaminants from & Thallium \\
plating & Lead \\
& Chromium \\
& Nickel \\
& Iron \\
& Copper \\
& Hydrogen \\
& Brighteners \\
& Epoxy \\
& Ambient air (due to poor storage) \\
& Human contaminants (spittle, mucus, small particles of \\
& skin, hair, sweat, etc...) \\
Photoresist \\
\hline Organic contaminants \\
Sodium \\
Phosphorus \\
Carbon \\
Copper \\
Titanium \\
Bismuth \\
Cadmium \\
Soft oxides \\
Moisture \\
\hline Others & \\
& \\
& \\
& \\
& \\
& \\
& \\
& \\
& \\
& \\
& \\
& \\
& \\
&
\end{tabular}

\subsection{Effects of flexible substrates}

Wire bonds are generally made on rigid substrates to ensure efficient energy distribution into the bonds. When bonded on flexible substrates such as FR-4, which is 
the same material the substrates in this study was made of, the nonrigid backing serves as damping so there is less energy going into the bonds themselves. For this reason, bonding on flexible substrates is considerably more difficult than it would be otherwise, requiring compromises to be made in regards to bonding strength or speed. Also, some polyimides or epoxies are known to absorb moisture during storage, causing further difficulties to bonding by damping the ultrasonic vibrations even more as well as potentially causing reliability problems down the road [Hall, et al., 1996].

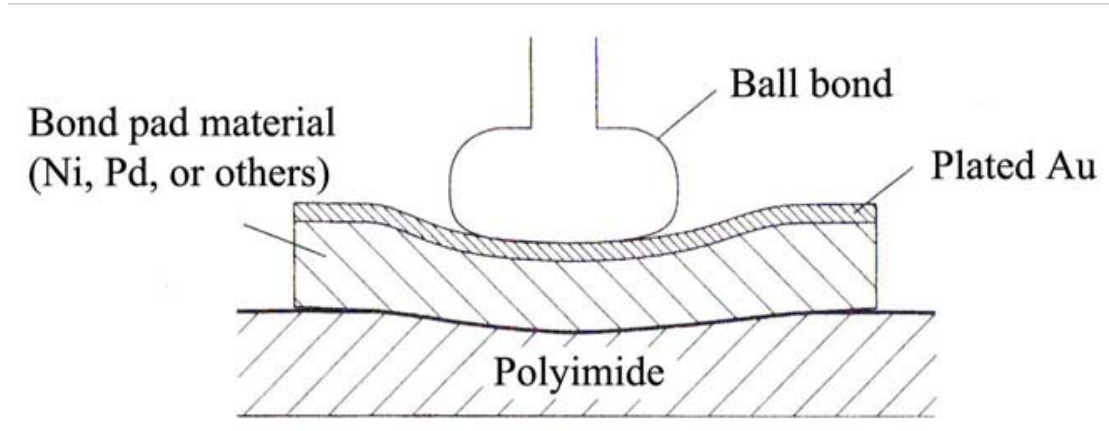

Figure 3.2 Exaggerated deformation of bond pad and flexible substrate after bonding. With enough vertical force, the bond pad may even delaminate from the substrate [Harman, 1997]

\subsection{Failure mechanisms}

For certain applications such as traction, electronic devices typically see voltages up to $3.3 \mathrm{kV}$ and current levels up to $1200 \mathrm{~A}$. With that much power flowing through a device, wire bonds experience high levels of thermomechanical stress as heat is generated and dissipated by the device. Several aluminum wires, each $500 \mu \mathrm{m}$ (20 mils) thick, are bundled together to handle rated currents as high as $75 \mathrm{~A}$, with each wire being responsible for delivering almost $10 \mathrm{~A}$ when the device is operating. Wire bond reliability is extremely important here [Ramminger, et al., 1998]. 
The primary failure mechanism for the wire bonds in these devices is crack formation at the bond interface due to thermal cycling. As the wire is unable to flex at the terminations, highest levels of thermomechanical stress can be found there. Localized strains formed due to the different thermal expansion rates cannot be accommodated by the brittle intermetallic layer and thus cracks begin to form and propagate. During bonding, the deformed wire material lead to the growth of small grains near the interface. At the center of the wire, grain sizes are much larger. Cracks grow along the grain boundaries into the welded interface [Ramminger, et al., 1998].

A finite element model is used to study this phenomenon. Initially, the model is free of stresses and tensions at $\mathrm{T}=100^{\circ} \mathrm{C}$. The input is an instantaneous temperature drop of $75 \mathrm{~K}$. The stress caused by this drop is relieved by plastic deformation of surrounding areas. When the model is modified to simulate thermal cycling using nonlinear fracture analysis, the model shows that the cracks stop growing after a certain amount of time because the strain energy density decreased until it can only cause elastic instead of plastic deformation. However, when the model is simulated as being active, the cracks kept growing due to the current density and the associated temperature rise [Ramminger, et al., 1998].

Damage to wire bonds can occur at several points during the bonds' lifetime. During bonding, a worn out tool may cause cracks in the heel of the wedge bonds, making them more likely to fail. The cracks would propagate in the field when the bonds are subjected to excessive flexing such as during thermal cycling and eventually end in fatigue failure [Harman, 1974]. 
Overbonding sometimes leads to cratering of the silicon substrate under the bonding pad. This can result in mechanical failure of the bond where the pad separates from the substrate or electrical failure where the crater causes an open circuit. Wire hardness, ultrasonic power level, bonding force, impact velocity, or any combination of these can cause cratering. Using hard wires typically require higher bonding force and ultrasonic power to make a bond, further aggravating the area [Harman, 1974].

If the as-made wire bonds are subjected to extreme environments, other failure modes will occur. High temperatures accelerate diffusion, causing growth of intermetallic layers and eventually formation of Kirkendall or Horsting voids. Thermal cycling, especially with encapsulated packages, causes fatigue failures by repeatedly flexing the wires. Humidity can cause corrosion, eventually leading to mechanical failures. Wire bonds need to be subjected to these tests to ensure that they are robust in manufacturing and in the field. Even though the wire bonds in this particular study may not be used for power devices, it is still crucial to examine the wire bonds after reliability tests to ensure that the bond integrity has not been compromised.

\subsection{Optimization of wire bond parameters}

Optimization of wire bond parameters requires four different variables with many different levels for each. In a typical experiment, every variable except one is held constant. A change in data can then be confidently attributed to the changes in that variable. However, the number of experiments that needs to be conducted to fully understand the results grows exponentially as the number of variables increase, making it extremely cumbersome. Also, interaction between two or more variables cannot be captured since the effect on the data can only be observed when those interacting 
variables are varied simultaneously. The methods of design of experiment and analysis of variance are the perfect tools for structured and efficient control of a process with a large number of variables, such as wire bonding. The analysis can identify the main effects and interactions of variables and how they affect the pull and shear strengths of wire bonds [Sheaffer and Levine, 1990].

\subsection{Testing wire bond integrity}

To quantify bond integrity, the industry standards are the destructive pull and shear tests. The wire bond pull test, along with the ball bond (and sometimes wedge bond) shear test, makes up a part of the process evaluation and bond reliability testing methodology available to the wire bond engineer today. Though the pull test is a widely accepted method, standards must be strictly followed to ensure that the test results are valid. An engineer who lacks full understanding of the variables of the wire bond pull test could unintentionally cheat, reporting high pull strength and misinterpreting the results.
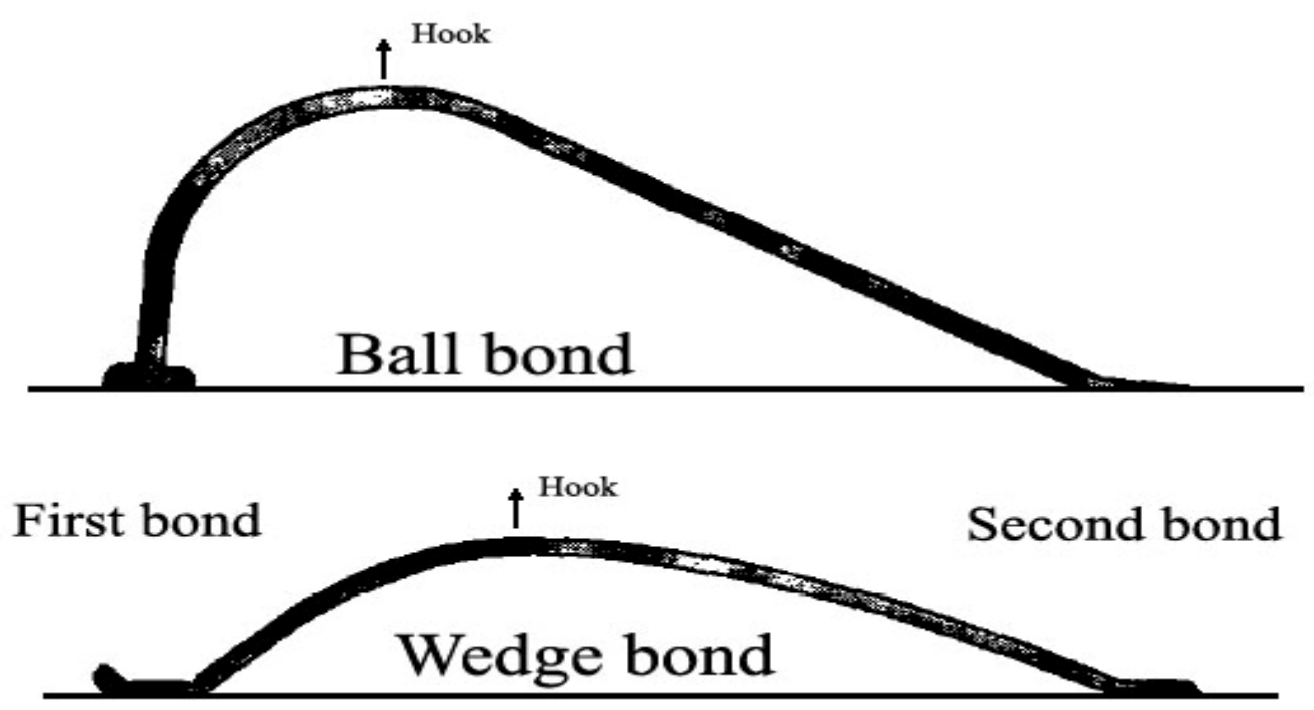

Figure 3.3 Wire bond pull test for ball-wedge bond (top) and wedge-wedge bond (bottom) [Harman, 1978] 


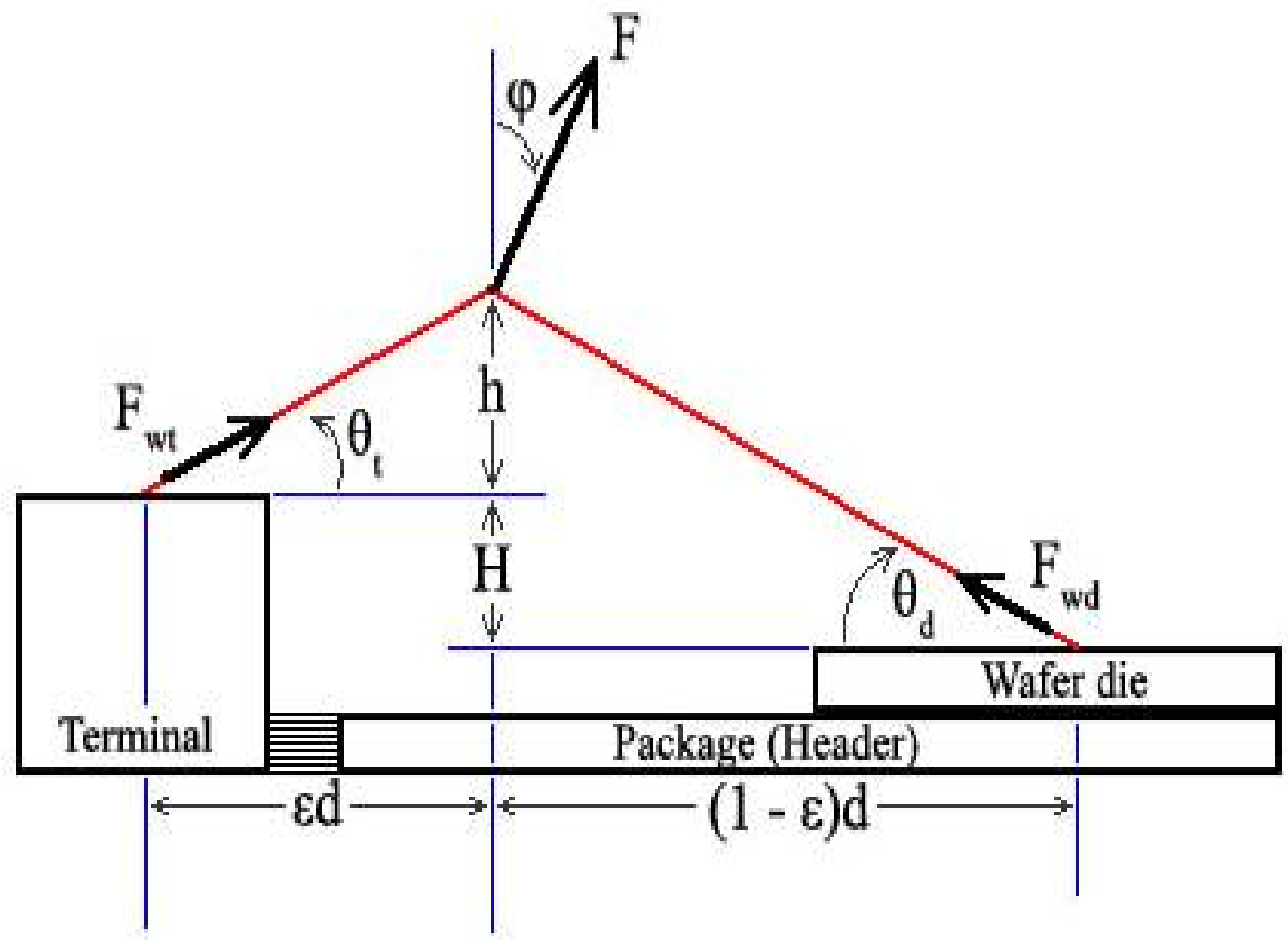

Figure 3.4 Force components of a wire bond pull test [Harman, 1978]

The force in the wire at the die side is

$F_{w d}=F\left[\frac{\left\{1+\frac{(1-\varepsilon)^{2} d^{2}}{(H+h)^{2}}\right\}^{1 / 2}(h+H)\left\{\varepsilon \cos (\phi)-\frac{h}{d} \sin (\phi)\right\}}{h+\varepsilon H}\right]$

(2) [Harman, 1978]

The force in the wire at the terminal side is

$$
F_{w t}=F\left[\frac{\left\{h^{2}+\varepsilon^{2} d^{2}\right\}^{1 / 2}\left\{(1-\varepsilon) \cos (\phi)-\frac{(h+H)}{d} \sin (\phi)\right\}}{h+\varepsilon H}\right]
$$

(3) [Harman, 1978] 
If the first and second bonds are on the same level, and the hook is straight and placed in the middle of the bond, then $\mathrm{H}=0, \varphi=0, \varepsilon=0.5$, and $\theta_{\mathrm{w}}=\theta_{\mathrm{t}}=\theta$, and the force in the wire is [Harman, 1978]

$$
F_{w d}=F_{w t}=\frac{F}{2} \sqrt{1+\left(\frac{d}{2 h}\right)^{2}}=\frac{F}{2 \sin (\theta)}
$$

The pull strength reading must be carefully reviewed to ensure meaningful results. For example, bonds with higher $h / d$ (wire loop height per loop length, see Figure 3.4) ratios typically register higher pull strength, so consistent loop height and loop length must be maintained. A bent pull hook may introduce an angle $\varphi$ of 5-10 degrees. Misjudgment of the position of the pull hook may result in off-center placement. Even worse, the pull hook may slip on the wire to another location as the pull test is conducted. The limitations of the 2-D model do not take into account the out of plane misalignment of the hook, which may tear the bond and alter the pull strength reading. Also, for overly deformed bonds, the change in strength could be significant [Harman, 1978]. For production purposes, then, the pull strength need to be converted from tester readings to actual bond strength based on geometry of the loop, and the placement and alignment of the hook. For bonds that are identical, the pull strength as read can be used to evaluate bond integrity since the general trend of the pull test is important and the absolute value of the wire tensile strength is less so.

For ball bonds, the wedge bond is generally weaker than the ball bond due to the amount of bonded area under each location. When the hook is placed at the high point of the loop, the second bond is rarely tested due to the geometry. Thus, placing the hook at 
the high point of the loop tests the strong bond for ball-wedge bonds and the weak bond for wedge-wedge bonds. For this reason, it is recommended that the pull test place the hook in between the first and the second bond regardless of bond type. For ball-wedge bonds, the formation of the ball using EFO creates a weak zone in the ball neck. The wire will tend to break in this zone with a force that is lower than its tensile strength. This is also true for overly deformed bonds due to excessive application of ultrasonic energy [Harman, 1978].

Even with all the possible mistakes when conducting the pull test, the test itself is forgiving. Assuming that both bonds are equally strong (in the case of the ball bond, no bond lifts are expected), not overly deformed (bonding parameters properly optimized to ensure good bonds with no overbonding), and the break mode is tensile (no bond lifts), the bond pull strength is not expected to deviate more than $20 \%$ from results obtained through standard procedures, even with the wide range of hook positions and angled pull hook [Harman, 1978].

The pull test is extremely sensitive to overly deformed bonds with test data showing that overly deformed bonds have lower pull strength [Harman, 1978]. For wedge bonds, the deformed heel may lose a large portion of its cross sectional area, resulting in a critically weak spot that will break when the pull test is applied. For a ball bond, large deformations over work the metal at the bond heel, causing weak pull strength due to fatigue. Ultrasonic energy softens the metal in the wire and the pressure applied by the bonding capillary deforms it. Excessive ultrasonic energy will cause the metal to become too soft and it will flow more easily when the same amount of bonding pressure is applied to it. In a wedge bond, the result is a thinner neck. In a ball bond, the result is a 
larger ball. However, the vibration amplitude overworks the wire and causes it to weaken [Harman, 1978].

For ball bonds, proper optimization is dependent on both the pull and the shear strength. The pull test is a good indicator of excessively deformed bonds. Along with the shear test, it is a key tool for initial set up of wire bonders. However, care must be taken to ensure that the pull test is conducted properly and that the test results are interpreted correctly. Pull testers should be properly calibrated and the operator should fully understand the implications of the results.

The pull test is the first test developed for determining the integrity of wedge bonds. While pull test data are often adequate to determine bonding machine setup for wedge bonders, they are not good enough to allow setup of ball bonders. Ball bonds have interfacial weld areas that are typically six to ten times the cross sectional area of the wire itself, thus even a poorly made bond will most likely break at the wire rather than lift the ball bond. Additionally, the heat affected zone in the wire is annealed and recrystallized due to the heat from the EFO process, resulting in significantly larger metallic grain sizes in the area and thus creating the weakest point in the ball bond. In a pull test, the wire would most often break at this point. Since the weakest point in the bond is not the area of interest (that is, the adhesion between the wire itself and the bond pad is not tested), the shear test can be used to verify the bond strength at the interface directly [Harman, 1984].

The first shear tests are done without any force indicators, allowing the technician and the engineer to only qualitatively assess the bond strength (Figure 3.5). The first shear tester designed with force readout did so by loading a blunt shear tip with a spring 
connected to a force scale. The force was indicated on a dial. Later evolution of the shear testing apparatus saw the use of strain gages and computerized data acquisition systems replacing spring scales and dial indicators. Figure 3.6 shows an early shear tester. The shear blade is positioned manually. The motor drives the translation stage and the load cell registers a force against the shear blade. Even if such sophisticated equipment is not available, technicians and engineers can use manual shear tools to check for bond integrity by simply breaking bonds with a tweezers tine or a ground down jeweler's screwdriver (Figure 3.5). It is difficult to maintain the vertical clearance and the direction of force and so the test is only qualitative, but the shear remnants give an idea of bond integrity. The shear remnants provide information about how much of the bond area is weldment and how much is left unbonded and ball bond machine parameters can be adjusted to compensate [Harman, 1984]. For an ultrasonic bond, the heel becomes metallurgically overworked as ultrasonic power is applied, weakening the bond heel as deformation increases. Meanwhile, the weldment area increases. As the bond heel weaken, the pull strength decreases. The shear test is completely insensitive to the condition of the heel.

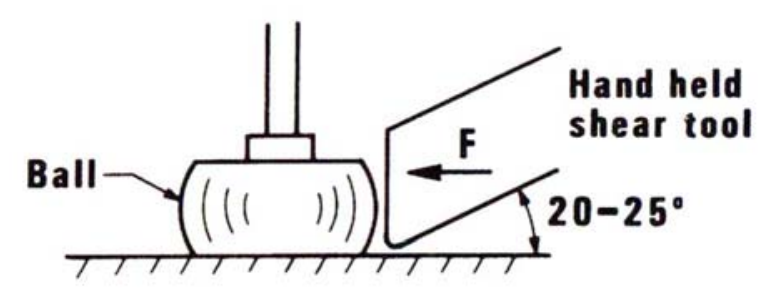

Figure 3.5 Schematic diagram of a manual shear probe [Harman, 1997] 


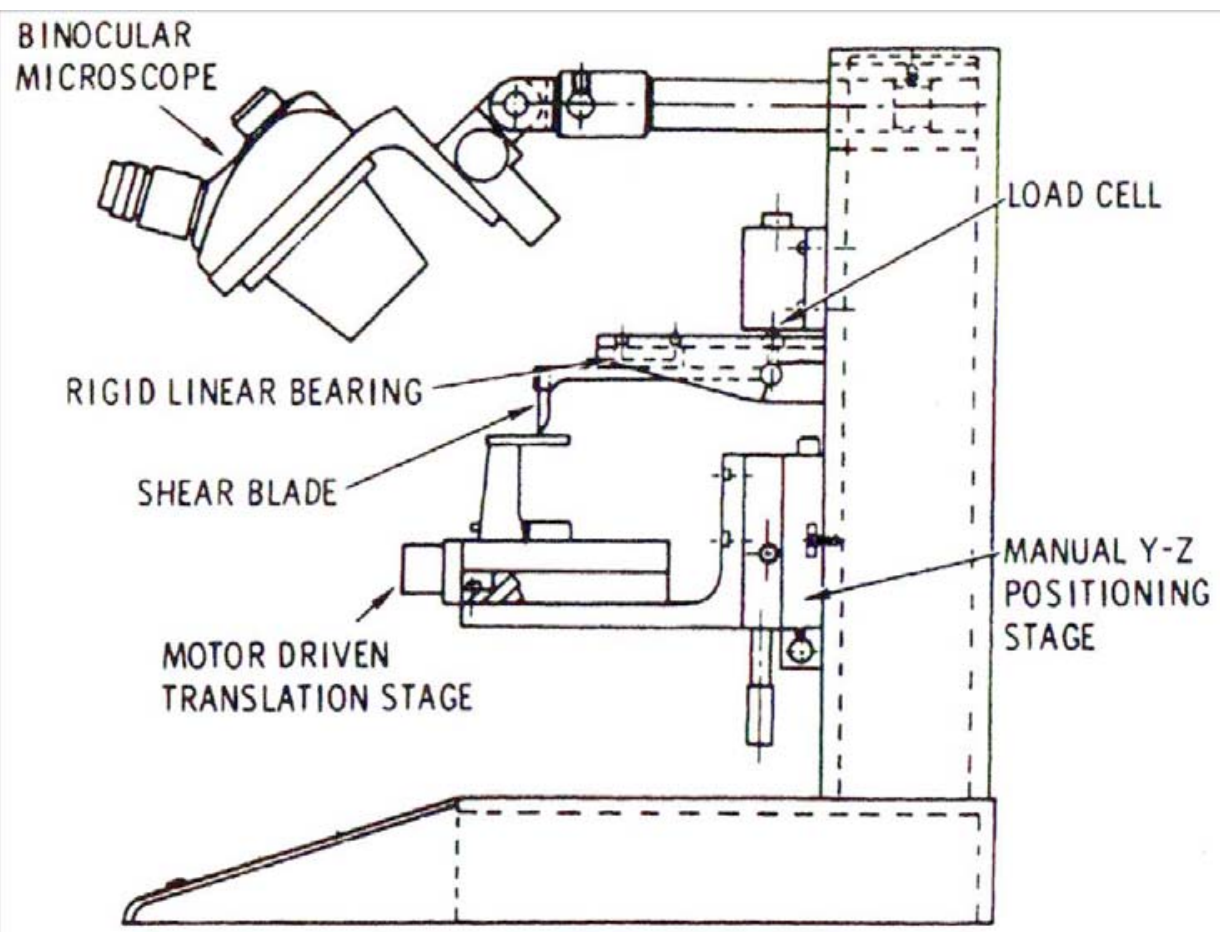

Figure 3.6 Schematic diagram of an early shear tester [Jellison, found in

\section{Harman, 1997]}

The shear test, besides being used to setup the bond parameters for ball bonders, can be used to study other external factors that affect bondability. Jellison and White conducted studies on the effect of contamination on bondability [Jellison, 1975]. The lower shear strength show that contaminations had an adverse effect on bondability, and perhaps more crucially, that cleaning the bond pads with oxygen-plasma or ultravioletozone restored bondability and even improved reliability, seen through significantly improved shear strength.

One of the main concerns for Au-Al bonding is the growth of intermetallics and Kirkendall voids, and the shear test is the only one with the sensitivity to follow the decrease in bond integrity as the intermetallic layer grows and voids develop. The lower tensile strength of the wire compared to the strength of the bonded area tend to mask the 
weakness of the bond. Engineers using the pull test will not notice the weakening bonds until the strength reaches that of the wire pull strength, especially since electrical testing shows no impairment in device operation due to voids. If not caught, the growth of intermetallics and Kirkendall voids will cause mechanical failure of wire bonds far before an electrical failure can be detected. This is not acceptable, especially if the devices are used in life critical applications [Harman, 1984].

The shear test is also used extensively in production quality control. Like the nondestructive pull test, the nondestructive shear test can be used to randomly check the quality of bonds and then statistically determine the condition of the production batch.

Ball bonds benefit greatly from the shear test, but wedge-wedge bonds can also benefit from the shear test as well. Since the ball bond capillary differs so greatly from the wedge bond capillary, the shapes of the bonds are different as well. The wedge in a ball-wedge bond is much too low and the shear test cannot be applied to it. However, the wedge in a wedge-wedge bond is considerably taller and shear testing is possible, especially for large diameter wire such as those used in power devices. The shear test can be used to aid the pull test in bonding machine setup.

When conducting a shear test, the vertical position of the tool is extremely critical. When placed too low, the tool would drag on the metal bonding pad, causing a false readout. When placed too high, the tool would shear the wire's heel or simply smear over the ball. Even with the tool placed correctly, the rigidity of the linear bearing is also important since it is extremely undesirable to have the shear tool dig into the ball as it travels across [Harman, 1984]. 
One of the most unusual problems with the shear test for gold-gold bonding is that gold can friction weld to gold. Figure 3.7 shows a ball bond with rewelds after shear testing. The ball is grossly deformed from the shear blade as a result of friction rewelding and the shear remnants show more bonded areas than just the ball bond itself. According to Vine in private communications to Harman, a histogram of the shear force shows successive peaks in the readings due to the ball rewelding itself onto the gold surfaces [Harman, 1984]. Charles, through another private conversation, reported that data with a peak reading system will report the highest shear strength and thus well bonded balls will not experience issues with rewelds [Charles, 1983]. However, for poorly bonded balls, the reweld strength may exceed the initial bond strength and thus caution must be taken to resolve this issue. Vine, in private conversations with Harman, prevented rewelds by spraying thinned oil on the substrate after bonding but before shearing so that as the remains of the ball crash down on the bonding pad, the layer of oil will prevent rewelding [Harman, 1984]. Charles designed a tool that lifted the remains of the ball and thus prevented rewelds. Au-Al bonds do not reweld after shearing, presumably due to the aluminum oxide layer on the bonding pad acting as a barrier to rebonding [Charles, 1983].

If the metallization adheres weakly to the substrate, the shear test will register lower values than normal. However, judging the quality of the bond on the shear strength alone is not enough. Additional review of the weld area may be necessary since it may not be possible to visually identify lifted metallization. Also, applying excessive force when bonding to semiconductor may cause the material to fracture. When the shear test is applied to these bonds, the fractured semiconductor material would crater and the result is 
low shear force with high standard deviation [Harman, 1984]. The shear test thus can also be used to identify weak metallization adhesion as well as excessive bonding force when setting up the bonding parameters.

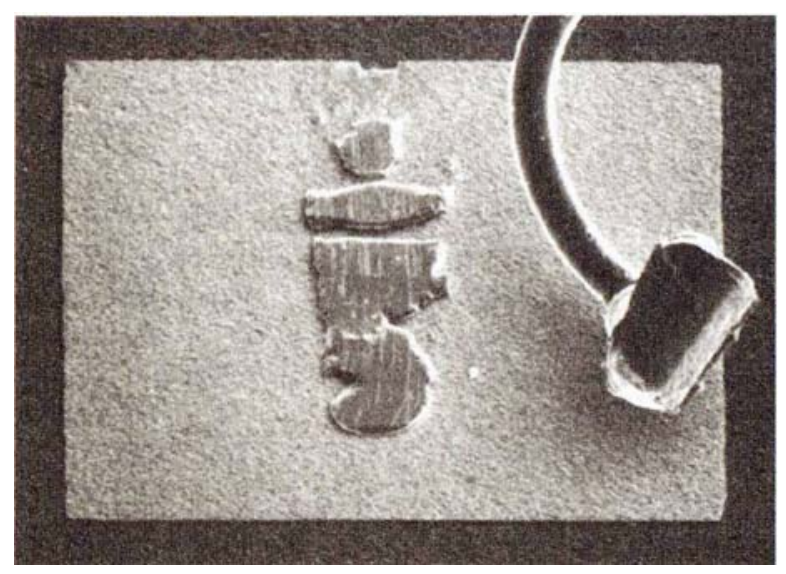

Figure 3.7 Friction rewelding of a gold ball bond [Weiner, found in Harman, 1997]

The shear test and the pull test are good tools to judge the integrity of wire bonds. For ball bonds, the pull test alone is not good enough to judge the integrity since the cross section area of the wire is much smaller than the welded area in the interface between the ball and the bonding pad. The pull test is thus only as sensitive as the tensile strength of the wire and the actual integrity of the ball bond is left unchecked. The shear test checks not only the interfacial weldment but allows the bonding engineer an insight into the actual condition of the bond, whether it is bond pad contamination or cratering of semiconductor material and he or she can then alter the bonding machine parameters appropriately.

The pull and shear tests are the best methods to quickly and cheaply quantify wire bonds' integrity, especially as process control tools in a manufacturing plant. For 
researchers, other, more sophisticated tools are available to study the interaction at the bond interface. Given the scale of wire bonds, the areas of interest typically cannot be examined visually. Along with the focused ion beam, the transmission electron microscope (TEM) allows one to peer deep into the metallic structure and learn how it affects bond strength and reliability. The TEM requires that samples being examined be less than 500 nanometers thick. Existing metal slicing and polishing techniques as well as FIB can be employed for this purpose.

The TEM technique is responsible for discovering the mechanism of thermosonic bonding between the same metal. When bonding two dissimilar metals, atoms diffuse across the interfacial boundary into each other, forming a layer of intermetallic compounds in the process. When bonding the same metal, diffusion may not necessarily occur. Instead, bond formation is primarily due to the formation of interfaces that closely resemble grain boundaries found in polycrystalline metals. This means that if the process is perfectly controlled, it is theoretically possible to completely join two pieces of metal and the resulting piece would behave as if it was never broken apart. The implication this has for structural engineering is practically limitless. Sadly, no process is ever perfectly controlled and practical limitations mean that this is limited to the wire bond scale [Krzanowski, 1990].

TEM studies also revealed that the plastic deformation observed during wire bonding is not simply plastic deformation as seen when a metal is strained beyond its elastic limits. Acoustic softening does not lead to an increase in dislocation density and a cell structure. When ultrasound is applied to a mechanically deformed aluminum sample, the dislocation density greatly decreased and replaced by a fine grained structure. The 
hypothesis is that ultrasonic energy leads to dynamic recrystallization of the wire as it deforms [Krzanowski, 1990].

It would have been impossible to discover these behaviors in the visual spectrum, whether the bond is inspected by the naked eye or through an optical microscope. The significantly shorter wavelength of the electron allows one to "see" these effects. The transmission electron microscope and other sophisticated tools allow better understanding of the manufacturing technique that is so important to the electronics industry.

One of the more recent techniques for failure analysis and process monitoring of VLSI is Focused Ion Beam, or FIB. The FIB is mainly used for microscopic selective etching, partial deposition, and microscopy as a Scanning Ion Microscope (SIM). The latter use is directly analogous to the Scanning Electron Microscope (SEM), but Gallium ions are used in place of electrons. The larger ions' smaller wavelengths allow magnification levels as high as $100,000 \mathrm{X}$. However, the technology is directly applicable to wire bonding as a way to prepare sample for examination under high power microscopes, most notably sectioning. Given the scale of the wire bonds, the ion beam's width (from $5 \mathrm{~nm}$ to $.5 \mu \mathrm{m}$ ) is the perfect way to cut through a ball bond to reveal the cross section of the bond, the pad, and the diffused metallic or intermetallic layers. After sectioning, the sample is examined under a SEM or similar to find defects or voids that lead to poor bonds.

Gallium is the liquid metal ion source (LMIS) of choice for FIB systems. Gallium's melting point is close to room temperature, thus it is easy to maintain its liquid state. Liquid gallium wets the system's tungsten needle, and a large electric field causes the gallium to ionize and emit from the needle. The ions are accelerated by more electric 
fields and then focused by electrostatic lenses. Based on the strength of the electric fields used to accelerate the gallium, the beam can be used to etch, deposit metals, or simply image a sample. However, FIB is inherently destructive since the fast moving gallium atoms will dislodge the atoms from the samples (sputter), or the gallium atoms themselves will be implanted into the top few nanometers of the surface [Nikawa, et al., 1989].

The size of the wire bonds makes FIB the perfect alternative to micro milling when cross sectioning test samples for viewing under high magnifications thanks to the thin width of the beam. An FIB system can mill away one layer of atoms at a time without disturbing the next layer, something micro milling cannot do. However, the sputtered material can redeposit on the etched surface, and etching one layer of atoms at a time takes too much time and no tests require such precision [Nikawa, et al., 1989].

When conducting failure analysis of a wire bond, the precision of the micro machining operation by FIB and the large magnification afforded by the SEM allow close examination of the bond interface. Here, the diffused metallic layer is clearly visible along with any voids or substrate cracks that may have formed during bonding. Any particulate contamination may be visible as well. With this information, the bonding process can be properly controlled.

\subsection{Bond reliability}

While the pull test is highly regarded in the industry as a reliability and quality assurance tool, it provides little information on the strength of the bonds at the interface. Except for cases of catastrophic failure (which are relatively rare), the pull test yield little more information than the relative strength of the wire. The shear test is the perfect 
complement to the pull test as it is able to directly test the integrity of the ball bond itself. Wire bonding involves many complex mechanisms, and things get even more complicated when long term effects are considered. Correct application of the pull and shear tests allows an understanding of some of these complexities and make good, robust bonds. The shear test has been used to study the $\mathrm{Au}-\mathrm{Al}$ interface and what happens there after thermal processing [Charles and Clatterbaugh, 1983].

While it is crucial that strong bonds are formed during the bonding process, it is equally important that the bonds remain strong after operating in the field. For reliability testing, bonds are typically subjected to an array of temperature tests and the effects are documented. In Charles' study, Au-Al bonds are baked for several hundred hours.

The bonding temperature has a significant effect on the shear strength but not on the ball deformation. For fine pitch applications where the size of the bonding pad is an issue, increasing the substrate bonding temperature instead of increasing the ultrasonic power is a viable option to ensure stronger bonds. The latter may lead to increasingly deformed ball bonds that may short out on neighboring bonds. Before thermal aging, pull test results show that the bonds do not differ significantly from each other. After the bake, the pull strength generally improved. The improvement can be attributed to recrystallization during the thermal aging process. The EFO process causes the grain size in the heat affected zone of the wire to grow as much as 100 times larger. The ultrasonic scrubbing causes the ball and the neck to become susceptible to recrystallization. Post heating at high temperatures reduced the grain size and thus improved the tensile strength of the wire [Charles and Clatterbaugh, 1983]. 
Controversy has risen over whether the pull test would influence the results of a shear test when both tests are conducted on the same wire bond. The pulling action may possibly break some of the ball's welded area, lowering the subsequent shear strength. If this actually happens, stricter definition and regulation of the shear test will have to be adopted, such as conducting the shear test exclusive of the pull test or both have to be done together. The former would mean that a wire bond cannot have both its pull and shear strength tested at the same time. The latter would create nonstandard testing due to the occasional use of the stud bump (a ball bond only with no second bond) in production. Another option would be to specify slightly lower fail criteria for shear tests conducted after the pull tests. Charles and Clatterbaugh's study found that destructive wire bond pull test and nondestructive ball bond shear test do not affect the result of a subsequent destructive shear test [Charles and Clatterbaugh, 1983]. Not only does the pull test not influence the shear strength, even the nondestructive shear test does not affect the destructive test.

To test the reliability of Au-Al wire bonds, Charles and Clatterbaugh subjected several sets of wire bonds to heat bake at $125^{\circ}$ for up to 400 hours. The test results for these thin film wire bonds show that the shear strength had risen and will continue to rise for some time more for the groups with the thicker film while the thinner films' shear strengths have flatten out or even decreased. The results indicate that shear strength is a function of the thickness of the film layer. As the bond is formed, the intermetallic layer grows into the film. A thinner film layer would be consumed completely by the diffusion process and thus have no material left for intermetallic growth. The diffusion process is fueled by the thermal bake, and so as long as the thin 
film still has material left, the intermetallic layer will continue to grow and thus increase the shear strength. When the material is consumed, the growth slows and stops. At that point, other effects such as formation of different intermetallics start to take over and shear strength starts to decrease [Charles and Clatterbaugh, 1983]. An optimized wire bond, by definition, is the best balance between the pull and shear strengths, but this will by no means return the strongest shear strength since the integrity of the wire itself must be taken into account to ensure overall robustness of the bonds.

Charles and Clatterbaugh reported that the bonding dwell time is a significant factor for making bonds with low ultrasonic power, where longer dwell times resulted in stronger bonds. At higher power settings, the rate of increase was even higher than at low power, but it flattens and even decreases at longer dwell times. This is attributed to formation of strain induced micro cracks at the bond interface when high ultrasonic power is applied for extended periods of time [Charles and Clatterbaugh, 1983].

For gold wires, ultrasonic scrub at the bond termination has the side effect of influencing the atomic structure at the bond's heat affected zones. When subjected to heat, the wire is easier to anneal and its tensile strength is restored to its original condition. After reliability testing with heat, pull strength for wire bonds is expected to increase. If the wire or the bonding joints and its intermetallic compounds are susceptible to corrosion, humidity testing may reduce the pull strength after extended test times. Since gold is not corrosive, bonded gold wires on gold metallizations can expect increased pull strength after reliability testing, even under humidity.

For Au-Al ball bonds, the diffusion process continues even after removal of ultrasonic energy. The intermetallic layer grows uncontrollably until the thin film 
material is fully consumed and Kirkendall voids start to form. The shear strength increases after the first phase. When Kirkendall voids have formed, the shear strength would start to decrease until the ball bonds fail catastrophically. For gold on gold wire bonds, the shear strength is expected to increase until $100 \%$ of the bond interface has diffused through. 


\section{Chapter 4. Methodology}

\subsection{Method}

The full study is an amalgam of two smaller experiments, the optimization step and the final experiment. The goal of the optimization step is to determine the set of bonder parameters that will form the strongest bonds possible, balancing pull and shear strength. This experiment is an iterative process, each successive stage refining the bonding parameters used in the previous stage. The optimized parameters are applied to substrates made up of five metallizations for the final experiment. When the entire bond samples are complete, one set is tested with the Dage 4000 pull and shear tester, and then the rest are put into the ovens for the reliability tests. At 150, 300, 500, and 1000 hours, the samples are taken out and tested by the pull and shear tests. The data are recorded and analyzed and the results reported. The final experiment calls for a total of 8100 wire bonds to be made. The initial tests destroy 900 bonds. Each test after destroys 1800 bonds. With so many wires, great care must be taken to ensure the bonds are not damaged during handling. Since each substrate can hold only a certain number of bonds, many substrates are used and each one is named and numbered for documentation purposes. Specific substrates are chosen for each set of reliability test in a random manner, but they must be documented well so that substrates are not mixed when removed and reinstalled in the ovens. The bonds must also be divided evenly on each substrate so that no one test gets too many of a certain parameter. Due to these reasons, the final experiment employed an orthogonal design instead of random like the optimization step. The 
collected data from the pull and shear tests are analyzed using Analysis of Variance (ANOVA).

\subsection{The optimization step}

The optimization step was done in three stages. Each new stage is a further refinement on experimental design. The intention of the first optimization stage is to get a broad range of bonding parameters that will be narrowed down in later steps. Each bond is made on one pad. To make sure that effects specific to a particular substrate do not interfere with all or most of the bonds in one set of parameters and thus change the validity of the results, the bonds are divided between many different substrates. The substrate divisions are listed below in Figure 4.1 to 4.3.

In each case, each set of bonding parameter is concentrated on one row. The bonds were made without any randomization, making substrate specific effects a concern. If one section of the substrate was contaminated, for example, it could change the validity of the data. Stage 2 data was randomized in an attempt to minimize such effects.

The results of stage 1 suggest that the force selected for the parameters were wrong. The bonding force is translated into pressure at the interface, and the thicker wire requires higher bond force settings. The bonds were made on six substrates, each having four rows and each row having four sectors (see Figure 4.1. $\mathrm{R}^{*}$ are the rows and $\mathrm{Sr}^{*}$ are the sectors. The sectors have five bonds each with an empty bonding pad in between to aid in identifying where one sector ends and another begins.) Each sector is a block on which five bonds of the same parameter would be made. First, a table is created, sorted by substrates, then rows, then sectors. These values are assigned a sequence number. Each sequence is then assigned a random number and then sorted by these random 
values. After the sorting, the substrates, rows, and sectors are randomized. These are then assigned a run number and the bonding parameters.

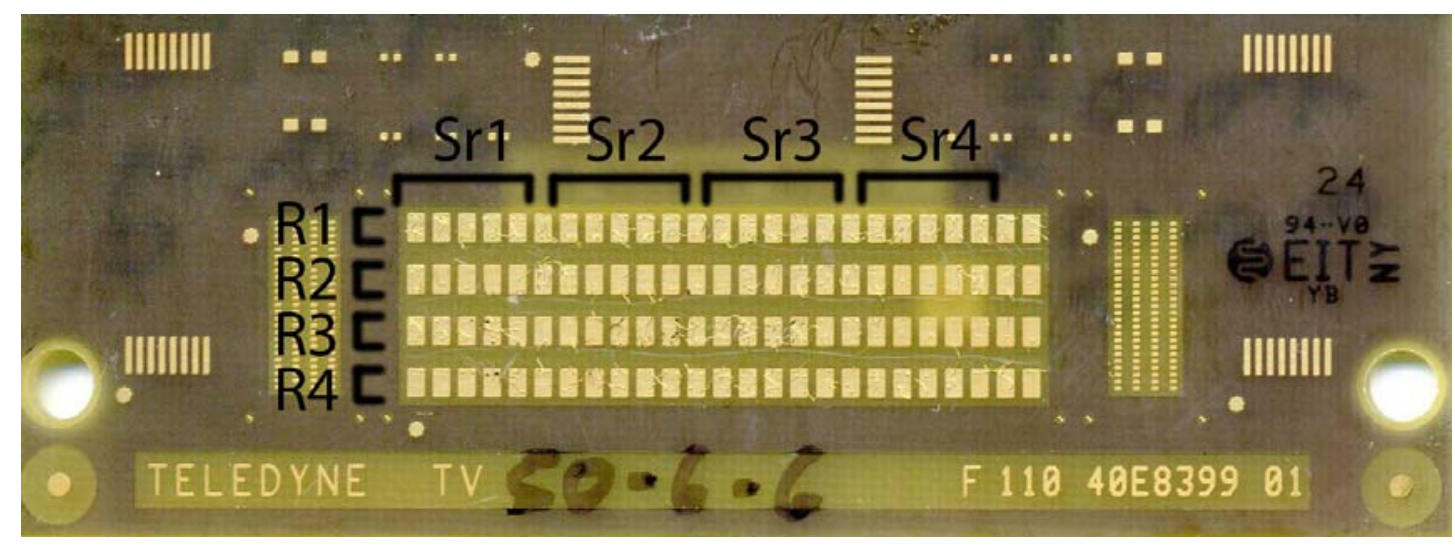

Figure 4.1 Substrate division for experiments 1 and 2.

Stage 3 was randomized in the same way. Each row now has eight sectors and each sector contains three bonds instead of five (Fig. 4.2). The dividing pad between two sectors is lost but it is easier to keep count of three bonds instead of five during pull/shear tests. Without losing space to empty bonding pads, all the bonds were able to fit on the limited number of substrates available. After bonds are made, pull and shear tests are again performed to verify bond strength.

The optimization stage was done on one substrate type. However, different substrate types require different optimization parameters. This was mentioned in the reviewed literature and confirmed by the final experiment, since other metallizations return much lower shear strengths, often as lifted ball bonds. 


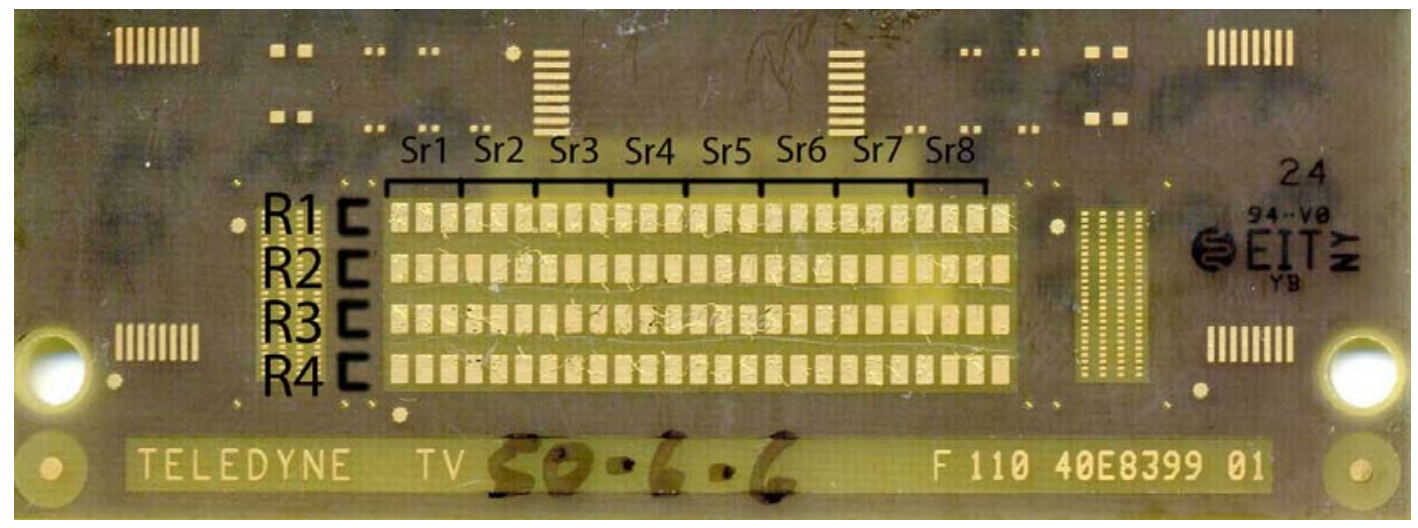

Figure 4.2 Row and sector divisions for stage 3 .

\subsection{The final experiment}

The final experiment employed an orthogonal experiment design. Each of five metallizations has nine samples, and each sample is divided into nine sectors. Each sector contains four parameters distributed in such a way that the bonds are easily recognized in groups of five. See Figure 4.3 for a visual depiction of a typical substrate.

Each $\mathrm{Sr}^{*}$ refers to a sector. On each sector, all four bond types are present, denoted by blocks $\mathrm{B}^{*}$. Each $\mathrm{B}^{*}$ is distributed around the circular arrangement to have all bond types in each sector and to avoid the same problems mentioned in the optimization step. The end result is forty-five substrates with 180 bonds each for a total of 8100 bonds, 2025 of each bond type. Since there are nine substrates per metallization and every substrate has the same number of bonds in the same places, three substrates per metallization are subjected to each reliability test. For the pull and shear testing, the initial step pulls and shears one sector per substrate. At each test time interval thereafter, two sectors per substrate are tested. The sectors under test are chosen randomly using the method described above. 


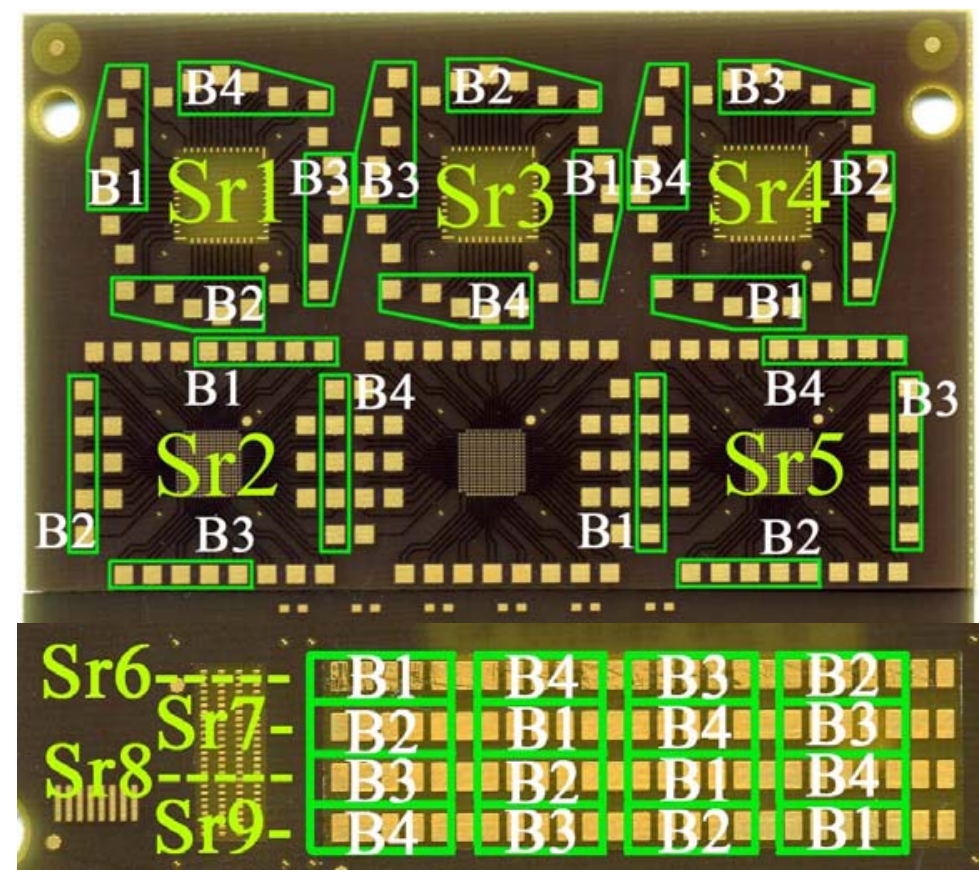

Figure 4.3 Sector and parameter division for the final substrate.

The material composition of the bond pad for each metallization is proprietary information of Teledyne and cannot be published. 


\section{Chapter 5. Results}

\subsection{Optimization}

Tables 5-1 through 5-4 below summarize the pull and shear strengths as well as the corresponding failure modes for $17.8 \mu \mathrm{m}$ wire size, $120 \mathrm{KHz}, 25.4 \mu \mathrm{m}$ wire size, 120 $\mathrm{KHz}, 17.8 \mu \mathrm{m}$ wire size, $60 \mathrm{KHz}$, and $25.4 \mu \mathrm{m}$ wire size, $120 \mathrm{KHz}$ combinations, respectively. The sample size is twenty bonds per power/time parameter combination.

The criteria for selecting optimized bond parameters are as followed:

- Maximum pull strength mean

- Minimum pull strength standard deviation

- Wire loop break failure modes

- Maximum shear strength mean

- Minimum shear strength standard deviation

- Ball shear failure modes

Based on these criteria, the optimum bonding parameters are summarized in Table 5-5. One of the key considerations when choosing an optimized bonding parameter is balancing between maximum pull and shear strengths while paying close attention to the failure modes observed during these destructive tests.

As Table 5-5 shows, the power required to make bonds at $120 \mathrm{KHz}$ is lower than that required to make bonds at $60 \mathrm{KHz}$ while the dwell times required are the same. Since energy is the product of power and time, adjusting the power input for the $120 \mathrm{KHz}$ transducer to be on par with that for the $60 \mathrm{KHz}$ transducer would require a corresponding decrease in dwell time. The results indicate that higher frequencies are 
more efficient at distributing its energy to the bond interface, thus requiring lower power or shorter dwell time to achieve the same bond strength. For a production process, switching to high frequency wire bonding would result in greater throughput from production lines.

Table 5-1 Pull strength, shear strength, and failure modes of $17.8 \mu \mathrm{m} \mathrm{Au}$ wire bonds at $120 \mathrm{kHz}$

\begin{tabular}{|c|c|c|c|c|c|c|c|c|c|c|}
\hline \multirow{3}{*}{$\begin{array}{c}1^{\text {st }} \text { Bond } \\
\text { Power } \\
\text { (setting) }\end{array}$} & \multirow{3}{*}{$\begin{array}{l}1^{\text {st }} \\
\text { Bond } \\
\text { Time } \\
\text { (ms) }\end{array}$} & \multicolumn{5}{|c|}{$\begin{array}{r}\text { Wire Pull Test } \\
\end{array}$} & \multicolumn{4}{|c|}{ Ball Shear Test } \\
\hline & & \multicolumn{2}{|c|}{$\begin{array}{c}\begin{array}{c}\text { Pull Strength } \\
\text { (gram-f) }\end{array} \\
\end{array}$} & \multicolumn{3}{|c|}{ Failure Modes (\%) } & \multicolumn{2}{|c|}{$\begin{array}{c}\text { Shear Strength } \\
\text { (gram-f) }\end{array}$} & \multicolumn{2}{|c|}{$\begin{array}{c}\text { Failure Modes } \\
(\%)\end{array}$} \\
\hline & & Mean & $\begin{array}{c}\text { St } \\
\text { Dev. }\end{array}$ & $\begin{array}{c}\text { Ball } \\
\text { neck } \\
\text { break }\end{array}$ & $\begin{array}{c}\text { Wedge } \\
\text { heel } \\
\text { break }\end{array}$ & $\begin{array}{l}\text { Loop } \\
\text { break }\end{array}$ & Mean & St Dev. & $\begin{array}{l}\text { Ball } \\
\text { lift }\end{array}$ & $\begin{array}{l}\text { Ball } \\
\text { shear }\end{array}$ \\
\hline 160 & 30 & 4.30 & 0.77 & 90 & 5 & 5 & 55.81 & 3.92 & 0 & 100 \\
\hline 180 & 30 & 4.64 & 0.69 & 85 & 5 & 10 & 57.11 & 2.78 & 0 & 100 \\
\hline 200 & 30 & 4.70 & 0.74 & 70 & 10 & 20 & 54.86 & 8.16 & 0 & 100 \\
\hline 160 & 40 & 4.69 & 0.67 & 90 & 0 & 10 & 55.76 & 3.88 & 0 & 100 \\
\hline 180 & 40 & 4.71 & 0.48 & 93 & 0 & 7 & 57.12 & 2.07 & 0 & 100 \\
\hline 200 & 40 & 4.51 & 0.68 & 87 & 0 & 13 & 56.99 & 2.62 & 0 & 100 \\
\hline 100 & 20 & 4.29 & 0.75 & 100 & 0 & 0 & 47.14 & 7.45 & 33 & 67 \\
\hline 120 & 20 & 4.46 & 0.67 & 93 & 0 & 7 & 53.33 & 3.12 & 0 & 100 \\
\hline 140 & 20 & 4.42 & 0.67 & 80 & 0 & 20 & 53.20 & 5.77 & 0 & 100 \\
\hline 100 & 30 & 4.13 & 0.71 & 93 & 7 & 0 & 54.03 & 4.16 & 0 & 100 \\
\hline 120 & 30 & 4.46 & 0.84 & 80 & 0 & 20 & 53.82 & 4.74 & 0 & 100 \\
\hline 140 & 30 & 4.00 & 0.64 & 93 & 0 & 7 & 54.86 & 3.21 & 0 & 100 \\
\hline 100 & 40 & 4.57 & 0.54 & 87 & 0 & 13 & 53.18 & 6.77 & 13 & 87 \\
\hline 120 & 40 & 4.41 & 0.64 & 100 & 0 & 0 & 54.63 & 3.71 & 0 & 100 \\
\hline 140 & 40 & 4.38 & 0.81 & 87 & 0 & 13 & 55.45 & 2.98 & 0 & 100 \\
\hline
\end{tabular}


Table 5-2 Pull strength, shear strength, and failure modes of $25.4 \mu \mathrm{m} \mathrm{Au}$ wire bonds at $120 \mathrm{kHz}$

\begin{tabular}{|c|c|c|c|c|c|c|c|c|c|c|}
\hline \multirow{3}{*}{$\begin{array}{c}1^{\text {st }} \text { Bond } \\
\text { Power } \\
\text { (setting) }\end{array}$} & \multirow{3}{*}{$\begin{array}{l}1^{\text {st }} \\
\text { Bond } \\
\text { Time } \\
\text { (ms) }\end{array}$} & \multicolumn{5}{|c|}{ Wire Pull Test } & \multicolumn{4}{|c|}{ Ball Shear Test } \\
\hline & & \multicolumn{2}{|c|}{$\begin{array}{c}\text { Pull Strength } \\
\text { (gram-f) }\end{array}$} & \multicolumn{3}{|c|}{ Failure Modes (\%) } & \multicolumn{2}{|c|}{$\begin{array}{c}\text { Shear Strength } \\
\text { (gram-f) }\end{array}$} & \multicolumn{2}{|c|}{$\begin{array}{c}\text { Failure Modes } \\
(\%)\end{array}$} \\
\hline & & Mean & $\begin{array}{c}\text { St } \\
\text { Dev. }\end{array}$ & $\begin{array}{c}\text { Ball } \\
\text { neck } \\
\text { break }\end{array}$ & $\begin{array}{c}\text { Wedge } \\
\text { heel } \\
\text { break }\end{array}$ & $\begin{array}{c}\text { Loop } \\
\text { break }\end{array}$ & Mean & St Dev. & $\begin{array}{l}\text { Ball } \\
\text { lift }\end{array}$ & $\begin{array}{l}\text { Ball } \\
\text { shear }\end{array}$ \\
\hline 160 & 40 & 9.85 & 0.66 & 40 & 0 & 60 & 62.00 & 3.04 & 0 & 100 \\
\hline 180 & 40 & 9.91 & 0.51 & 30 & 0 & 70 & 65.20 & 2.90 & 0 & 100 \\
\hline 200 & 40 & 9.77 & 0.42 & 33 & 0 & 67 & 60.52 & 7.35 & 0 & 100 \\
\hline 160 & 50 & 9.68 & 0.53 & 40 & 0 & 60 & 62.75 & 3.46 & 0 & 100 \\
\hline 180 & 50 & 9.66 & 0.50 & 15 & 5 & 80 & 63.41 & 5.46 & 5 & 95 \\
\hline 200 & 50 & 9.88 & 0.32 & 47 & 0 & 53 & 64.64 & 6.07 & 5 & 95 \\
\hline 150 & 20 & 9.42 & 0.70 & 53 & 0 & 47 & 37.99 & 7.15 & 87 & 13 \\
\hline 170 & 20 & 9.69 & 0.55 & 40 & 0 & 60 & 40.16 & 10.47 & 87 & 13 \\
\hline 190 & 20 & 9.53 & 0.92 & 33 & 0 & 67 & 44.02 & 9.82 & 73 & 27 \\
\hline 150 & 30 & 9.90 & 0.56 & 20 & 0 & 80 & 48.77 & 4.65 & 47 & 53 \\
\hline 170 & 30 & 9.24 & 1.29 & 60 & 0 & 33 & 45.35 & 16.03 & 47 & 53 \\
\hline 190 & 30 & 9.61 & 0.86 & 40 & 0 & 53 & 45.13 & 6.75 & 57 & 43 \\
\hline 150 & 40 & 9.11 & 1.22 & 27 & 0 & 53 & 42.15 & 10.47 & 67 & 33 \\
\hline 170 & 40 & 9.34 & 0.74 & 53 & 0 & 47 & 46.80 & 11.56 & 73 & 27 \\
\hline 190 & 40 & 9.78 & 0.49 & 33 & 0 & 60 & 48.57 & 9.07 & 53 & 47 \\
\hline
\end{tabular}

Table 5-6 summarizes the mean pull and shear strengths as well as the associated standard deviation for the selected optimized bonding parameters. Table 5-7 details the loop profile for each wire size/frequency combination. While the pull strength for 120 $\mathrm{KHz}$ bonds appears to be lower, it is very similar to that for $60 \mathrm{KHz}$ bonds when adjusted to take into account the different loop height. As seen in Figure 5.1, ball deformation for $120 \mathrm{KHz}$ bonds are slightly smaller than for $60 \mathrm{KHz}$ bonds and thus result in slightly lower shear strength. However, since there is a wide window for bonding parameters where strong bonds will form without being overly deformed, small variations in pull and shear strengths do not cause concern in the confidence that the chosen parameters are optimized. 
Table 5-3 Pull strength, shear strength, and failure modes of $17.8 \mu \mathrm{m}$ Au wire bonds at $60 \mathrm{kHz}$

\begin{tabular}{|c|c|c|c|c|c|c|c|c|c|c|}
\hline \multirow{3}{*}{$\begin{array}{c}1^{\text {st }} \text { Bond } \\
\text { Power } \\
\text { (setting) }\end{array}$} & \multirow{3}{*}{$\begin{array}{l}1^{\text {st }} \\
\text { Bond } \\
\text { Time } \\
\text { (ms) }\end{array}$} & \multicolumn{5}{|c|}{ Wire Pull Test } & \multicolumn{4}{|c|}{ Ball Shear Test } \\
\hline & & \multicolumn{2}{|c|}{$\begin{array}{c}\text { Pull Strength } \\
\text { (gram-f) }\end{array}$} & \multicolumn{3}{|c|}{ Failure Modes (\%) } & \multicolumn{2}{|c|}{$\begin{array}{c}\text { Shear Strength } \\
\text { (gram-f) }\end{array}$} & \multicolumn{2}{|c|}{$\begin{array}{c}\text { Failure Modes } \\
(\%)\end{array}$} \\
\hline & & Mean & $\begin{array}{c}\text { St } \\
\text { Dev. }\end{array}$ & $\begin{array}{c}\text { Ball } \\
\text { neck } \\
\text { break }\end{array}$ & $\begin{array}{c}\text { Wedge } \\
\text { heel } \\
\text { break }\end{array}$ & $\begin{array}{c}\text { Loop } \\
\text { break }\end{array}$ & Mean & St Dev. & $\begin{array}{l}\text { Ball } \\
\text { lift }\end{array}$ & $\begin{array}{l}\text { Ball } \\
\text { shear }\end{array}$ \\
\hline 80 & 30 & 4.63 & 0.86 & 95 & 0 & 5 & 52.35 & 7.55 & 5 & 95 \\
\hline 100 & 30 & 4.97 & 0.82 & 85 & 0 & 15 & 53.88 & 7.11 & 5 & 95 \\
\hline 120 & 30 & 5.97 & 0.49 & 60 & 10 & 30 & 56.47 & 5.15 & 0 & 100 \\
\hline 80 & 40 & 4.86 & 0.99 & 87 & 0 & 13 & 54.04 & 5.78 & 0 & 100 \\
\hline 100 & 40 & 5.13 & 0.73 & 80 & 0 & 20 & 55.66 & 5.95 & 0 & 100 \\
\hline 120 & 40 & 5.36 & 0.53 & 75 & 0 & 25 & 55.33 & 6.16 & 0 & 100 \\
\hline
\end{tabular}

Table 5-4 Pull strength, shear strength, and failure modes of $25.4 \mu \mathrm{m} \mathrm{Au}$ wire bonds at $60 \mathrm{kHz}$

\begin{tabular}{|c|c|c|c|c|c|c|c|c|c|c|}
\hline \multirow{3}{*}{$\begin{array}{c}\mathbf{1}^{\text {st }} \text { Bond } \\
\text { Power } \\
\text { (setting) }\end{array}$} & \multirow{3}{*}{$\begin{array}{l}1^{\text {st }} \\
\text { Bond } \\
\text { Time } \\
\text { (ms) }\end{array}$} & \multicolumn{5}{|c|}{$\begin{array}{r}\text { Wire Pull Test } \\
\end{array}$} & \multicolumn{4}{|c|}{$\begin{array}{l}\text { Ball Shear Test } \\
\end{array}$} \\
\hline & & \multicolumn{2}{|c|}{$\begin{array}{l}\text { Pull Strength } \\
\text { (gram-f) }\end{array}$} & \multicolumn{3}{|c|}{ Failure Modes (\%) } & \multicolumn{2}{|c|}{$\begin{array}{l}\text { Shear Strength } \\
\text { (gram-f) }\end{array}$} & \multicolumn{2}{|c|}{$\begin{array}{c}\text { Failure Modes } \\
(\%)\end{array}$} \\
\hline & & Mean & $\begin{array}{c}\text { St } \\
\text { Dev. }\end{array}$ & $\begin{array}{c}\text { Ball } \\
\text { neck } \\
\text { break }\end{array}$ & $\begin{array}{c}\text { Wedge } \\
\text { heel } \\
\text { break }\end{array}$ & $\begin{array}{l}\text { Loop } \\
\text { break }\end{array}$ & Mean & St Dev. & $\begin{array}{l}\text { Ball } \\
\text { lift }\end{array}$ & $\begin{array}{l}\text { Ball } \\
\text { shear }\end{array}$ \\
\hline 120 & 40 & 9.72 & 0.52 & 20 & 0 & 80 & 58.42 & 10.33 & 10 & 90 \\
\hline 150 & 40 & 9.71 & 0.80 & 20 & 0 & 80 & 62.13 & 5.57 & 0 & 100 \\
\hline 180 & 40 & 10.22 & 0.50 & 10 & 0 & 90 & 67.16 & 6.47 & 0 & 100 \\
\hline 120 & 60 & 9.82 & 0.63 & 25 & 0 & 75 & 61.43 & 6.36 & 0 & 100 \\
\hline 150 & 60 & 10.09 & 0.46 & 15 & 0 & 85 & 64.97 & 7.26 & 0 & 100 \\
\hline 180 & 60 & 9.71 & 0.48 & 30 & 0 & 70 & 65.69 & 6.49 & 0 & 100 \\
\hline
\end{tabular}


Table 5-5 Optimized bonding parameters

\begin{tabular}{|c|c|c|c|c|c|c|c|c|}
\hline \multirow[b]{2}{*}{$\begin{array}{l}\text { Wire } \\
\text { Size } \\
(\mu \mathrm{m})\end{array}$} & \multirow[b]{2}{*}{$\begin{array}{c}\text { Ultrasonic } \\
\text { Frequency } \\
\text { (KHz) }\end{array}$} & \multicolumn{3}{|c|}{ 1st bond (Ball) } & \multicolumn{3}{|c|}{ 2nd bond (Wedge) } & \multirow[b]{2}{*}{$\begin{array}{c}\text { Substrate } \\
\text { Temperature } \\
\left({ }^{\circ} \mathbf{C}\right)\end{array}$} \\
\hline & & $\begin{array}{c}\text { Power in } \\
\text { Watts } \\
\text { (Setting) }\end{array}$ & $\begin{array}{c}\text { Force } \\
\text { (gram-f) }\end{array}$ & $\begin{array}{l}\text { Time } \\
(\mathrm{ms})\end{array}$ & $\begin{array}{l}\text { Power in } \\
\text { Watts } \\
\text { (Setting) }\end{array}$ & $\begin{array}{c}\text { Force } \\
\text { (gram- } \\
\text { f) }\end{array}$ & $\begin{array}{l}\text { Time } \\
\text { (ms) }\end{array}$ & \\
\hline \multirow{2}{*}{17.8} & 60 & $\begin{array}{c}2.35 \\
(120)\end{array}$ & 25 & 30 & $0.98(50)$ & 47 & 50 & 135 \\
\hline & 120 & $\begin{array}{c}1.55 \\
(120)\end{array}$ & 25 & 30 & $0.91(70)$ & 47 & 30 & 135 \\
\hline \multirow{2}{*}{25.4} & 60 & $\begin{array}{c}3.53 \\
(180) \\
\end{array}$ & 31 & 40 & $\begin{array}{c}2.35 \\
(120) \\
\end{array}$ & 53 & 60 & 135 \\
\hline & 120 & $\begin{array}{c}2.33 \\
(180)\end{array}$ & 31 & 40 & $\begin{array}{c}1.81 \\
(140)\end{array}$ & 53 & 60 & 135 \\
\hline
\end{tabular}
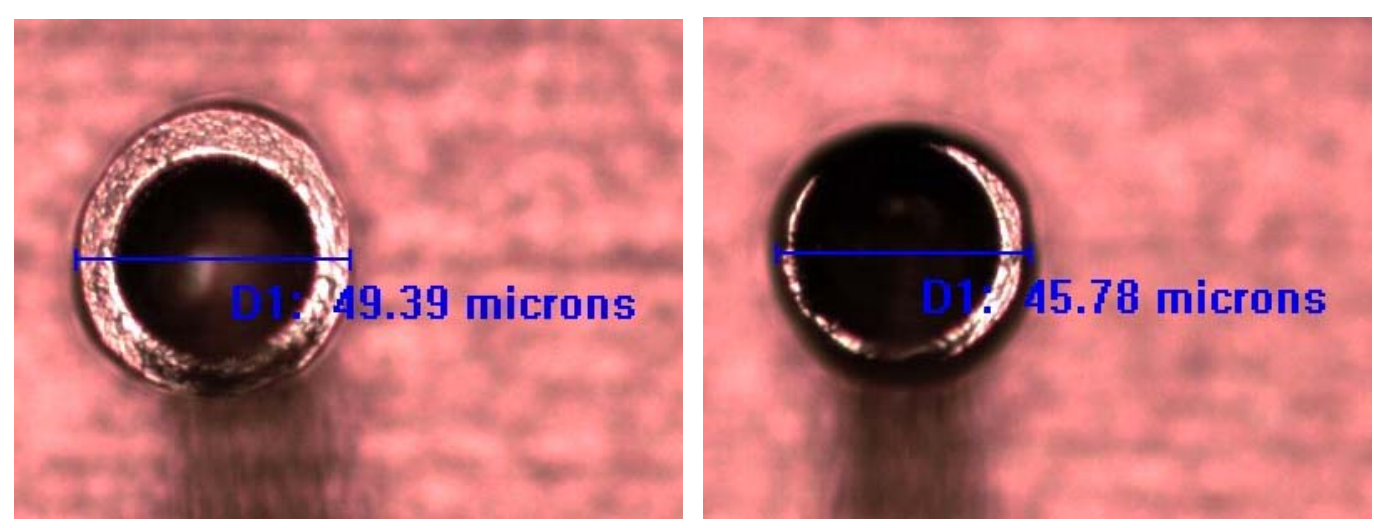

Figure 5.1 Wire bond ball size for $60 \mathrm{KHz}$ (left) and $120 \mathrm{KHz}$ (right)

Table 5-6 Mean pull strength and shear strength for the corresponding optimized bonding parameters

\begin{tabular}{cccccc}
\hline \multirow{2}{*}{$\begin{array}{c}\text { Wire Size } \\
(\boldsymbol{\mu m})\end{array}$} & $\begin{array}{c}\text { Ultrasonic } \\
\text { Frequency } \\
(\mathbf{K H z})\end{array}$ & \multicolumn{2}{c}{ Pull Strength (gram-f) } & \multicolumn{2}{c}{ Shear Strength (gram-f) } \\
\cline { 3 - 6 } & 60 & Mean & Std. Dev. & Mean & Std. Dev. \\
\hline \multirow{2}{*}{17.8} & 120 & 5.97 & 0.49 & 56.47 & 5.15 \\
\hline \multirow{2}{*}{25.4} & 60 & 4.46 & 0.84 & 53.82 & 4.74 \\
\cline { 2 - 6 } & 120 & 10.22 & 0.50 & 67.16 & 6.47 \\
\hline
\end{tabular}


Table 5-7 Loop profile

\begin{tabular}{cccc}
\hline $\begin{array}{c}\text { Wire Size } \\
(\boldsymbol{\mu} \mathbf{m})\end{array}$ & $\begin{array}{c}\text { Ultrasonic } \\
\text { Frequency }(\mathbf{K H z})\end{array}$ & Loop length $(\boldsymbol{\mu m})$ & Loop height $(\boldsymbol{\mu m})$ \\
\hline \multirow{2}{*}{17.8} & 60 & 875 & 215 \\
\cline { 2 - 4 } & 120 & 880 & 170 \\
\hline \multirow{2}{*}{25.4} & 60 & 882 & 220 \\
\cline { 2 - 4 } & 120 & 884 & 190 \\
\hline
\end{tabular}

After the sample bonds have been made, the control group, designated as initial (test time 0) is subject to the pull and shear test. First, the bonds are subjected to the destructive pull test. When all the pull testing is completed, the remaining ball bonds are sheared and the shear strength recorded. Previous studies have shown that the destructive pull test has very minimal if any influence on subsequent testing, so there is $100 \%$ confidence that the shear testing results are valid [Charles and Clatterbaugh, 1983]. After gathering the control data, the rest of the samples are divided up randomly, and three substrates per metallization are inserted into the appropriate test chambers for reliability testing. After each time interval (test time 1, 150 hours; test time 2, 300 hours; test time 3, 500 hours; test time 4, 1000 hours), the samples are removed from the chambers and a predetermined number of bonds are pull and shear tested. After the data have been gathered, the samples are reinserted into the ovens and the reliability testing resumed.

\subsection{Initial test}

The final data set is analyzed using Analysis of Variance (ANOVA), one of the many analysis tools available in the statistical analysis software Minitab. The main effects are ultrasonic frequency, metallization, test time, and test type. The interactions between the main effects are also investigated. The bonding parameters are not the main effects in this analysis because the items of interest are the four listed main effects, since 
each wire size/frequency combination is assumed to be optimized and thus direct comparisons can be drawn between these combinations. Tables 5-8 to 5-11 are the ANOVA tables with the corresponding $f$ and $p$-values that indicate significance of each variable.

Table 5-8 ANOVA table for $17.8 \mu \mathrm{m}$ pull strength

\begin{tabular}{ccccccc}
\hline Source & \# DoF's & Seq. SS & Adj. SS & Adj. MS & F & P \\
\hline Freq & 1 & 8.627 & 10.101 & 10.101 & 14.08 & 0 \\
Met & 4 & 2308.569 & 2138.015 & 534.504 & 745.23 & 0 \\
Test time & 4 & 107.26 & 105.872 & 26.468 & 36.9 & 0 \\
Test type & 2 & 1.773 & 2.211 & 1.106 & 1.54 & 0.214 \\
\hline Freq*Met & 4 & 2379.729 & 2378.658 & 594.664 & 829.1 & 0 \\
Freq*Test time & 4 & 3.831 & 3.767 & 0.942 & 1.31 & 0.263 \\
Freq*Test type & 2 & 2.042 & 2.138 & 1.069 & 1.49 & 0.225 \\
\hline $\begin{array}{l}\text { Met*Test time } \\
\text { Met*Test type }\end{array}$ & 16 & 19.118 & 19.434 & 1.215 & 1.69 & 0.041 \\
Test time*Test & 8 & 26.898 & 26.988 & 3.374 & 4.7 & 0 \\
type & 8 & 9.411 & 9.411 & 1.176 & 1.64 & 0.108 \\
\hline
\end{tabular}

Table 5-9 ANOVA table for $17.8 \mu \mathrm{m}$ shear strength

\begin{tabular}{ccccccc}
\hline Source & \# DoF's & Seq. SS & Adj. SS & Adj. MS & F & P \\
\hline Freq & 1 & 54757.3 & 49183.5 & 49183.5 & 699.6 & 0 \\
Met & 4 & 184933.9 & 171863.2 & 42965.8 & 611.15 & 0 \\
Test time & 4 & 1743.9 & 1784.3 & 446.1 & 6.35 & 0 \\
Test type & 2 & 175.9 & 225.6 & 112.8 & 1.6 & 0.201 \\
\hline Freq*Met & 4 & 92090 & 92109.6 & 23027.4 & 327.55 & 0 \\
Freq*Test time & 4 & 679.1 & 667.9 & 167 & 2.38 & 0.05 \\
Freq*Test type & 2 & 142.7 & 140.8 & 70.4 & 1 & 0.367 \\
\hline $\begin{array}{c}\text { Met*Test time } \\
\text { Met*Test type }\end{array}$ & 16 & 2210.4 & 2217.4 & 138.6 & 1.97 & 0.012 \\
$\begin{array}{c}\text { Test time*Test } \\
\text { type }\end{array}$ & 8 & 3196.4 & 3194.1 & 399.3 & 5.68 & 0 \\
\hline
\end{tabular}


Table 5-10 ANOVA table for $25.4 \mu \mathrm{m}$ pull strength

\begin{tabular}{ccccccc}
\hline Source & \# DoF's & Seq. SS & Adj. SS & Adj. MS & F & P \\
\hline Freq & 1 & 2328.11 & 2334.73 & 2334.73 & 1722.14 & 0 \\
Met & 4 & 7944.81 & 7692.7 & 1923.17 & 1418.57 & 0 \\
Test time & 4 & 352.75 & 353.06 & 88.26 & 65.11 & 0 \\
Test type & 2 & 1.77 & 1.63 & 0.82 & 0.6 & 0.547 \\
\hline Freq*Met & 4 & 8619.86 & 8614.56 & 2153.64 & 1588.56 & 0 \\
Freq*Test time & 4 & 59.41 & 59.36 & 14.84 & 10.95 & 0 \\
Freq*Test type & 2 & 3.41 & 3.31 & 1.65 & 1.22 & 0.296 \\
\hline Met*Test time & 16 & 100.22 & 100.3 & 6.27 & 4.62 & 0 \\
Met*Test type & 8 & 48.43 & 48.67 & 6.08 & 4.49 & 0 \\
\hline Test time*Test & & & & & & \\
type & 8 & 10.24 & 10.24 & 1.28 & 0.94 & 0.478 \\
\hline
\end{tabular}

Table 5-11 ANOVA table for $25.4 \mu \mathrm{m}$ shear strength

\begin{tabular}{ccccccc}
\hline Source & \# DoF's & Seq. SS & Adj. SS & Adj. MS & F & P \\
\hline Freq & 1 & 29781.6 & 25925.7 & 25925.7 & 307.43 & 0 \\
Met & 4 & 343500.8 & 320358.2 & 80089.6 & 949.72 & 0 \\
Test time & 4 & 5507.1 & 5386.4 & 1346.6 & 15.97 & 0 \\
Test type & 2 & 1896.4 & 1253.9 & 626.9 & 7.43 & 0.001 \\
\hline Freq*Met & 4 & 12058.2 & 12078.9 & 3019.7 & 35.81 & 0 \\
Freq*Test time & 4 & 337 & 335.6 & 83.9 & 0.99 & 0.409 \\
Freq*Test type & 2 & 577.7 & 574.5 & 287.3 & 3.41 & 0.033 \\
\hline $\begin{array}{c}\text { Met*Test time } \\
\text { Met*Test type }\end{array}$ & 16 & 4684.8 & 4669.4 & 291.8 & 3.46 & 0 \\
\hline $\begin{array}{c}\text { Test time*Test } \\
\text { type }\end{array}$ & 8 & 29090.8 & 3075.8 & 384.5 & 4.56 & 0 \\
\hline
\end{tabular}

Figures 5.2 to 5.5 show the interaction between frequency and metallization for $17.8 \mu \mathrm{m}$ pull test, $17.8 \mu \mathrm{m}$ shear test, $25.4 \mu \mathrm{m}$ pull test, and $25.4 \mu \mathrm{m}$ shear test, respectively. These plots show the mean pull and shear strength for these frequency/wire size combinations on each of the five metallizations. Tables 5-12 to 5-23 list the failure modes for the pull and shear tests. The interaction plots visually depict the trend of the pull and shear test data over all five metallizations and allow any weakness to be 
pinpointed. The failure modes allow analysis of the weaknesses seen in the interaction plots.

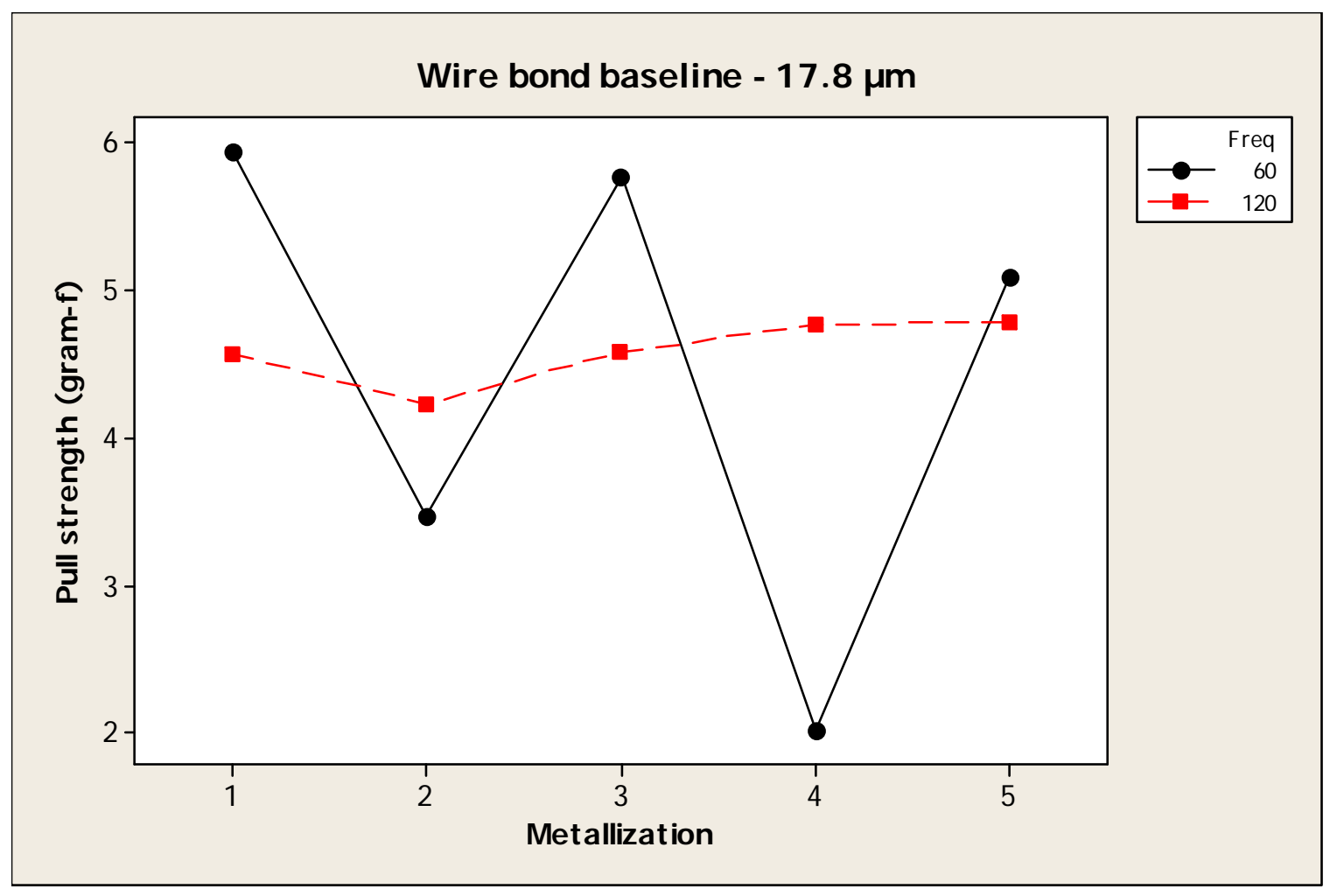

Figure 5.2 Frequency and metallization interactions influencing pull strength for

$17.8 \mu \mathrm{m}$ wire size. The rise and fall of the $60 \mathrm{KHz}$ curve indicates strong interaction.

The relatively flat $120 \mathrm{KHz}$ curve indicates that the interaction is weak and that

bonds made at that frequency are robust against lifts

For $17.8 \mu \mathrm{m}$ wires bonded at $60 \mathrm{KHz}$, pull strength is highest on metallizations 1 , 3 , and 5. They are lowest on metallizations 2 and 4 . The primary failure mode for metallizations 1,3 , and 5 are ball neck break or wedge heel break with some loop break. On metallizations 2 and 4, the primary failure modes are wedge bonds lifting. The bonding pad shows a dark shadow where the wedge bond used to be with no remnants of welded metal left over. These failures indicate that either the second bond is not 
optimized properly for metallizations 2 and 4 for $60 \mathrm{KHz}$ or that the thin gold film does not adhere to the base metal underneath. If the metallization is thin enough, it is not possible to visually confirm the latter case since higher magnification is required to see the very small crater left behind. If it is metallization peel, it is possible that the reliability tests will aggravate the poor bond condition.

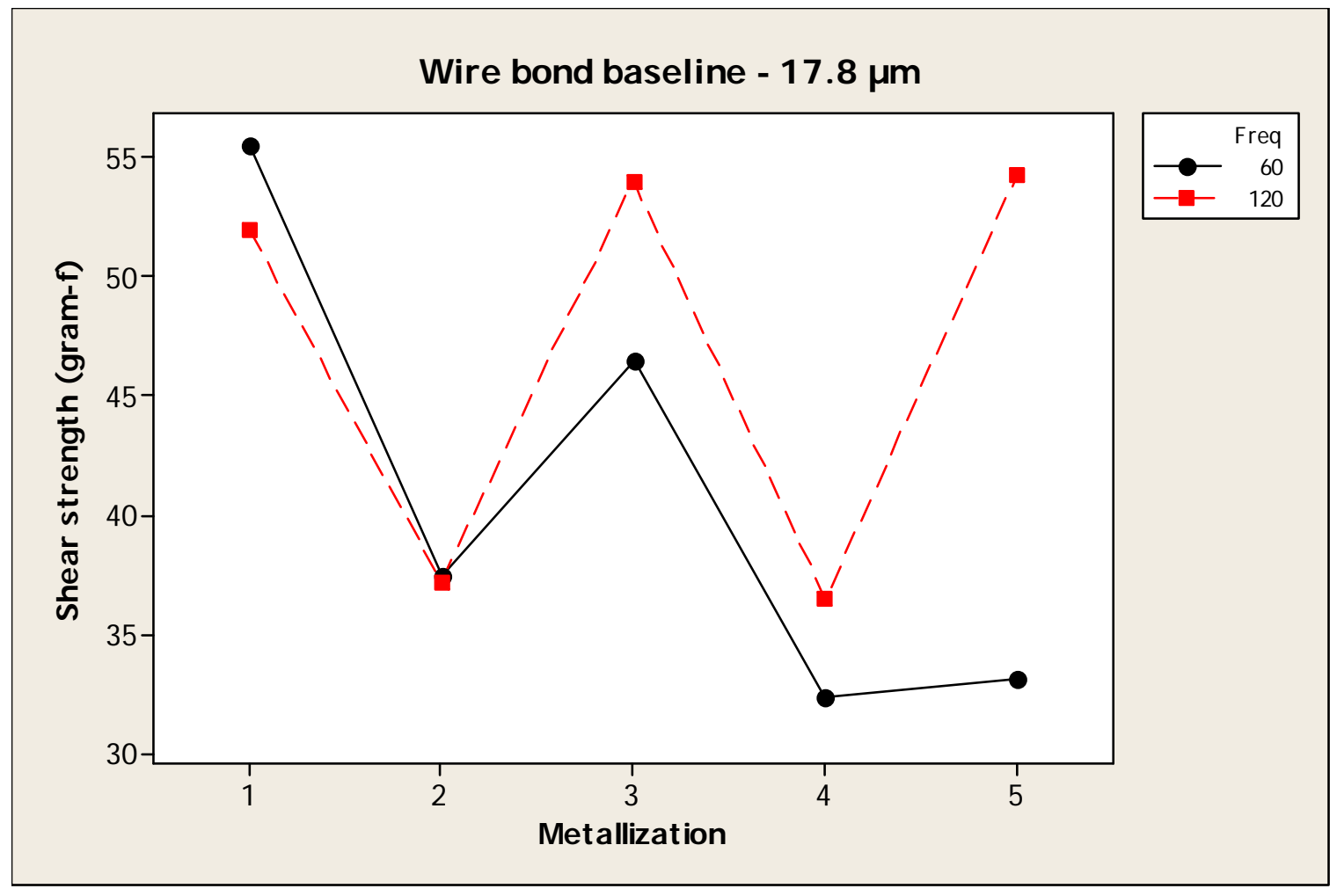

Figure 5.3 Frequency and metallization interactions influencing shear

strength for $17.8 \mu \mathrm{m}$ wire size. Strong interactions are visible here. Not even 120 KHz bonds are immune to the poor bond conditions on Metallizations 2 and 4. 


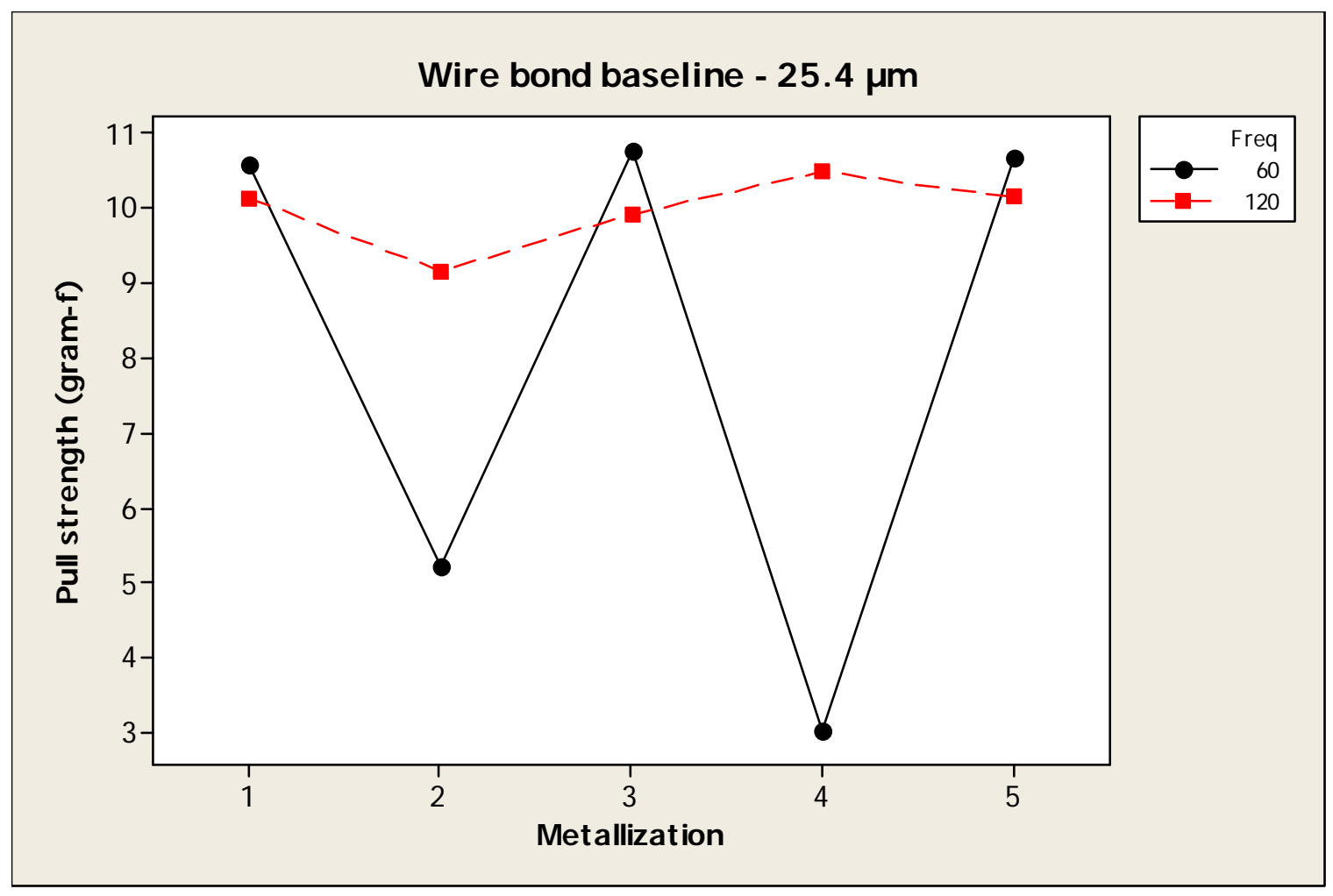

Figure 5.4 Frequency and metallization interactions influencing pull strength for $25.4 \mu \mathrm{m}$ wire size.

The shear strength for this same wire size/frequency combination shows similar trends across these five metallizations, with relatively higher shear strength on metallizations 1 and 3 and weak bonds on metallizations 2, 4, and 5. The bonds, being optimized on metallization 1, are stronger on that metallization than any other, even though bond strength is still resilient on metallization 3. However, the bonds are incredibly weak on the other three metallizations with the balls mostly lifting away from the bond pad when the shear force is applied. On metallizations 1 and 3, the shear test leaves behind large amount of shear remnants, often at least $75 \%$ of the ball bond area.

For $25.4 \mu \mathrm{m}$ wires bonded at $60 \mathrm{KHz}$, the pull and shear test results show the same trends as those for $17.8 \mu \mathrm{m}$ wires, specifically weak pull and shear strength on metallizations 2 and 4 . The main difference here is that the shear strength on 
metallization 5 is closer to those on metallizations 1 and 3 . The failure modes are similar for $25.4 \mu \mathrm{m}$ wires as well, consistently lifting both bonds on metallizations 2 and 4 with no visible weld remnants left over.

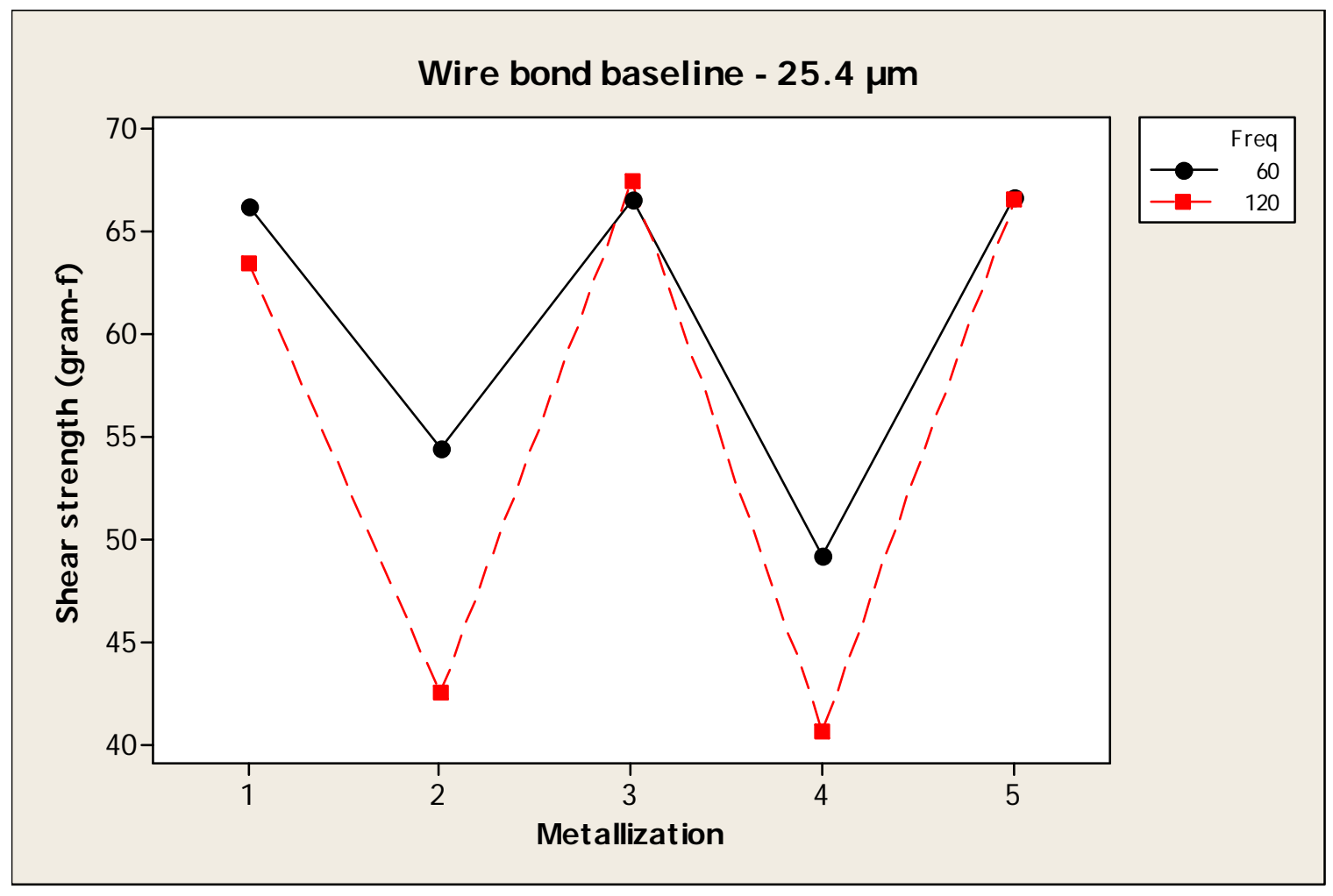

Figure 5.5 Frequency and metallization interactions influencing shear

strength for $25.4 \mu \mathrm{m}$ wire size.

For wires bonded at $120 \mathrm{KHz}$, the pull strength is consistently high across all five metallizations with the majority of the wires breaking at the neck of the ball. Even on metallizations 2 and 4, wires bonded at $120 \mathrm{KHz}$ show resilience against wedge lifts. These results suggest that the cohesion between the metallized layers on the bonding substrates are at least strong enough to resist the pull force from the tester and that the weak second bonds made with $60 \mathrm{KHz}$ ultrasonic power were not fully optimized for those metallizations. 
The ball shear test for both wire sizes bonded at higher frequency shows distinctly weak bond integrity on metallizations 2 and 4 . The majority of failures on these metallizations are ball lifts, just as they were for bonds made at $60 \mathrm{KHz}$. However, considering the better formed second bond, the bond parameters are only barely outside of the settings window. A slightly longer dwell time or more power input would ensure better bond integrity. As it is, all bonds are lifted cleanly off the pads with no shear remnants.

Several hypotheses can be employed to explain the weak bond strength on metallizations 2 and 4. As seen in Tables 5-12 to 5-23, the primary failure mode for the pull test on those metallizations is wedge bond lifting. Table 5-12 shows that on metallizations 1, 3, and 5, the primary failure modes (wire breaks) are dominant. Table 513 shows that on metallizations 2 and 4, the primary failure modes (wire breaks) are not dominant. Instead, the wires mainly lift on the second bond. One hypothesis for this is that the wedge bonds are not properly optimized for these metallizations and the bonds simply lift when a pull force is applied to them. Metallization 1 has the thickest gold layer and the bond parameters resulted from the optimization step is tailored for this thickness. The layer of underlying metal on metallizations 3 and 5 somehow aided in bonding and resulted in decently strong bonds. The thin gold layer and the lack of underlying metal on metallizations 2 and 4 are the main reasons for poor bond integrity on these two metallizations. The different compositions of the bonding pads require different bond settings to ensure diffusion. Another hypothesis is that the metallization does not properly adhere to the metal pad underneath it, suggesting a problem with the deposition process. If the latter is the case, closer examination of the bond site would 
show craters where the wedge bonds were. However, this was not the case as visual inspection showed no cratering. Besides, on the same metallizations, $120 \mathrm{KHz}$ bonds did not exhibit this wedge bond lift problem and thus these bonds are more properly optimized than those made with $60 \mathrm{KHz}$ ultrasonic frequency. This study confirms previous studies that optimization needs to be done for any change made to the process to ensure maximum bond integrity, be it wire size, ultrasonic frequency, wire and metallization material, or substrate type.

Table 5-14 shows that on metallizations 1,3 , and 5, the failure mode is primarily ball shear. On metallizations 2 and 4, the failure mode is primarily ball lift. As test time increase, the failure mode improves with percentage of ball lift decreasing and ball shear increasing. Table 5-17 shows that the ball lift failure mode decrease in frequency as reliability test interval increases, showing an improvement in bond integrity with extended temperature baking.

Table 5-12 Pull failure modes for $17.8 \mu \mathrm{m}$ wires bonded at $60 \mathrm{KHz}$ on metallizations 1, 3, and 5 .

\begin{tabular}{ccccccccccc}
\hline & \multicolumn{10}{c}{ Metallization } \\
\cline { 2 - 10 } $\begin{array}{c}\text { Test } \\
\text { time } \\
\text { hours) }\end{array}$ & $\begin{array}{c}\text { Ball } \\
\text { neck } \\
\text { break }\end{array}$ & $\begin{array}{c}\text { Wedge } \\
\text { heel } \\
\text { break }\end{array}$ & $\begin{array}{c}\text { Loop } \\
\text { break }\end{array}$ & $\begin{array}{c}\text { Ball } \\
\text { neck } \\
\text { break }\end{array}$ & $\begin{array}{c}\text { Wedge } \\
\text { heel } \\
\text { break }\end{array}$ & $\begin{array}{c}\text { Loop } \\
\text { break }\end{array}$ & $\begin{array}{c}\text { Ball } \\
\text { neck } \\
\text { break }\end{array}$ & $\begin{array}{c}\text { Wedge } \\
\text { heel } \\
\text { break }\end{array}$ & $\begin{array}{c}\text { Loop } \\
\text { break }\end{array}$ \\
\hline 0 & 54 & 4 & 40 & 46 & 15 & 37 & 46 & 15 & 26 \\
150 & 48 & 33 & 17 & 37 & 50 & 12 & 52 & 28 & 19 \\
300 & 46 & 32 & 18 & 51 & 42 & 5 & 58 & 24 & 12 \\
500 & 54 & 27 & 17 & 51 & 41 & 7 & 63 & 19 & 15 \\
1000 & 61 & 20 & 17 & 46 & 46 & 5 & 66 & 26 & 6 \\
\hline
\end{tabular}


Table 5-13 Pull failure modes for $17.8 \mu \mathrm{m}$ wires bonded at $60 \mathrm{KHz}$ on metallizations 2 and 4.

\begin{tabular}{ccccccc}
\hline \multicolumn{7}{c}{ Metallization 2 } \\
\hline $\begin{array}{c}\text { Test } \\
\text { time } \\
\text { (hours) }\end{array}$ & $\begin{array}{c}\text { Ball neck } \\
\text { break }\end{array}$ & $\begin{array}{c}\text { Wedge } \\
\text { heel } \\
\text { break }\end{array}$ & $\begin{array}{c}\text { Loop } \\
\text { break }\end{array}$ & $\begin{array}{c}\text { Wedge } \\
\text { lift }\end{array}$ & $\begin{array}{c}\text { Met. peel } \\
\text { ball }\end{array}$ & $\begin{array}{c}\text { Met. peel } \\
\text { wedge }\end{array}$ \\
\hline 0 & 2 & 6 & 2 & 0 & 2 & 86 \\
150 & 0 & 44 & 0 & 55 & 0 & 0 \\
300 & 2 & 15 & 0 & 82 & 0 & 0 \\
500 & 3 & 12 & 0 & 79 & 0 & 1 \\
1000 & 3 & 1 & 0 & 93 & 0 & 0 \\
\hline
\end{tabular}

Metallization 4

\begin{tabular}{ccccccc}
\hline \multicolumn{7}{c}{ Metallization 4 } \\
\hline $\begin{array}{c}\text { Test } \\
\text { time } \\
\text { (hours) }\end{array}$ & $\begin{array}{c}\text { Ball neck } \\
\text { break }\end{array}$ & $\begin{array}{c}\text { Wedge } \\
\text { heel } \\
\text { break }\end{array}$ & $\begin{array}{c}\text { Loop } \\
\text { break }\end{array}$ & $\begin{array}{c}\text { Wedge } \\
\text { lift }\end{array}$ & $\begin{array}{c}\text { Met. peel } \\
\text { ball }\end{array}$ & $\begin{array}{c}\text { Met. peel } \\
\text { wedge }\end{array}$ \\
\hline 0 & 0 & 0 & 2 & 97 & 0 & 0 \\
150 & 0 & 1 & 0 & 98 & 0 & 0 \\
300 & 0 & 0 & 0 & 98 & 0 & 0 \\
500 & 1 & 0 & 0 & 98 & 0 & 0 \\
1000 & 1 & 1 & 0 & 97 & 0 & 0 \\
\hline
\end{tabular}

Table 5-14 Shear failure modes for $17.8 \mu \mathrm{m}$ wires bonded at $60 \mathrm{KHz}$.

\begin{tabular}{cccccccccccc}
\hline & \multicolumn{10}{c}{ Metallization } \\
\cline { 2 - 12 } $\begin{array}{c}\text { Test } \\
\text { time } \\
\text { (hours) }\end{array}$ & \begin{tabular}{c} 
1 \\
\cline { 2 - 12 } \\
lift
\end{tabular} & $\begin{array}{c}\text { Ball } \\
\text { shear }\end{array}$ & Ball lift & $\begin{array}{c}\text { Ball } \\
\text { shear }\end{array}$ & $\begin{array}{c}\text { Ball } \\
\text { lift }\end{array}$ & $\begin{array}{c}\text { Ball } \\
\text { shear }\end{array}$ & Ball lift & $\begin{array}{c}\text { Ball } \\
\text { shear }\end{array}$ & $\begin{array}{c}\text { Ball } \\
\text { lift }\end{array}$ & $\begin{array}{c}\text { Ball } \\
\text { shear }\end{array}$ \\
\hline 0 & 13 & 86 & 100 & 0 & 13 & 86 & 100 & 0 & 71 & 28 \\
150 & 5 & 94 & 100 & 0 & 21 & 78 & 100 & 0 & 61 & 38 \\
300 & 10 & 88 & 98 & 1 & 15 & 84 & 100 & 0 & 92 & 7 \\
500 & 14 & 85 & 95 & 2 & 28 & 70 & 100 & 0 & 86 & 12 \\
1000 & 12 & 87 & 97 & 1 & 18 & 81 & 98 & 1 & 79 & 20 \\
\hline
\end{tabular}


Table 5-15 Pull failure modes for $17.8 \mu \mathrm{m}$ wires bonded at $120 \mathrm{KHz}$ on metallizations 1,3 , and 5 .

\begin{tabular}{|c|c|c|c|c|c|c|c|c|c|c|}
\hline \multirow{3}{*}{$\begin{array}{c}\text { Test } \\
\text { time } \\
\text { (hours) }\end{array}$} & \multicolumn{10}{|c|}{ Metallization } \\
\hline & \multicolumn{2}{|c|}{1} & \multicolumn{2}{|c|}{2} & \multicolumn{2}{|c|}{$\mathbf{3}$} & \multicolumn{2}{|c|}{4} & \multicolumn{2}{|c|}{5} \\
\hline & Ball lift & $\begin{array}{r}\text { Ball } \\
\text { shear }\end{array}$ & Ball lift & $\begin{array}{c}\text { Ball } \\
\text { shear }\end{array}$ & Ball lift & $\begin{array}{c}\text { Ball } \\
\text { shear }\end{array}$ & Ball lift & $\begin{array}{c}\text { Ball } \\
\text { shear }\end{array}$ & Ball lift & $\begin{array}{c}\text { Ball } \\
\text { shear }\end{array}$ \\
\hline 0 & 13 & 86 & 100 & 0 & 13 & 86 & 100 & 0 & 71 & 28 \\
\hline 150 & 5 & 94 & 100 & 0 & 21 & 78 & 100 & 0 & 61 & 38 \\
\hline 300 & 10 & 88 & 98 & 1 & 15 & 84 & 100 & 0 & 92 & 7 \\
\hline 500 & 14 & 85 & 95 & 2 & 28 & 70 & 100 & 0 & 86 & 12 \\
\hline 1000 & 12 & 87 & 97 & 1 & 18 & 81 & 98 & 1 & 79 & 20 \\
\hline
\end{tabular}

Table 5-16 Pull failure modes for $17.8 \mu \mathrm{m}$ wires bonded at $120 \mathrm{KHz}$ on metallizations 2 and 4.

\begin{tabular}{ccccccc}
\hline \multicolumn{7}{c}{ Metallization 2 } \\
\hline $\begin{array}{c}\text { Test } \\
\text { time } \\
\text { (hours) }\end{array}$ & $\begin{array}{c}\text { Ball neck } \\
\text { break }\end{array}$ & $\begin{array}{c}\text { Wedge } \\
\text { heel } \\
\text { break }\end{array}$ & $\begin{array}{c}\text { Loop } \\
\text { break }\end{array}$ & $\begin{array}{c}\text { Wedge } \\
\text { lift }\end{array}$ & $\begin{array}{c}\text { Met. peel } \\
\text { ball }\end{array}$ & $\begin{array}{c}\text { Met. peel } \\
\text { wedge }\end{array}$ \\
\hline 0 & 55 & 4 & 4 & 0 & 0 & 0 \\
150 & 63 & 14 & 14 & 0 & 0 & 0 \\
300 & 56 & 12 & 12 & 0 & 0 & 0 \\
500 & 56 & 10 & 11 & 0 & 0 & 0 \\
1000 & 61 & 12 & 13 & 0 & 0 & 0 \\
\hline
\end{tabular}

Metallization 4

\begin{tabular}{ccccccc}
\hline \multicolumn{7}{c}{ Metallization 4 } \\
\hline $\begin{array}{c}\text { Test } \\
\text { time } \\
\text { (hours) }\end{array}$ & $\begin{array}{c}\text { Ball neck } \\
\text { break }\end{array}$ & $\begin{array}{c}\text { Wedge } \\
\text { heel } \\
\text { break }\end{array}$ & $\begin{array}{c}\text { Loop } \\
\text { break }\end{array}$ & $\begin{array}{c}\text { Wedge } \\
\text { lift }\end{array}$ & $\begin{array}{c}\text { Met. peel } \\
\text { ball }\end{array}$ & $\begin{array}{c}\text { Met. peel } \\
\text { wedge }\end{array}$ \\
\hline 0 & 66 & 4 & 11 & 0 & 0 & 0 \\
150 & 60 & 21 & 5 & 0 & 0 & 0 \\
300 & 54 & 27 & 7 & 0 & 0 & 0 \\
500 & 68 & 17 & 6 & 0 & 0 & 0 \\
1000 & 60 & 21 & 6 & 0 & 0 & 0 \\
\hline
\end{tabular}


Table 5-17 Shear failure modes for $17.8 \mu \mathrm{m}$ wires bonded at $120 \mathrm{KHz}$.

\begin{tabular}{|c|c|c|c|c|c|c|c|c|c|c|}
\hline \multirow{3}{*}{$\begin{array}{c}\text { Test } \\
\text { time } \\
\text { (hours) }\end{array}$} & \multicolumn{10}{|c|}{ Metallization } \\
\hline & \multicolumn{2}{|c|}{1} & \multicolumn{2}{|c|}{2} & \multicolumn{2}{|c|}{3} & \multicolumn{2}{|c|}{4} & \multicolumn{2}{|c|}{5} \\
\hline & Ball lift & $\begin{array}{c}\text { Ball } \\
\text { shear }\end{array}$ & Ball lift & $\begin{array}{c}\text { Ball } \\
\text { shear }\end{array}$ & Ball lift & $\begin{array}{c}\text { Ball } \\
\text { shear }\end{array}$ & Ball lift & $\begin{array}{c}\text { Ball } \\
\text { shear }\end{array}$ & Ball lift & $\begin{array}{r}\text { Ball } \\
\text { shear }\end{array}$ \\
\hline 0 & 11 & 88 & 100 & 0 & 2 & 97 & 100 & 0 & 20 & 80 \\
\hline 150 & 3 & 96 & 100 & 0 & 1 & 98 & 100 & 0 & 19 & 80 \\
\hline 300 & 8 & 91 & 98 & 1 & 0 & 100 & 100 & 0 & 6 & 93 \\
\hline 500 & 1 & 98 & 97 & 2 & 0 & 100 & 100 & 0 & 1 & 98 \\
\hline 1000 & 1 & 98 & 98 & 0 & 0 & 98 & 97 & 2 & 11 & 88 \\
\hline
\end{tabular}

Table 5-18 Pull failure modes for $25.4 \mu \mathrm{m}$ wires bonded at $60 \mathrm{KHz}$ on metallizations 1,3 , and 5 .

\begin{tabular}{|c|c|c|c|c|c|c|c|c|c|}
\hline \multirow[b]{3}{*}{$\begin{array}{l}\text { Test time } \\
\text { (hours) }\end{array}$} & \multicolumn{9}{|c|}{ Metallization } \\
\hline & \multicolumn{3}{|c|}{1} & \multicolumn{3}{|c|}{3} & \multicolumn{3}{|c|}{5} \\
\hline & $\begin{array}{c}\text { Ball } \\
\text { neck } \\
\text { break }\end{array}$ & $\begin{array}{c}\text { Wedge } \\
\text { heel } \\
\text { break }\end{array}$ & $\begin{array}{l}\text { Loop } \\
\text { break }\end{array}$ & $\begin{array}{c}\text { Ball } \\
\text { neck } \\
\text { break }\end{array}$ & $\begin{array}{c}\text { Wedge } \\
\text { heel } \\
\text { break }\end{array}$ & $\begin{array}{c}\text { Loop } \\
\text { break }\end{array}$ & $\begin{array}{c}\text { Ball } \\
\text { neck } \\
\text { break }\end{array}$ & $\begin{array}{c}\text { Wedge } \\
\text { heel } \\
\text { break }\end{array}$ & $\begin{array}{l}\text { Loop } \\
\text { break }\end{array}$ \\
\hline 0 & 2 & 4 & 93 & 2 & 6 & 91 & 4 & 11 & 82 \\
\hline 150 & 1 & 66 & 32 & 0 & 63 & 36 & 2 & 31 & 66 \\
\hline 300 & 1 & 47 & 48 & 4 & 47 & 46 & 0 & 38 & 61 \\
\hline 500 & 5 & 35 & 58 & 4 & 52 & 42 & 0 & 23 & 76 \\
\hline 1000 & 4 & 58 & 35 & 2 & 66 & 28 & 3 & 38 & 57 \\
\hline
\end{tabular}


Table 5-19 Pull failure modes for $25.4 \mu \mathrm{m}$ wires bonded at $60 \mathrm{KHz}$ on metallizations 2 and 4.

\begin{tabular}{ccccccc}
\hline \multicolumn{7}{c}{ Metallization 2 } \\
\hline $\begin{array}{c}\text { Test time } \\
\text { (hours) }\end{array}$ & $\begin{array}{c}\text { Ball } \\
\text { neck } \\
\text { break }\end{array}$ & $\begin{array}{c}\text { Wedge } \\
\text { heel } \\
\text { break }\end{array}$ & $\begin{array}{c}\text { Loop } \\
\text { break }\end{array}$ & $\begin{array}{c}\text { Wedge } \\
\text { lift }\end{array}$ & $\begin{array}{c}\text { Met. } \\
\text { peel } \\
\text { ball }\end{array}$ & $\begin{array}{c}\text { Met. } \\
\text { peel } \\
\text { wedge }\end{array}$ \\
\hline 0 & 0 & 0 & 2 & 0 & 0 & 97 \\
150 & 0 & 2 & 5 & 92 & 0 & 0 \\
300 & 0 & 2 & 8 & 88 & 0 & 0 \\
500 & 0 & 4 & 13 & 70 & 1 & 8 \\
1000 & 3 & 1 & 8 & 83 & 0 & 2 \\
\hline
\end{tabular}

\begin{tabular}{ccccccc}
\hline \multicolumn{7}{c}{ Metallization 4 } \\
\hline $\begin{array}{c}\text { Test time } \\
\text { (hours) }\end{array}$ & $\begin{array}{c}\text { Ball } \\
\text { neck } \\
\text { break }\end{array}$ & $\begin{array}{c}\text { Wedge } \\
\text { heel } \\
\text { break }\end{array}$ & $\begin{array}{c}\text { Loop } \\
\text { break }\end{array}$ & $\begin{array}{c}\text { Wedge } \\
\text { lift }\end{array}$ & $\begin{array}{c}\text { Met. } \\
\text { peel } \\
\text { ball }\end{array}$ & $\begin{array}{c}\text { Met. } \\
\text { peel } \\
\text { wedge }\end{array}$ \\
\hline 0 & 0 & 0 & 0 & 100 & 0 & 0 \\
150 & 0 & 0 & 0 & 100 & 0 & 0 \\
300 & 0 & 0 & 4 & 95 & 0 & 0 \\
500 & 0 & 0 & 1 & 97 & 0 & 0 \\
1000 & 2 & 0 & 0 & 97 & 0 & 0 \\
\hline
\end{tabular}

Table 5-20 Shear failure modes for $25.4 \mu \mathrm{m}$ wires bonded at $60 \mathrm{KHz}$.

\begin{tabular}{|c|c|c|c|c|c|c|c|c|c|c|}
\hline \multirow{3}{*}{$\begin{array}{c}\text { Test } \\
\text { time } \\
\text { (hours) }\end{array}$} & \multicolumn{10}{|c|}{ Metallization } \\
\hline & \multicolumn{2}{|c|}{1} & \multicolumn{2}{|c|}{2} & \multicolumn{2}{|c|}{3} & \multicolumn{2}{|c|}{4} & \multicolumn{2}{|c|}{5} \\
\hline & Ball lift & $\begin{array}{c}\text { Ball } \\
\text { shear }\end{array}$ & Ball lift & $\begin{array}{c}\text { Ball } \\
\text { shear }\end{array}$ & Ball lift & $\begin{array}{c}\text { Ball } \\
\text { shear }\end{array}$ & Ball lift & $\begin{array}{c}\text { Ball } \\
\text { shear }\end{array}$ & Ball lift & $\begin{array}{c}\text { Ball } \\
\text { shear }\end{array}$ \\
\hline 0 & 13 & 86 & 97 & 2 & 11 & 88 & 100 & 0 & 35 & 64 \\
\hline 150 & 17 & 82 & 98 & 1 & 7 & 92 & 100 & 0 & 44 & 55 \\
\hline 300 & 24 & 74 & 97 & 2 & 1 & 98 & 100 & 0 & 65 & 34 \\
\hline 500 & 40 & 60 & 95 & 3 & 10 & 88 & 100 & 0 & 54 & 45 \\
\hline 1000 & 15 & 84 & 97 & 1 & 4 & 95 & 98 & 1 & 25 & 74 \\
\hline
\end{tabular}


Table 5-21 Pull failure modes for $25.4 \mu \mathrm{m}$ wires bonded at $120 \mathrm{KHz}$ on metallizations 1,3 , and 5 .

\begin{tabular}{|c|c|c|c|c|c|c|c|c|c|}
\hline \multirow[b]{3}{*}{$\begin{array}{c}\text { Test time } \\
\text { (hours) }\end{array}$} & \multicolumn{9}{|c|}{ Metallization } \\
\hline & \multicolumn{3}{|c|}{1} & \multicolumn{3}{|c|}{3} & \multicolumn{3}{|c|}{5} \\
\hline & $\begin{array}{c}\text { Ball } \\
\text { neck } \\
\text { break }\end{array}$ & $\begin{array}{c}\text { Wedge } \\
\text { heel } \\
\text { break }\end{array}$ & $\begin{array}{l}\text { Loop } \\
\text { break }\end{array}$ & $\begin{array}{c}\text { Ball } \\
\text { neck } \\
\text { break }\end{array}$ & $\begin{array}{c}\text { Wedge } \\
\text { heel } \\
\text { break }\end{array}$ & $\begin{array}{l}\text { Loop } \\
\text { break }\end{array}$ & $\begin{array}{c}\text { Ball } \\
\text { neck } \\
\text { break }\end{array}$ & $\begin{array}{c}\text { Wedge } \\
\text { heel } \\
\text { break }\end{array}$ & $\begin{array}{l}\text { Loop } \\
\text { break }\end{array}$ \\
\hline 0 & 28 & 8 & 62 & 46 & 0 & 53 & 48 & 2 & 48 \\
\hline 150 & 37 & 28 & 33 & 46 & 18 & 34 & 27 & 28 & 43 \\
\hline 300 & 33 & 12 & 54 & 50 & 13 & 36 & 28 & 20 & 51 \\
\hline 500 & 45 & 19 & 34 & 47 & 20 & 31 & 33 & 24 & 42 \\
\hline 1000 & 48 & 40 & 11 & 45 & 32 & 21 & 61 & 26 & 12 \\
\hline
\end{tabular}

Table 5-22 Pull failure modes for $25.4 \mu \mathrm{m}$ wires bonded at $60 \mathrm{KHz}$ on metallizations 2 and 4.

\begin{tabular}{ccccccc}
\hline \multicolumn{7}{c}{ Metallization 2 } \\
\hline $\begin{array}{c}\text { Test } \\
\text { time } \\
\text { (hours) }\end{array}$ & $\begin{array}{c}\text { Ball } \\
\text { neck } \\
\text { break }\end{array}$ & $\begin{array}{c}\text { Wedge } \\
\text { heel } \\
\text { break }\end{array}$ & $\begin{array}{c}\text { Loop } \\
\text { break }\end{array}$ & $\begin{array}{c}\text { Wedge } \\
\text { lift }\end{array}$ & $\begin{array}{c}\text { Met. } \\
\text { peel } \\
\text { ball }\end{array}$ & $\begin{array}{c}\text { Met. } \\
\text { peel } \\
\text { wedge }\end{array}$ \\
\hline 0 & 37 & 4 & 31 & 0 & 0 & 0 \\
150 & 35 & 8 & 46 & 0 & 0 & 0 \\
300 & 28 & 3 & 53 & 0 & 0 & 0 \\
500 & 47 & 3 & 41 & 0 & 0 & 0 \\
1000 & 52 & 10 & 30 & 0 & 0 & 0 \\
\hline
\end{tabular}

\begin{tabular}{ccccccc}
\hline \multicolumn{7}{c}{ Metallization 4 } \\
\hline $\begin{array}{c}\text { Test } \\
\text { time } \\
\text { (hours) }\end{array}$ & $\begin{array}{c}\text { Ball } \\
\text { neck } \\
\text { break }\end{array}$ & $\begin{array}{c}\text { Wedge } \\
\text { heel } \\
\text { break }\end{array}$ & $\begin{array}{c}\text { Loop } \\
\text { break }\end{array}$ & $\begin{array}{c}\text { Wedge } \\
\text { lift }\end{array}$ & $\begin{array}{c}\text { Meteel } \\
\text { ball }\end{array}$ & $\begin{array}{c}\text { Meteel } \\
\text { wedge }\end{array}$ \\
\hline 0 & 57 & 0 & 42 & 0 & 0 & 0 \\
150 & 38 & 6 & 53 & 0 & 0 & 0 \\
300 & 40 & 3 & 55 & 0 & 0 & 0 \\
500 & 31 & 6 & 62 & 0 & 0 & 0 \\
1000 & 56 & 2 & 39 & 0 & 0 & 0 \\
\hline
\end{tabular}


Table 5-23 Shear failure modes for $25.4 \mu \mathrm{m}$ wires bonded at $120 \mathrm{KHz}$.

\begin{tabular}{|c|c|c|c|c|c|c|c|c|c|c|}
\hline \multirow{3}{*}{$\begin{array}{c}\text { Test } \\
\text { time } \\
\text { (hours) }\end{array}$} & \multicolumn{10}{|c|}{ Metallization } \\
\hline & \multicolumn{2}{|c|}{1} & \multicolumn{2}{|c|}{2} & \multicolumn{2}{|c|}{3} & \multicolumn{2}{|c|}{4} & \multicolumn{2}{|c|}{5} \\
\hline & Ball lift & $\begin{array}{c}\text { Ball } \\
\text { shear }\end{array}$ & Ball lift & $\begin{array}{c}\text { Ball } \\
\text { shear }\end{array}$ & Ball lift & $\begin{array}{c}\text { Ball } \\
\text { shear }\end{array}$ & Ball lift & $\begin{array}{c}\text { Ball } \\
\text { shear }\end{array}$ & Ball lift & $\begin{array}{c}\text { Ball } \\
\text { shear }\end{array}$ \\
\hline 0 & 20 & 80 & 100 & 0 & 0 & 100 & 100 & 0 & 6 & 93 \\
\hline 150 & 11 & 88 & 100 & 0 & 5 & 94 & 95 & 4 & 6 & 93 \\
\hline 300 & 27 & 72 & 97 & 2 & 2 & 97 & 100 & 0 & 10 & 90 \\
\hline 500 & 6 & 93 & 95 & 4 & 4 & 95 & 100 & 0 & 5 & 94 \\
\hline 1000 & 6 & 93 & 100 & 0 & 2 & 97 & 100 & 0 & 16 & 83 \\
\hline
\end{tabular}

The results of the initial set of samples show that $120 \mathrm{KHz}$ ultrasonic frequency forms more robust bonds across all five metallizations. While the wedge bonds made at $60 \mathrm{KHz}$ lifted cleanly off of the bonding pads, the ones made at $120 \mathrm{KHz}$ were strong enough to remain bonded. The bond parameters window was wide enough for the higher frequency that even for substrates that the parameters are not optimized, decently strong bonds can still be formed. For the ball bond, however, the window is not big enough. For any wire bonding process, bond parameters must be optimized for the wire, bond pad, and substrate type, and tradeoffs must also be taken to balance bond integrity and other process specific requirements.

\subsection{Reliability tests}

\subsubsection{Test type}

The reliability tests are designed to rigorously test the wire bonds in adverse environmental conditions to ensure reliability in the field. Historically, wires and bond pads are made of dissimilar metals and the bond interface results in a necessary intermetallic layer. Environmental stress tests are used to determine the weak link within 
the wire bonds and possibly a remedy. Humidity corrodes parts of the wire bonds. Thermal cycling causes fatigue failures. Thermal aging causes overgrowth of the intermetallic layer, eventually consuming one or both bond materials and leaving behind voids. Since bonding gold on gold does not result in an intermetallic layer, it is still important to see how these environmental effects may damage wire bonds and if there is a way to prevent it.

Rows 4 of Tables 5-8 to 5-11 given above are the F values for the test type. They indicate that test type is not a significant factor. The mean pull and shear strengths do not vary significantly between test types for either frequency for each metallization. This result is not surprising due to the fact that gold on gold bonds do not rely on an intermetallic layer to form a strong bond, and that gold's material properties make it the ideal candidate for highly stressful environments. One key advantage of this fact is that statistically, gold on gold wire bonds need to be subjected to only one type of reliability testing to characterize long term wire bond integrity under different environmental conditions.

In terms of oxidation, gold is an inert metal. Therefore, it is not subject to corrosion like other metals would be. Neither the gold pad nor the gold wire would then oxidize and create structural concerns, and the lack of an intermetallic layer means the bond interface is also immune from humidity effects. This means that gold on gold bonds are highly robust against wet or humid conditions, and temperature effects only help the integrity of wire bonds, as the thermal aging test will show.

Previous studies have shown that the intermetallic layer continues to grow with the application of heat after ultrasonic bonding [Charles and Clatterbaugh, 1983]. This 
can be attributed to the diffusion mechanism of wire bonds. The continuous energy input raises the internal energy of atoms, and when these internal energies rise beyond the activation energy required for diffusion, the atoms would move. The end result is growth of the intermetallic layer. The negative aspect of this mechanism is the growth of voids as the minor material is consumed. When the growth limit is reached, severe voiding is observed at the bond interface, and these voids are the cause of the higher resistance across the bond as well as poor mechanical adhesion between ball and pad. Since the intermetallic layer is not formed at the interface between the gold ball and the gold bonding pad, the problem of Kirkendall (and Horsting) voiding is sidestepped. Instead, the thermal energy enables diffusion long after the removal of the ultrasonic power.

The thermal cycling test subjects wire bonds and the surrounding areas to continuous thermal expansion and contraction. Since the substrate, bond pads, and wire (and potting compound for encapsulated packages) are made of different materials and have different coefficients of thermal expansion; each material would expand and contract differently. The loop profile is critical in the fatigue life of wire bonds. A low, tightly stretched wire would leave little room for a wire to flex, making it more likely to be severely weakened after several heat/cool cycles. Taller loops are therefore preferred. With encapsulated packages, a thermoset plastic is poured around the chip and the lead frame, encasing the wire bonds in a resin block. However, thermal cycling causes the encapsulating compound to apply shear tractions on the surface of the wire. This is especially problematic for wires that have weakened heels or necks as the tensile stress may cause the wire to break at those weak points. 
While the bond interface as well as the wire itself is crucial to bond integrity, the layers of metal that constitute the bonding pad should not be taken for granted.

While temperature is the common element between these three tests, only the thermal cycling test actively stress the mechanical bond. Compared to corrosion and growth of voids, fatigue is the more likely failure mechanism for gold on gold bonds. For this reason, this is the most necessary reliability test to characterize the wire bond's long term integrity and behavior in the field.

\subsubsection{Test time}

According to the ANOVA tables, the length of time the wire bond samples were subjected to reliability tests is more significant than the test type. The mean values of the bond pull and shear tests do not vary much between test types, but there is a marked increase after the wire bonds have been in the oven for long periods of time. Figures 5.6 to 5.9 are the main effects plot for test time. At the 1000-hour mark, pull and shear tests yield significantly higher values than observed at 0 hours for bonds made with either frequency. Even bonds made on metallizations 2 and 4 improve their integrity: the failure mode for shear tests shows a shift from ball lifts to ball shears, and pull test failures move away from wedge bond lifting and towards more wire breaks.

For the shorter test periods, the increase in bond strength is not very dramatic, and the mean values can become worse than at a previous test time. However, between 500 and 1000 hours, the bond strength consistently increases regardless of wire size or frequency. This effect suggests that improvement in bond integrity in hot environments rely not on overall time spent in those environments. Instead, the increase in bond 
integrity is dependent on how long the bonds have been heated undisturbed. The proposed mechanism below may suggest a reason for this.

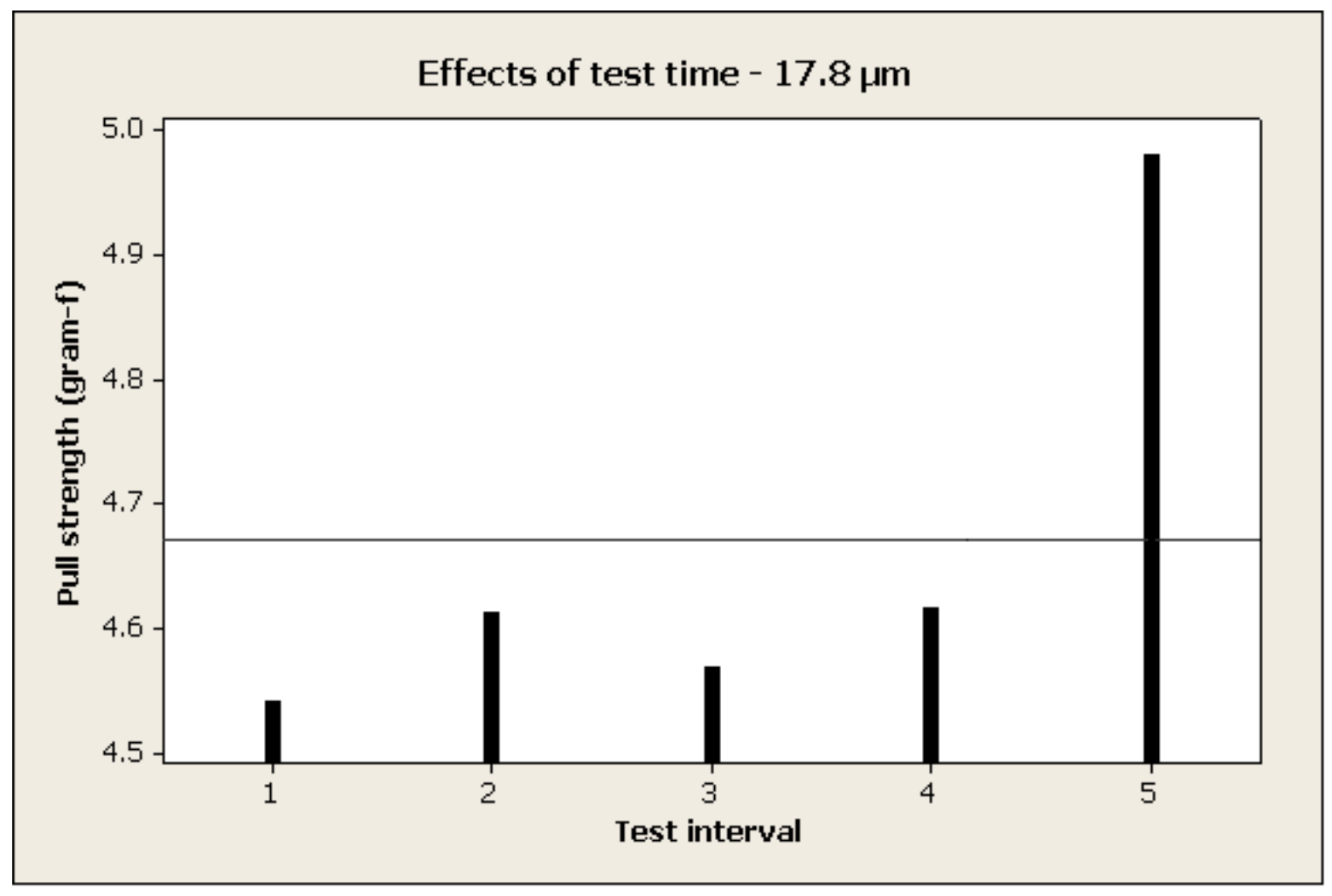

Figure 5.6 Effects of test interval on pull strength for $17.8 \mu \mathrm{m}$ wire size.

For the sake of modeling, material properties are identified in bulk. That is, materials are assumed to be homogeneous. This applies to internal energy as well. Realistically, however, each individual atom is at its individual internal energy state. A specimen is constantly in thermal flux, internal energies transferring from one atom to another. Even with these transfers, the internal energy levels can be presented as a normal distribution. The activation energy is a threshold that these atoms' internal energy levels need to reach or exceed to initiate diffusion. The overall average value of these energy levels is the bulk internal energy of the specimen. While it is possible that some atoms' internal energies are higher than the activation energy, their number is statistically insignificant compared to the number of atoms that are not as energetic. In other words, 
while there may be a few fuse points at the atomic level, the number is so small that any disturbance would break the bonds and thus not seen as adhesion at the macroscopic point.

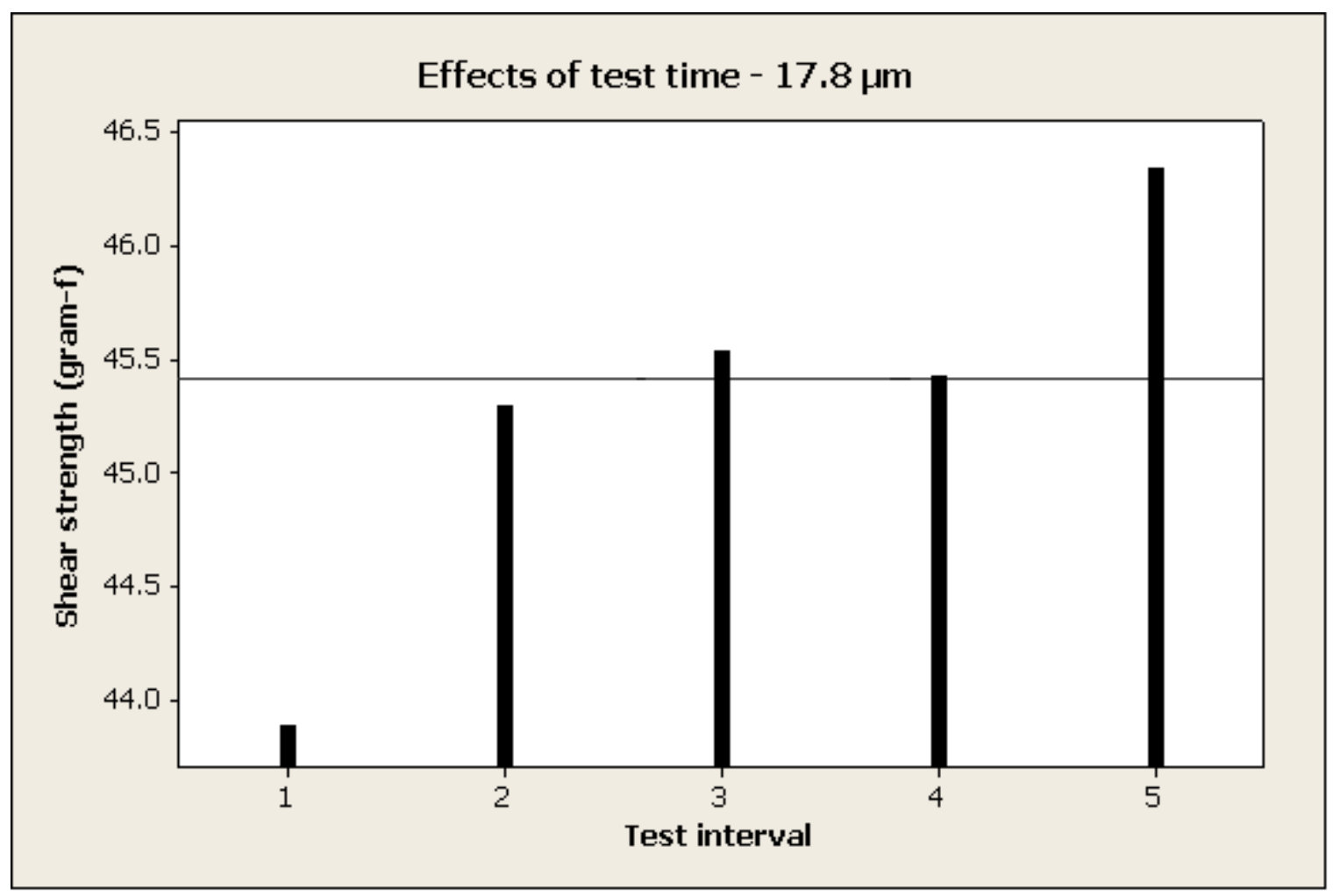

Figure 5.7 Effects of test interval on shear strength for $17.8 \mu \mathrm{m}$ wire size.

As seen in Figure 5.10, the threshold activation energy needs to be overcome for diffusion to occur. With low energy input, only poor bonds can be made as only a few atoms at the interface reached the level of internal energy necessary. With more input, more atoms can diffuse. Too much energy, however, and almost all the atoms will diffuse through but the wire will be excessively deformed. With extended exposure to heat, the internal energy level of the material shifts higher, requiring less energy to enable diffusion and can even spontaneously form weldments.

Infusion of thermal and kinetic energy (through application of ultrasonic vibrations) raises the internal energy levels of these atoms. Alternatively, this can be 
viewed as lowering the activation energy of diffusion. At the same time, plastic deformation occurs and intimate contact is formed at the bond interface. The net result is a higher number of atoms can now diffuse from one medium to another and the bond starts to form. If not enough energy is applied, not enough atoms would have diffused through and thus a weaker bond is the result. Also, since atoms' internal energy levels are randomly distributed, those atoms that exceed the activation energy are not necessarily at the bond interface where they can undergo diffusion. Ideally, then, enough energy should be applied to raise the entire energy distribution above the threshold energy. However, at a certain point, the internal energy of the atoms would massively disrupt the crystal lattice and cause undue plastic flow. This is seen as excessive deformation and is the main cause of weakened ball necks and wedge heels. Therefore, the need to balance pull against shear strength is based on the need to balance the number of atoms overcoming the threshold energy at the bond interface and still not disrupt the crystal lattice. 


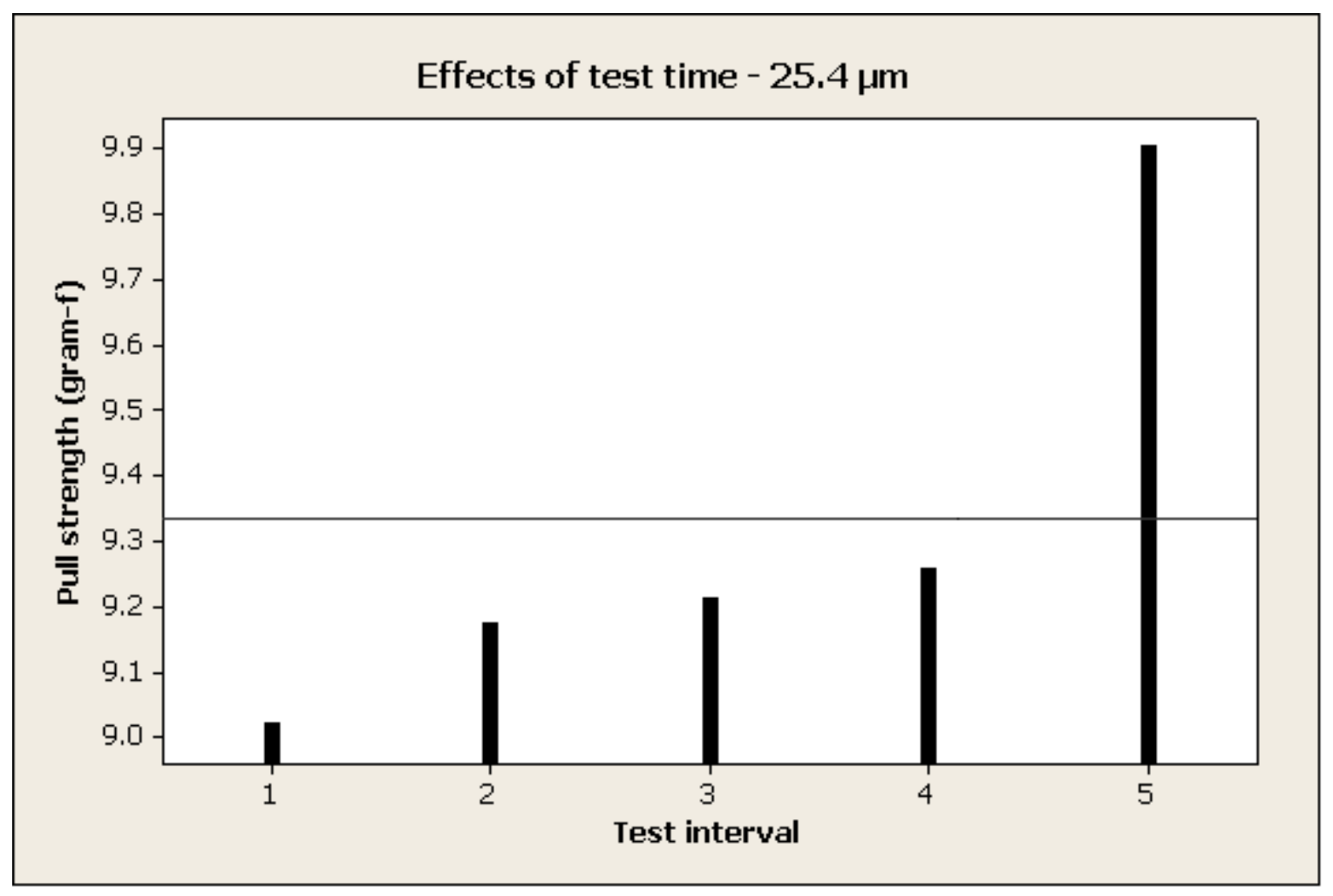

Figure 5.8 Effects of test interval on pull strength for $25.4 \mu \mathrm{m}$ wire size.

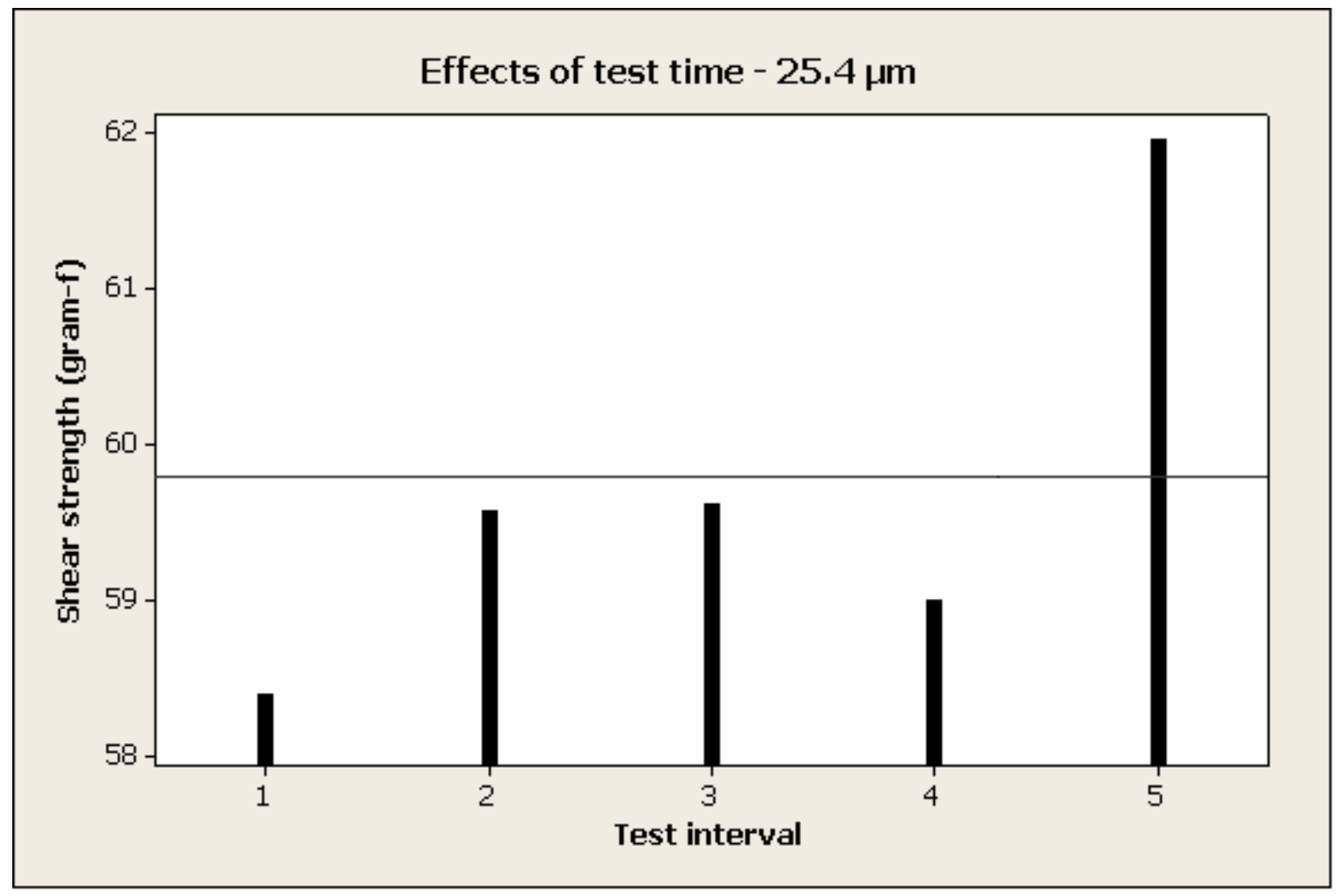

Figure 5.9 Effects of test interval on shear strength for $25.4 \mu \mathrm{m}$ wire size. 
After the source of energy input is removed, the internal energy levels return to normal. However, diffusion does not reverse and the wire remains adhered to the bond pad. When these bonds are subjected to reliability testing, the high temperatures raise the internal energy of the atoms again. The mechanism of heat transfer inside the reliability test chamber is primarily convection above and conduction below the substrate. The increase in internal energy of atoms thus flows in towards the bond interface. Even as the internal energy levels of atoms increase above the threshold energy required for diffusion, these atoms are not necessarily those at the interface and do not contribute directly to bond integrity improvement. After extended periods of time, atoms at the bond interface become more energetic and more willing to diffuse across the interface. This explains the overall increase in bond integrity after 500 hours of undisturbed reliability testing. Heating these bonds for short periods of time do improve bond strength somewhat, but the effect is erratic and unpredictable and may even be statistically detrimental. Heating these bonds for long periods of time allow more atoms to diffuse. The result is higher shear strength. Even bonds made with unoptimized parameters on metallizations 2 and 4 show improvement in the failure modes. 


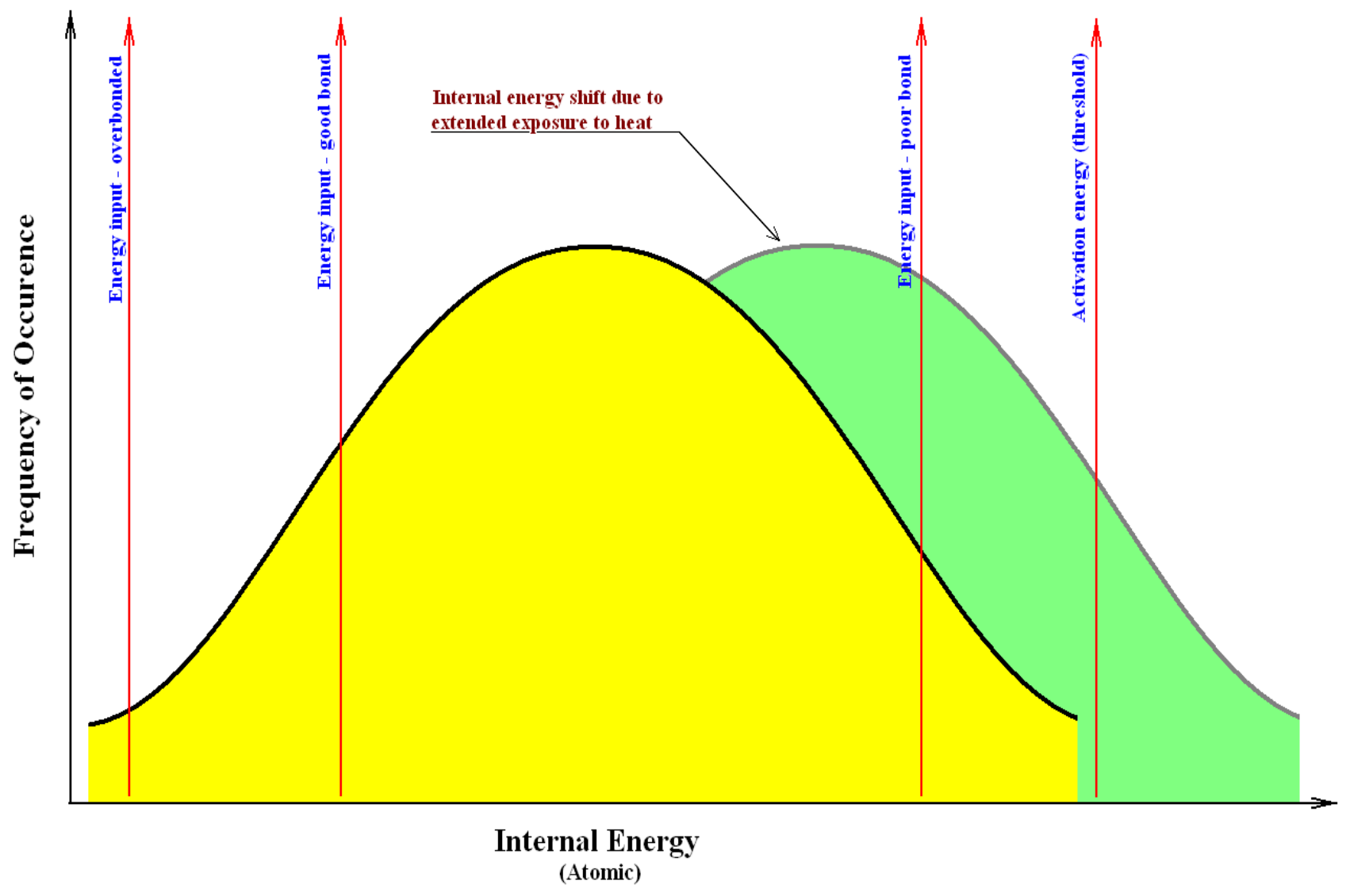

Figure 5.10 Internal energy band gap of materials.

The shear strength of a bond depends on diffusion of atoms across the bond interface. The pull strength depends on the condition of the wire where ultrasonic energy is applied. Typically, the bonding process leaves the wire in a distressed state, with various residual stresses in the metallic structure. The wire also becomes work hardened. Depending upon the condition of the capillary, there might even be nicks in the heel. All of these contribute to lower pull strength. However, the high temperature environment of the test chamber acts to anneal the wire. The work hardened area softens, residual stresses are relaxed, and grain boundaries can even reorganize. This accounts for the increased pull strength and better failure modes seen after extended reliability testing. 
For gold on gold bonding, the bond integrity at the interface will increase with extended heat treatment. The shear strength will reach an asymptote as more and more of the surface area of the bond interface undergoes diffusion with extended heat treatment. For bonding dissimilar metals, however, and dependent upon how optimized the bonding parameters were, the bond integrity may peak and then drop dramatically as the intermetallic layer grows and then Kirkendall voids start to form. At this point, both the pull and shear strength will suffer. The voids will cause the bonds to lift when pull force is applied. For processes that undergo severe heating, problems with the intermetallic layer can be avoided by choosing to bond the same metals together.

Would changing the ultrasonic frequency of thermosonic gold/gold wire bonding affect the bond quality positively, especially concerning bonding time as a method of improving productivity, and would the wire bonds made with higher ultrasonic frequency have long term reliability? It is worthwhile to answer these questions since streamlining production techniques is always desirable, as is a thorough understanding of the long term effects of switching to those new techniques. As shown by previous research and confirmed in this thesis, changing the ultrasonic frequency does not negatively impact the bond quality. It is actually improved. The optimized bonding parameters show that bonding time does decrease, which means production throughput can increase. Reliability testing shows no long term problems in terms of mechanical bonding. 


\section{Chapter 6. Conclusion and recommendations}

\subsection{Conclusion}

Several conclusions can be drawn from these results:

- Bonding at higher ultrasonic energy requires less power overall. This means that switching to higher frequency may potentially improve throughput by virtue of decreased bonding dwell time, but this is not proven here. Instead, high ultrasonic frequency reduces energy required to make bonds, which impacts power consumption.

- Baseline tests indicate that optimization needs to be done for individual metallizations, wire size, and ultrasonic frequency.

- The thickness of the substrate's gold layer is important to the full strength of the wire bond. The next metal layer underneath the gold surface also serves to help or hinder metallic diffusion. Harder backing metals make bonding more difficult. It is possible to solve these problems by optimization specifically tailored to the situation.

- Reliability tests indicate that only one set of test needs to be conducted, since the test type is not a significant factor in mean pull and shear strength. Due to the nature of the test, thermal cycling is the recommended reliability test to conduct since it tests fatigue of the wire bond, whether exposed or fully encapsulated.

- For gold on gold bonding, extended test periods increase the pull and shear strength. The longer the bonds are left undisturbed, the more 
pronounced and predictable the increase will be. The increase in shear strength is from post bonding diffusion by raising atomic internal energy by absorption of thermal energy. The increase in pull strength is from annealing the wire and relieving residual stresses left over from the bonding process. These mechanisms occur naturally and are not dependent on the ultrasonic frequency used to make the bonds.

\subsection{Recommendations}

- Switching to higher ultrasonic frequency improves bond throughput without any detrimental effects to reliability. Therefore switching to high frequency bond systems is recommended.

- Bond parameters must be optimized for each bond situation. A design-ofexperiment is recommended to ensure optimized parameters can be reached.

- Only thermal cycling is necessary to test wire bonds' reliability for gold on gold bonding. This eliminates the need to excessively test bonds over long periods of time.

\subsection{Future studies}

- This study has shown that higher frequency bonding is possible. Future studies should be conducted to understand the highest frequency of ultrasonic energy that can be applied to wire bonds and any possible detrimental effects that may have on metallurgy. 
- Deeper study needs to be conducted to fully understand the mechanism of wire bonding, particularly at high frequencies. This study should be repeated with cross sectioning (perhaps using the FIB) to review the bond interface and check for voids that the pull and shear tests may have missed. 


\section{References}

Chan, Yu Hin, Kim, Jang-Kyo, Liu, Deming, Liu, Peter C. K., Cheung, Yiu Ming, Ng, Ming Wai, "Effects of bonding frequency on Au wedge wire bondability," J Mater Sci: Mater Electron, No. 19, 2008, pp. 281 - 288

Charles, H. K., Clatterbaugh, G. V., "Ball bond shearing - A complement to the wire bond pull test," The International journal for hybrid microelectronics, Vol. 6, 1983, pp. $171-186$

Charles, H. K. Jr., Mach, K. J., Lehtonen, S. J., Francomacaro, A. S., DeBoy, J. S., Edwards, R. L., "High Frequency Wire Bonding: Its Impact on Bonding Machine Parameters and MCM Substrate Bondability," International Symposium on Microelectronics, 2001, pp. 350-360

Charles, H. K. Jr., Mach, K. J., Lehtonen, S. J., Francomacaro, A. S., DeBoy, J. S., Edwards, R. L., "Comparison of $60 \mathrm{KHz}$ and $100 \mathrm{KHz}$ Wirebonding on Organic and Inorganic Substances," Proceedings of the 35th IMAPS International Symposium on Microelectronics, September 4-6, 2002, Denver, CO

Charles, H. K. Jr., Mach, K. J., Lehtonen, S. J., Francomacaro, A. S., DeBoy, J. S., Edwards, R. L., "High Frequency Wire Bonding: Process and Reliability Implications," Proceedings of the 52nd Electronic Components and Technology Conference, 2002, pp. 881-890

Charles, H. K. Jr., Mach, K. J., Lehtonen, S. J., Francomacaro, A. S., DeBoy, J. S., Edwards, R. L., "Wirebonding at higher ultrasonic frequencies: reliability and process implications," Microelectronics Reliability, Vol. 43, 2003, pp. 141-153 
Davis, Dan, "Factors in High Reliability Wire Bonding," Reliability Physics Symposium, April 1970, Las Vegas, NV, USA

Ding, Yong, Kim, Jang-Kyo, Tong, Pin, "Effects of Bonding Force on Contact Pressure and Frictional Energy in Wire Bonding," Microelectronics Reliability, Vol. 46, 2006, pp. 1101-1112

Ding, Yong, Kim, Jang-Kyo, "Numerical Analysis of Ultrasonic Wire Bonding: Part 2. Effect of Bonding Parameters on Temperature Rise," Microelectronics Reliability, Vol. 48, 2008, pp. 149-157

Giannuzzi, L. A., Stevie, F. A., “A Review of Focused Ion Beam Milling Techniques for TEM Specimen Preparation,” Micron, Vol. 30, 1999, pp. 197-204

Gonzalez, Bill, Knecht, Sheera, Handy, Howard, Ramirez, Joe, "The effect of ultrasonic frequency on fine pitch aluminum wedge wirebond," Electronic Components and Technology Conference, 1996

Hall, Elizabeth, Lyons, Alan M., Weld, John D., "Gold wire bonding onto flexible polymeric substrates," IEEE Transactions on components, packaging, and manufacturing technology - Part A, Vol. 19, No. 1, March 1996

Harman, George G., "Metallurgical failure modes of wire bonds," Reliability Physics Symposium, 1974, Las Vegas, NV, USA

Harman, George G., Albers, John, "The ultrasonic welding mechanism as applied to aluminum and gold wire bonding in microelectronics," IEEE Transactions on parts, hybrids, and packaging, Vol. PHP-13, No. 4, December 1977 
Harman, George G., "Microelectronic Wire Bond Pull Test - How to Use It, How to Abuse It," IEEE Transactions on Components, Hybrids, and Manufacturing Technology, Vol. CHMT-1, No. 3, September 1978

Harman, George G., "Microelectronic Ball Bond Shear Test - A Critical Review and Comprehensive Guide to Its Uses," Solid State Technology, Vol. 27, No. 5, 1984

Harman, George G., wire bonding in microelectronics materials, processes, reliability, and yield, 2nd edition, McGraw-Hill 1997

Horsting, C. W., "Purple plague and gold purity," Reliability Physics Symposium, 1972, Las Vegas, NV, USA

Hu, Shze J., Lim, Richard K. S., Sow, G. Y., "Gold Wire Weakening in the Thermosonic Bonding of the First Bond," IEEE Transactions on Components, Packaging, and Manufacturing Technology - Part A, Vol. 18, No. 1, March 1995

Hund, Tom D., Plunkett, Paul V., "Improving Thermosonic Gold Ball Bond Reliability," IEEE Transactions on Components, Hybrids, and Manufacturing Technology, Vol. CHMT-8, No. 4, December 1985

Jellison, James L., "Effect of Surface Contamination on the Thermocompression Bondability of Gold," IEEE Transactions on Parts, Hybrids, and Packaging, Vol. PHP-11, No. 3, September 1975

Jellison, James L., "Kinetics of Thermocompression Bonding to Organic Contaminated Gold Surfaces," IEEE Transactions on Parts, Hybrids, and Packaging, Vol. PHP13, No. 2, June 1977

Johnson, K. I., Stockham, N. R., Abington, D. Worrall, "Optimization and Quality Control of Ultrasonic Wire Bonding,” DVS-Berichte, Vol. 102, 1986, pp. 13-20 
Kim, Jang-Kyo, Au, Benny P. L., "Effects of Metallization Characteristics on Gold Wire Bondability of Organic Printed Circuit Boards," Journal of Electronic Materials, Vol. 30, No. 8, 2001

Krzanowski, James E., “A Transmission Electron Microscope Study of Ultrasonic Wire Bonding," IEEE Transactions on Components, Hybrids, and Manufacturing Technology, Vol. 13, No. 1, 1990

Langenecker, Bertwin, "Effects of ultrasound on deformation characteristics of metals," IEEE Transactions on Sonics and Ultrasonics, Vol. SU-13, No. 1, March 1996 Le, Minh-Nhat, Pan, Jianbiao, Pham, Cuong-Van, “ The Effects of 120KHz Ultrasonic Frequency on the Reliability of Fine Pitch Gold Wire Bonding," IMAPS and SEMI Advanced Technology Workshop on Wire Bonding, July $14^{\text {th }}$, 2008, San Francisco, CA, USA

Liang, Z. N., Kuper, F. G., Chen, M. S., “A Concept to Relate Wire Bonding Parameters to Bondability and Ball Bond Reliability," Microelectronics Reliability, Vol. 38, 1998, pp. 1287-1291

Long, Zhi-li, Han, Lei, Wu, Yun-xin, Zhong, Jue, "Study of Temperature Parameter in Au-Ag Wire Bonding," IEEE Transactions on Electronics Packaging Manufacturing, Vol. 31, No. 3, July 2008

Lu, Albert Chee W., Fan, Wei, Wai, Lai L., "Design Optimization of Wire Bonding for High Frequency Applications," Electronics Packaging Technology Conference, 2002

Muller, Tobias, Schrapler, Lutz, Altmann, Frank, Knoll, Heiko, Petzold, Matthias, "Influence of Intermetallic Phases on Reliability in Thermosonic Au-Al Wire 
Bonding,” 2006 Electronics System Integration Technology Conference, 2006, Dresden, Germany

Murali, Sarangapani, Srikanth, Narasimalu, Vath, Charles J. III, "Effect of Wire Diameter on the Thermosonic Bond Reliability," Microelectronics Reliability, Vol. 46, 2006, pp. 467-475

Nikawa, K., Nasu, K., Murase, M., Kaito, T., Adachi, T., Inoue, S., "New Applications of Focused Ion Beam Technique to Failure Analysis and Process Monitoring of VLSI,” International Reliability Physics Symposium, April 1989, Phoenix, AZ, USA

Pan, Jianbiao, Le, Minh-Nhat, Pham, Cuong-Van, "The Effect of Ultrasonic Frequency on Gold Wire Bondability and Reliability," Proceedings of the 41st International Symposium on Microelectronics, November 2, 2008, Providence, RI, USA

Ramminger, S., Turkes, P., Wachutka, G., "Crack Mechanism in Wire Bonding Joints," Microelectronics Reliability, Vol. 38, 1998, pp. 1301-1305

Ramsey, Thomas H., Alfaro, Cesar, “The Effect of Ultrasonic Frequency on Intermetallic Reactivity of Au-Al Bonds," Solid State Technology, Vol. 34, No. 12, December 1991

Ramsey, Thomas H., Alfaro, Cesar, "High frequency enhancement for ambient temperature ball bonding," Semiconductor International, August 1997

Schafft, Harry A., "Failure analysis of wire bonds," Reliability Physics Symposium, 1973, Las Vegas, NV, USA 
Sheaffer, Michael, Levine, Lee, "How to Optimize and Control the Wire Bonding Process, Part I," Solid State Technology, Vol. 33, No. 11, November 1990, pp. $119-123$

Sheaffer, Michael, Levine, Lee, "How to Optimize and Control the Wire Bonding Process, Part II," Solid State Technology, Vol. 34, No. 1, January 1991, pp. 67-70

Shirai, Yuji, Otsuka, Kanji, Araki, Takashi, Seki, Isao, Kikuchi, Kouiti, Fujita, Nobuhiro, Miwa, Takashi, "High reliability wire bonding technology by the $120 \mathrm{KHz}$ frequency of ultrasonic,” ICEMM Proceedings '93, 1993

Tan, Cher Ming, Er, Eddie, Hua, Younan, Chai, Vincent, "Failure Analysis of Bond Pad Metal Peeling Using FIB and AFM," IEEE Transactions on Components, Packaging, and Manufacturing Technology - Part A, Vol. 21, No. 4, December 1998

Tan, Cher Ming, Gan, Zhenghao, "Failure Mechanisms of Aluminum Bondpad Peeling During Thermosonic Bonding," IEEE Transactions on Device and Materials Reliability, Vol. 3, No. 2, June 2003

Tsujino, Jiromaru, Mori, Takahiro, Hasegawa, Koichi, "Welding Characteristics of Ultrasonic Wire Bonding Using High Frequency Vibration Systems," Japan Journal of Applied Physics, Vol. 33, 1994, pp. 3048-3053

Tsujino, Jiromaru, Yoshihara, Hiroyuki, Sano, Tsutomu, Ihara, Shigeru, "High-frequency ultrasonic wire bonding systems", Ultrasonics 38 (2000) pp. 77-80

Wang, Fu-liang, Han, Lei, Zhong, Jue, "Study of Ultrasonic Power Parameter on the Large Aluminum Wire Wedge Bonding Strength," Conference on High Density 
Microsystem Design and Packaging and Component Failure Analysis, 2005, Shanghai, China

Wu, Yun-xin, Long, Zhi-li, Han, Lei, Zhong, Jue, “Temperature Effect in Thermosonic Wire Bonding," Transactions of Nonferrous Metaks Society of China, Vol. 16, 2006, pp. 618-622

Zhong, Z. W., Goh, K. S., "Investigation of Ultrasonic Vibrations of Wire Bonding Capillaries," Microelectronics Journal, Vol. 37, 2006, pp. 107-113 